Reconhecimento de padrões utilizando um anel de osciladores de fase

Fábio Alessandro Oliveira da Silva 
Data de Depósito:

Assinatura:

Fábio Alessandro Oliveira da Silva

\section{Reconhecimento de padrões utilizando um anel de osciladores de fase}

\footnotetext{
Tese apresentada ao Instituto de Ciências Matemáticas e de Computação - ICMC-USP, como parte dos requisitos para obtenção do título de Doutor em Ciências - Ciências de Computação e Matemática Computacional. VERSÃO REVISADA

Área de Concentração: Ciências de Computação e Matemática Computacional

Orientador: Prof. Dr. Zhao Liang
} 
Ficha catalográfica elaborada pela Biblioteca Prof. Achille Bassi e Seção Técnica de Informática, ICMC/USP,

com os dados fornecidos pelo(a) autor(a)

Silva, Fábio Alessandro Oliveira da
Reconhecimento de padrões utilizando um anel de
osciladores de fase / Fábio Alessandro Oliveira da
Silva; orientador Zhao Liang. -- São Carlos, 2017.
87 p.
Tese (Doutorado - Programa de Pós-Graduação em
Ciências de Computação e Matemática Computacional) --
Instituto de Ciências Matemáticas e de Computação,
Universidade de São Paulo, 2017.
1. Osciladores. 2. Padrões. 3. Fractais. I.
Liang, Zhao, orient. II. Título.




\section{Fábio Alessandro Oliveira da Silva}

\section{Pattern recognition using a ring of phase oscillators}

Doctoral dissertation submitted to the Instituto de Ciências Matemáticas e de Computação - ICMCUSP, in partial fulfillment of the requirements for the degree of the Doctorate Program in Computer Science and Computational Mathematics. FINAL VERSION

Concentration Area: Computer Science and Computational Mathematics

Advisor: Prof. Dr. Zhao Liang

USP - São Carlos

January 2017 


\section{AGRADECIMENTOS}

A Deus por me conceder saúde, inteligência, criatividade e motivação para persistir, desenvolver e concluir este trabalho.

À minha família por minha formação como pessoa e pelo constante incentivo ao meu desenvolvimento intelectual.

Ao meu orientador Prof. Dr. Zhao Liang por ter me estimulado a compreender e desenvolver na área de estudo da qual forneço minhas contribuições por meio deste trabalho.

Finalmente agradeço a todos os envolvidos que, de forma direta ou indireta, contribuíram para a conclusão e concretização desta tese. 


\section{RESUMO}

SILVA, F. A. O. Reconhecimento de padrões utilizando um anel de osciladores de fase.

2017. 87 f. Tese (Doutorado) - Instituto de Ciências Matemáticas e de Computação, Universidade de São Paulo, São Carlos, 2017.

Redes neurais caracterizadas por cadeias de osciladores acoplados são um dentre vários tipos de redes que possuem propriedades peculiares relacionadas com a sua estrutura topológica. A dinâmica que descreve o comportamento dessas redes é modelada por sistemas de equações diferenciais, nos quais cada neurônio (nó) é considerado como um oscilador. Estudos realizados em redes desse tipo, em tarefas de reconhecimento de padrões estáveis gerados aleatoriamente, têm apresentado resultados computacionais satisfatórios. Esta tese propôs um desenvolvimento teórico e computacional que forneceu um algoritmo, para o estudo do desempenho de redes neurais em forma de osciladores de Ciclo-Limite de Stuart-Landau, no reconhecimento de figuras fractais. Neste trabalho apresentaremos contextos reais em que podemos encontrar características deste tipo de redes e motivações. Em seguida, serão expostos conceitos de redes de Hopfield, reconhecimento de padrões, teorias dos fractais e dos osciladores de Ciclo-Limite de Stuart-Landau; tais conceitos, por sua vez, serviram como ferramentas principais para o algoritmo construído que será explicado posteriormente. Antes de apresentá-lo, será exposta a maneira como a dinâmica desses osciladores pode se tornar caótica, por meio de simulações computacionais alterando numericamente variáveis intrínsecas, como tempos de disparos entre neurônios, ou quantidades destes no sistema. Estas descobertas serviram como confirmações para elaborar e compor do algoritmo, bem como orientaram as simulações de reconhecimento de figuras fractais. Por fim, será apresentada a conclusão dos resultados encontrados.

Palavras-chave: Osciladores. Reconhecimento. Padrões. Fractais. 


\begin{abstract}
SILVA, F. A. O. Pattern recognition using a ring of phase oscillators. 2017. $87 \mathrm{f}$. Tese (Doutorado) - Instituto de Ciências Matemáticas e de Computação, Universidade de São Paulo, São Carlos, 2017.

Neural networks characterized by chains of coupled oscillators are one of several types of networks which have peculiar properties related with their topological structure. The dynamics that describes the behavior of these networks is modeled by systems of differential equations, of which each neuron (node) is considered as an oscillator. Studies on such networks, in tasks of recognizing randomly generated stable patterns, have presented satisfactory computational results. This thesis proposed a theoretical and computational development that provided an algorithm for the study of the performance of neural networks in the form of Cycle-Limit oscillators of Stuart-Landau, in the recognition of fractals. In this work we will present real contexts in which we can find characteristics of this type of networks and motivations. Next, concepts of Hopfield networks, pattern recognition, fractals theories and the Stuart-Landau Cycle-Limit oscillators will be presented; these concepts, in turn, served as the main tools for the algorithm constructed that will be explained later. Before presenting it, it will be exposed how the dynamics of these oscillators can become chaotic, through computer simulations numerically altering intrinsic variables, such as firing times between neurons, or quantities of these in the system. These findings served as confirmations for elaborating and composing the algorithm, as well as guiding the simulations of the recognition of fractals. Finally, the results will be presented.
\end{abstract}

Keywords: Oscillators. Recognition. Patterns. Fractals. 


\section{Sumário}

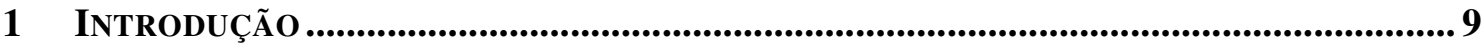

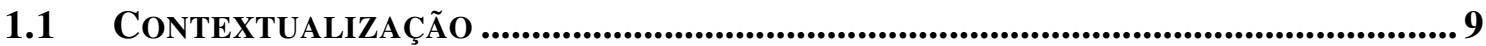

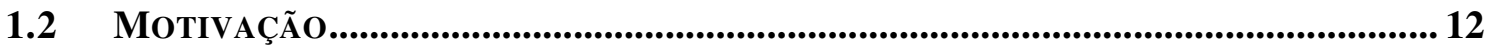

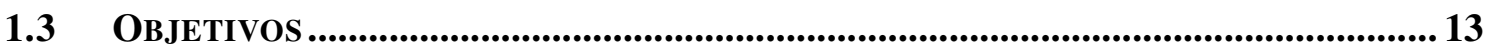

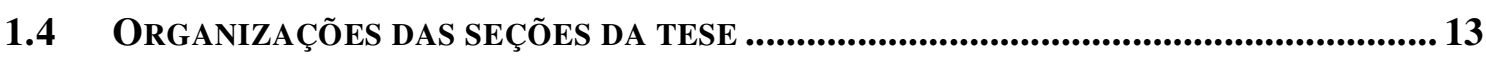

2 RECONHECIMENTO DE PADRÕES E REDES NEURAIS ................................................... 14

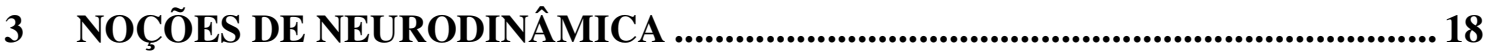

\subsection{CONCEITOS BÁSICOS DE NEURODINÂMICA E SISTEMAS DINÂMICOS18}

3.2 REDES DE HOPFIELD: CONCEITOS E APLICAÇÕES .............................. 19

4 TEORIA FRACTAL E APLICAÇÕES COMPUTACIONAIS ...........................................22

5 Osciladores de Ciclo Limite de Stuart-Landau ....................................... 27

6 RECONHECIMENTO DE PADRÕES FRACTAIS ALEATÓRIOS POR OSCILADORES DE CICLO

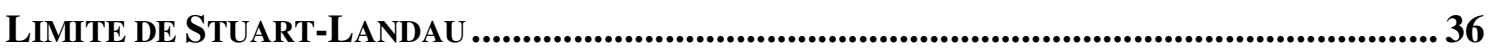

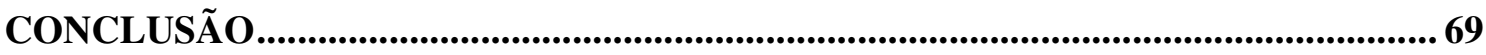

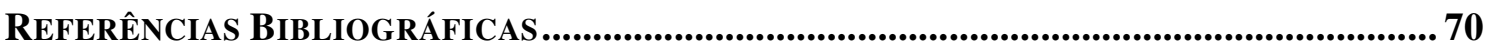

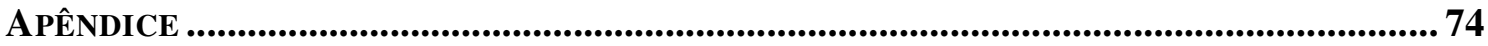




\section{INTRODUÇÃO}

Nesta seção apresentaremos os contextos e motivações que influenciaram o nosso objeto de estudo, bem como o objetivo que o direcionou. Por fim, exibiremos as sínteses dos capítulos que servirão como acompanhamento para o entendimento da tese.

\subsection{CONTEXTUAlização}

Redes neurais em formatos de laços fechados, ou, resumidamente, anéis neurais, são estudadas em alguns contextos e metodologias. Considerando cada neurônio constituinte ora um oscilador, ora um neurônio biológico, tais redes surgem em estudos que envolvem áreas como a física, a biologia e as neurociências, apenas para citar alguns exemplos.

Como pesquisas no campo da física, Jiang, N. et al. apresentaram resultados com conjuntos ópticos formados por lasers semicondutores acoplados. O que se observou foi uma sincronização caótica em transmissões de informações nos acoplamentos estudados sendo preservada e seus estudos são de grande interesse em comunicações seguras envolvendo os dispositivos ópticos citados. ${ }^{1}$

No campo da biologia, Gerstner et al. estudaram, por meio de simulações computacionais, o sistema auditivo da coruja de celeiro, a fim de explicar um paradoxo em sistemas neurais eletrossensoriais e auditivos. ${ }^{2}$

A descrição desse paradoxo se resume como:

Codificações de sinais comportamentais relevantes num limiar de uns poucos microssegundos com neurônios, ao menos, em ordem de magnitude, muitos lentos.

A partir desse paradoxo, surge uma questão central:

Disparo neural pode ser mais preciso do que as constantes de tempo dos processos neurais envolvidos?

Com os estudos neste tipo de coruja, eles identificaram três observações: 
a) Coerência entre sinais pré-sinápticos e potenciais pós-sinápticos;

b) Grau de coerência na chegada do sinal atribuído à regra de aprendizado hebbiano não supervisionado (aprendizado que seleciona conexões com correspondência de atraso numa distribuição total de neurônios) ${ }^{3}$

c) A regra de aprendizado seleciona os atrasos corrigidos de dois grupos independentes de entradas, por exemplo, do ouvido esquerdo e direito.

Em trabalhos baseados em neurociências, podemos apontar Ahissar, E. e Kleinfeld, D. que estudaram um tipo de arquitetura neural denominada "laços de realimentação de grande escala”. Suas descobertas sugeriram que um sistema sensório-motor está envolvido em cálculos de laços fechados. Tais laços são provavelmente componentes internos em um grande circuito fechado do sistema que otimiza o processo sensorial. ${ }^{4}$

$\mathrm{Na}$ Figura 1(a) temos um esquema de sistemas de computação feedforward e recorrentes para visualizações de informações passando de uma estação de processamento para a outra de maneira feedforward e processado em cada estação recorrente. Entretanto, a arquitetura cerebral não está completa sem incluir um terceiro componente principal, em grande escala, conexões de realimentação que alimentam a saída das áreas de recepção de volta para as áreas de transmissão, como exposto na Figura 1(b). Talvez as conexões de realimentação córtico-talâmico sejam os exemplos mais intensamente estudados deste tipo. As conexões de realimentação não ocorrem apenas entre o córtex e núcleos talâmicos, mas também entre o córtex e o tronco cerebral, entre áreas corticais que estão ligadas através de conexões feedforward e, a partir do núcleo de saída motor de volta para o córtex. 
(a)

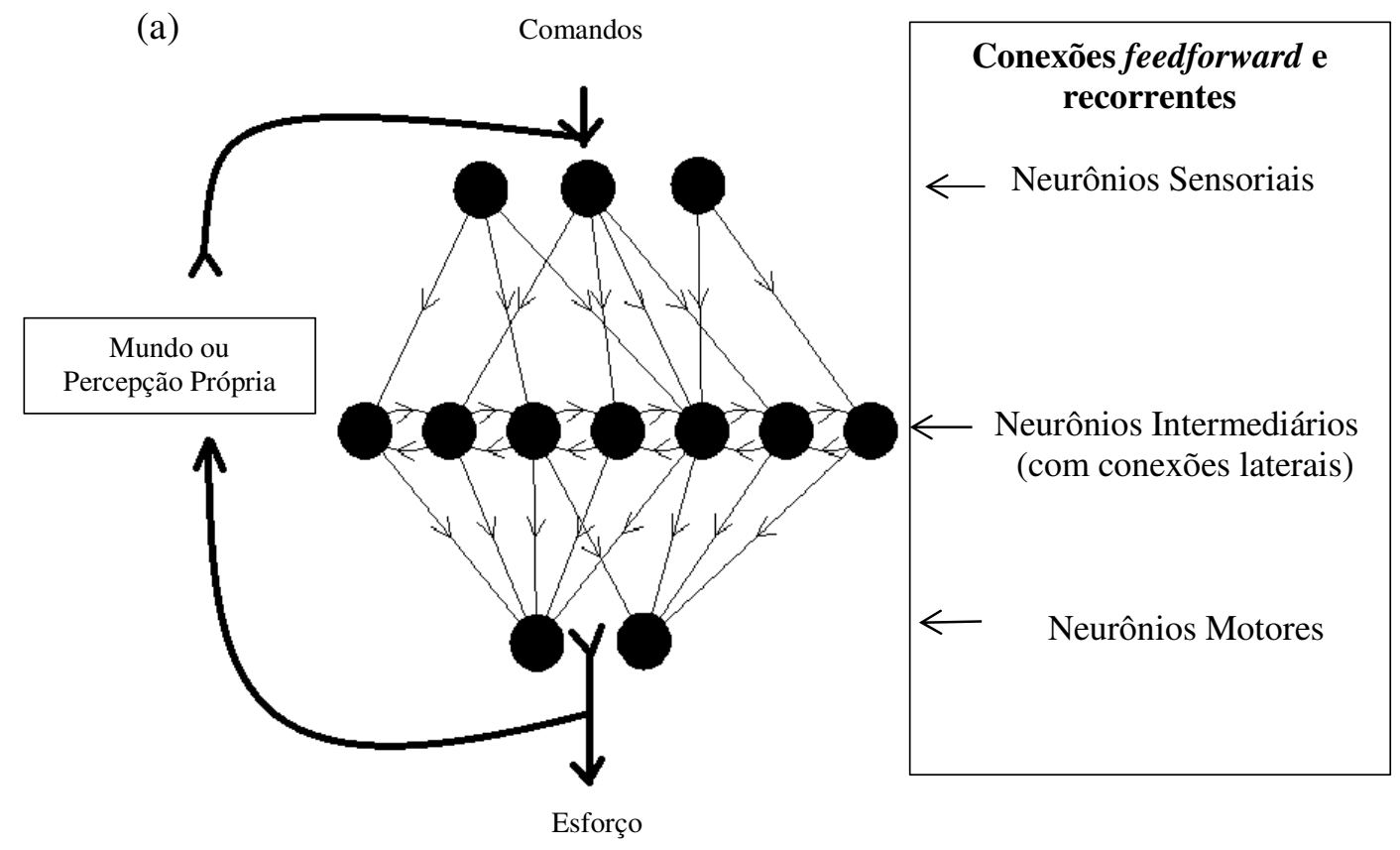

(b)

Comandos

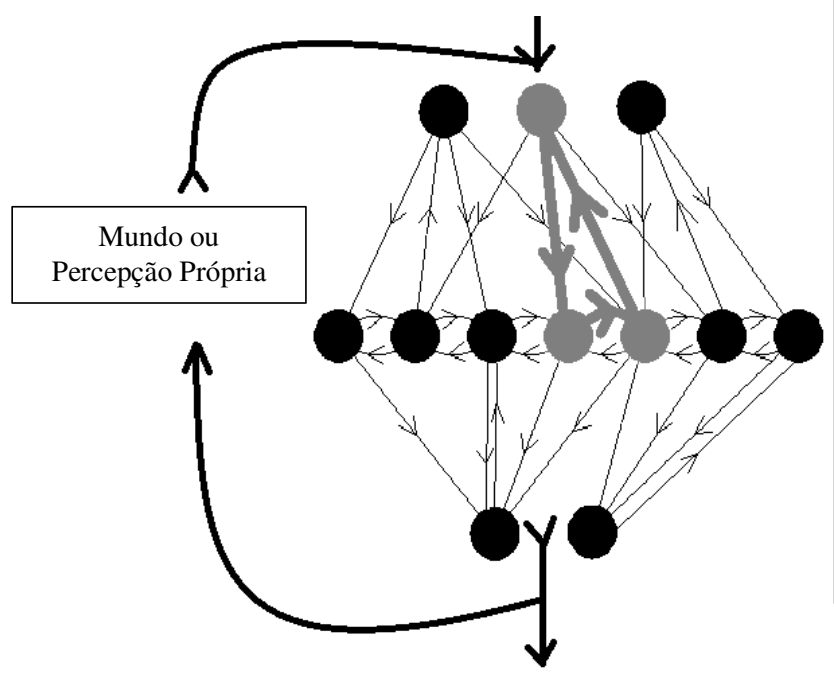

Conexões feedforward, recorrentes e de realimentação

Neurônios Sensoriais

Esforço

Um laço fechado de realimentação dentro de uma rede

Figura 1(a) - mistura de conexões feedforward e recorrentes. Externamente, o fluxo de informações é feedforward e internamente, recorrente.

Figura 1(b) - mistura de conexões de realimentação e as duas anteriores. O fluxo de informações é tanto feedforward como recorrente e de realimentação (laços fechados). Adaptado de: Ahissar, E. e Kleinfeld, D. ${ }^{4}$ 
O anel neural que será o nosso objeto de estudo possui características dos exemplos citados anteriormente. No caso da aplicação do problema físico envolvendo dispositivos ópticos, as justificativas teóricas apresentadas naquele estudo envolveram um ou dois osciladores (dispositivo transmissor e receptor de informação) acoplados que, ou se autoalimentavam (um dos osciladores em si mesmo), ou se realimentavam (dois osciladores), e as equações de Stuart-Landau modelaram tais argumentos. Nos estudos da coruja de celeiro, constatou-se que nos conjuntos neurais do ouvido esquerdo e direito ocorriam atrasos de comunicação entre estes; a rede neural usada em nosso trabalho possui tal peculiaridade entre os neurônios (osciladores). No último exemplo envolvendo estudos de um sistema de realimentação em grande escala, ocorrem interna e externamente em tal sistema, laços fechados de realimentação entre os neurônios e isto também é outro detalhe que topologicamente a nossa rede neural de estudo possui, ao menos internamente.

No próximo item será exposto o resultado dos desdobramentos que a contextualização contribuiu como inspirações.

\subsection{MotivaÇÃo}

Conforme a contextualização exposta no item anterior é notório que os estudos envolvendo redes neurais cuja topologia é anelar, expõem-nos à importância tecnológica dessas estruturas em melhoramentos e/ou inovações em áreas de telecomunicações e sistemas de informações que utilizam dispositivos ópticos, bem como em aplicações de autômatos e de aprendizado de máquina que não necessitam de hardwares tão robustos para o auxílio em tarefas que exijam locomoção ou reconhecimento de padrões, sejam de imagens, de sons etc. Em campos que abrangem a neurobiologia, esse tipo de rede permite melhores compreensões e, por fim, tratamentos mais eficazes de patologias como a esclerose múltipla, mal de Alzheimer ou Parkinson.

Por meio dessa síntese contextual, estudos e aplicações de redes neurais em formato de anel podem fornecer alternativas para a compreensão ou resolução de problemas em outras áreas do conhecimento humano, o que nos motivam a oferecer também contribuições adicionais no que tange ao reconhecimento de padrões geométricos. 


\subsection{OBJETIVOS}

O presente trabalho tem como objetivo apresentar propostas de estudo e aplicação de anéis neurais, modelados via osciladores de Ciclo Limite (CL) de Stuart-Landau, utilizando dinâmica caótica para o reconhecimento de padrões fractais.

Para a corroboração das propostas sugeridas nesta tese serão apresentadas simulações computacionais mostrando a eficiência dos algoritmos de reconhecimento de figuras fractais geradas aleatoriamente.

\subsection{ORgANIZAÇÕES DAS SEÇÕES DA TESE}

Apresentaremos na segunda seção o estado da arte do reconhecimento de padrões e sua relação com redes neurais na solução de problemas da vida real. Nessa parte, também serão expostos alguns exemplos ilustrativos.

A terceira seção será uma síntese conceitual sobre Sistemas Dinâmicos no contexto da Neurodinâmica, especificamente em redes de Hopfield e alguns exemplos de estudo. Esta parte do trabalho será essencial para a compreensão do objeto de estudo (osciladores de CL de Stuart-Landau) e das aplicações computacionais que confirmam o êxito da proposta algorítmica tratada nesta tese.

Será abordado na quarta seção um breve resumo teórico de fractais, conceitos e exemplos de algoritmos que utilizam esta teoria para o reconhecimento de padrões.

A quinta seção deste trabalho apresentará o estado da arte dos osciladores de Ciclo Limite de Stuart-Landau no contexto de anéis neurais, definições de conceitos que tais redes utilizam e os estudos que incentivaram o desenvolvimento dessa tese.

A sexta seção descreverá o desenvolvimento do método para a construção de um algoritmo para a rede neural estudada "aprender" a reconhecer figuras fractais. Também serão apresentadas simulações numéricas que ilustrarão o desempenho do anel no reconhecimento dessas figuras geradas aleatoriamente.

Na seção seguinte serão descritas a conclusão e as possíveis contribuições fornecidas por este trabalho. Em seguida, serão apresentadas as referências que direcionaram para o êxito da tese aqui proposta. Por fim, na última seção, estará o apêndice que apresentará as demonstrações das fórmulas importantes para o desenvolvimento deste trabalho e os códigos dos programas concebidos para as simulações. 


\section{RECONHECIMENTO DE PADRÕES E REDES} NEURAIS

Segundo Polikar, R., o estudo de reconhecimento de padrões deriva da necessidade de transportar esta tarefa, relativamente simples para um ser humano, para máquinas automatizadas, com vistas ao reconhecimento de objetos, sinais ou imagens ou da necessidade de tomar decisões automáticas, dado um conjunto de parâmetros. ${ }^{5}$

De acordo com Bishop, C. M., esta área tem como propósito descobrir regularidades em dados, por meio de algoritmos de computador e, com o uso dessas descobertas, tomar ações, como classificar dados em categorias. ${ }^{6}$

Como exemplo, considere o reconhecimento de dígitos escritos à mão, ilustrado na Figura 2:
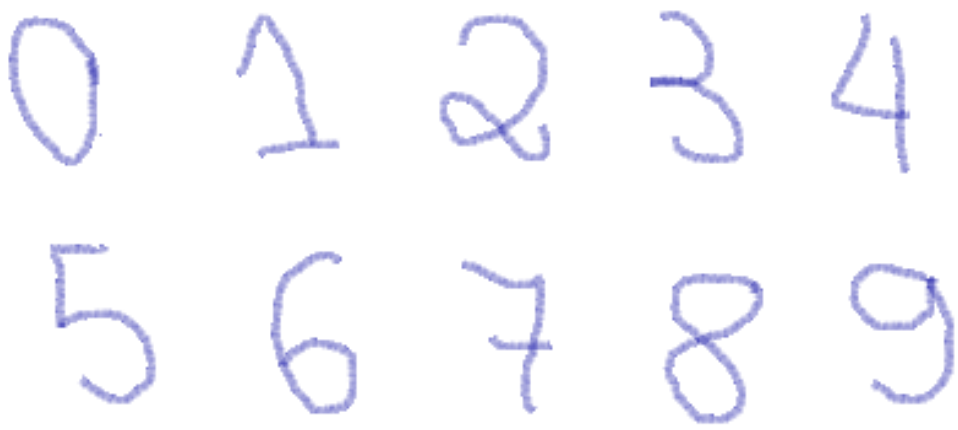

Figura 2 - Exemplo de dígitos escritos manualmente. Adaptado de: Bishop, C. M. ${ }^{6}$

Cada dígito corresponde uma imagem de 28 X 28 pixels podendo ser representada por um vetor de 784 números reais. Uma proposta seria construir uma máquina que usasse este vetor como entrada de dados, produzindo a identidade dos dígitos $0, . ., 9$, como saída. Não é um problema simples pelo fato de haver grande variabilidade destes escritos à mão. Este problema poderia ser abordado fazendo-se uso de regras artesanais ou heurísticas, distinguindo-lhes por meio das formas dos traços, porém, as regras proliferariam, suas exceções e assim por diante, dando resultados pobres. 
Outro exemplo, desta vez em problemas de classificação usando reconhecimento de padrões, seria o caso em identificação do sexo de um indivíduo por meio de representações visuais. Para um ser humano, pode ser relativamente simples esta tarefa, porém, aplicar esta mesma forma de classificar para uma máquina, pode ser desafiador, pois quais características haveria entre as classes macho e fêmea que esta deveria levar em consideração? É fácil notar que características como comprimento do cabelo, relação altura-peso, curvatura corporal, expressões faciais ou estrutura dos ossos da face, até mesmo quando usadas em combinação, podem falhar em fornecer classificações corretas. Assim, automatização de formas de reconhecimento de padrões para tarefas de classificação oferecem obstáculos difíceis de superar. A seguir, serão explicitadas algumas definições para uso posterior.

Seja um vetor de dados p-dimensional $\boldsymbol{x}=\left(x_{1}, \ldots, x_{p}\right)^{T}$ de medidas, onde $T$ indica transposição de tal vetor. Cada componente $x_{i}$ é uma medida de uma característica do objeto que se propõe classificar. Conforme Theodoridis, S. e Koutroumbas, K., cada $\boldsymbol{x}$, também denominado vetor de características, identifica unicamente um padrão singular; ele representa a assinatura do objeto a ser identificado. ${ }^{7}$

A assinatura descrita anteriormente pertence a alguma categoria denominada classe ou rótulo, tipicamente denotada por $\omega$. Um padrão é definido pela coleção das características de um objeto, juntamente com a informação da classe correta deste. Define-se qualquer padrão de amostra de um objeto de instância ou modelo.

Um treinamento é um procedimento que "ensina" um sistema de reconhecimento de padrões a relação de mapeamento entre vetores de características e o seus rótulos correspondentes. As fronteiras de decisão surgem desta relação e são responsáveis por separar padrões em diferentes classes no espaço de características p-dimensional.

Na Figura 3, os conceitos descritos anteriormente são ilustrados em um problema hipotético bidimensional de quatro classes. A característica 1 poderia ser a medida de pressão arterial sistólica e a de número 2, o peso de um paciente obtido a partir de um grupo com idade acima dos 60 anos. Classes diferentes poderiam indicar o número de ataques cardíacos sofridos durante o último período de 5 anos, como, por exemplo, nenhum, um, dois, ou mais do que dois. 


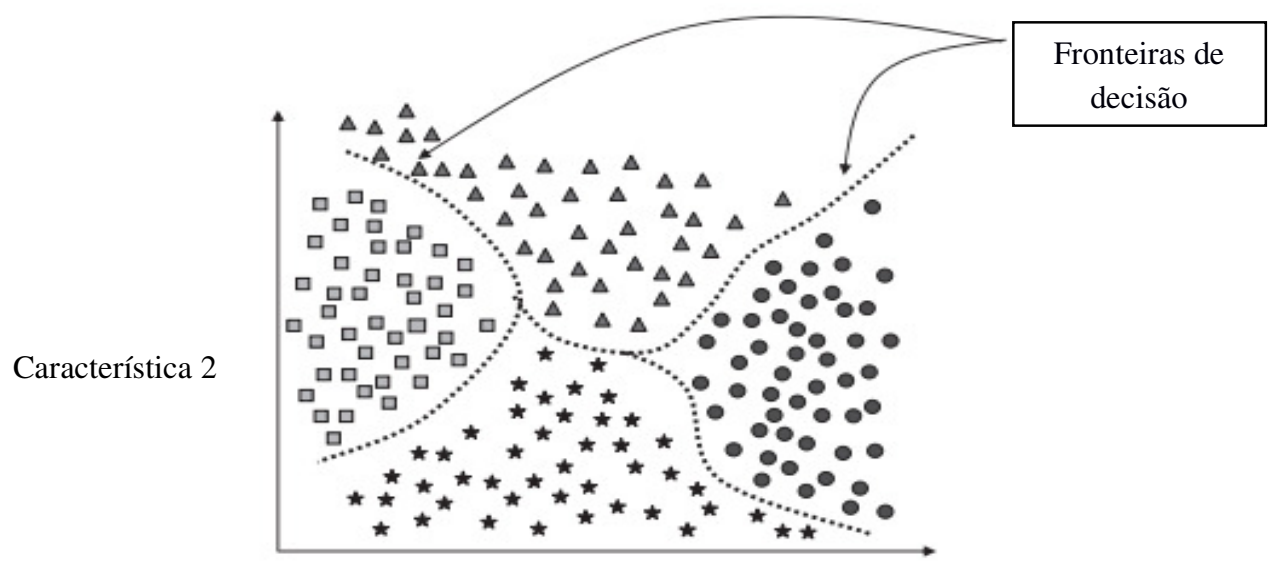

Característica 1

Figura 3 - Exemplo hipotético de um espaço de características bidimensional e suas fronteiras de decisão separando as classes. Adaptado de: Theodoridis, S. e Koutroumbas, K. ${ }^{7}$

A tarefa de reconhecimento de padrões é por si só, uma ciência não exata no sentido de que existem padrões que não podem ser bem estruturados ou estruturados de forma adequada. Tais padrões são de difícil modelagem, ou seja, o processo de definição de uma linguagem para a descrição de padrões não possui soluções gerais para o reconhecimento e sua escolha depende da natureza dos dados em disposição, da aplicação e da tecnologia envolvida.

As redes neurais artificiais tornam-se um meio alternativo para resolver estes tipos de problemas por dois motivos:

1- Ao invés da criação de processos lógicos, a construção de tais redes relacionase com a compreensão informal do comportamento que se deseja para resolver tal problema de reconhecimento;

2- Usando redes neurais artificiais, a necessidade de se estabelecer inicialmente quais são os fatores determinantes sobre o modelo do qual se está criando é menor. 
Como principais vantagens no uso de Redes Neurais Artificiais (RNA's) sobre outras técnicas tradicionais para o reconhecimento de padrões têm-se:

a) São hábeis em se ajustarem frente às informações inéditas;

b) São rápidas em processamento em vista do paralelismo massivo;

c) São capazes de fornecerem respostas satisfatórias mesmo com dados em falta, confusos ou ruidosos.

A habilidade das RNA's de generalização é outra vantagem apresentada para reconhecer padrões. Como exemplo ilustrativo, tem-se o reconhecimento de escrita de uma letra por uma mesma pessoa. Ela pode variar na escrita das letras, usando, como algumas variáveis, diferentes tipos de inclinação, tamanho, pressão e traçado, afetando o seu reconhecimento. Após a RNA utilizada aprender a diferenciar alguns A's de tamanhos distintos com B's de tamanhos também distintos, ela será hábil a diferenciar um A de qualquer tamanho com um B de qualquer tamanho também.

Assim, o uso de RNA's é uma abordagem bem recomendada para resolver sistemas abertos ou mais complicados, de conhecimentos incompletos e/ou inadequados para serem descritos por modelagens que utilizam regras ou equações.

No capítulo seguinte, iremos apresentar alguns conceitos da Neurodinâmica em uma RNA e algumas de suas aplicações em tarefas de reconhecimento de padrões. 


\section{NOÇÕES DE NEURODINÂMICA}

Neste capítulo serão apresentados os conceitos da Neurodinâmica, definições de alguns termos da teoria de sistemas dinâmicos que usaremos nos capítulos posteriores, bem como conceitos de redes de Hopfield e comparações destas com a rede modelada por osciladores de Stuart-Landau da qual é o foco de estudo nesta tese.

\subsection{CONCEITOS BÁSICOS DE NEURODINÂMICA E SISTEMAS DINÂMICOS}

De acordo com Haykin, S., podemos definir a Neurodinâmica como o estudo de redes neurais vistas como sistemas dinâmicos, tendo como ênfase particular problemas de estabilidade. $^{8}$

Considerando uma RNA como um sistema de equações diferenciais em que cada neurônio interpreta-se como uma função no tempo, podemos dizer que um ponto fixo (ou ponto de equilíbrio) é um ponto em que o estado do sistema quando o atinge, permanece nele indefinidamente. Para uma melhor compreensão de todos os aspectos dinâmicos da tese, abaixo estão resumidamente, as definições dos conceitos que serão mais utilizados:

Definição 3.1.1 Um sistema dinâmico discreto é um sistema em que o seu estado apenas se altera em tempo discreto, isto é, dado um conjunto de instantes $\left\{t_{0}, t_{1}, t_{2}, \ldots\right\}$, entre um instante e outro o estado de tal sistema permanece constante.

Definição 3.1.2 Uma equação de evolução de um sistema dinâmico discreto no plano complexo é dada por $z_{j+1}=f\left(z_{j}\right)$.

Definição 3.1.3 Seja $f$ uma evolução de um sistema dinâmico arbitrário e $z_{0} \in \mathbb{C}$. Uma órbita (ou trajetória) de $z_{0}$ é uma sequência formada por sucessivas iterações deste ponto com $f$, isto é,

$$
z_{0}, z_{1}=f\left(z_{0}\right), z_{2}=f\left(f\left(z_{0}\right)\right), \ldots, z_{N}=f^{N-1}\left(f\left(z_{0}\right)\right), \forall N \in \mathbb{R}
$$


Definição 3.1.4 Dado um sistema dinâmico de equações diferenciais $\dot{x}=f(x)$, o plano formado por pontos $(x, \dot{x})$ é denominado retrato de fase.

Definição 3.1.5 Uma órbita limitada é uma sequência de pontos de um sistema dinâmico no retrato de fase, que, iniciando-se desde um ponto $z_{0}$, a trajetória formada por essa sequência ficará sempre próxima naquele ponto.

Definição 3.1.6 Órbitas finitas são formadas por um conjunto finito de pontos. As que apresentam um conjunto infinito de pontos denominam-se órbitas ilimitadas.

Definição 3.1.7 Uma órbita será periódica, se ela retornar ao ponto onde se iniciou, isto é, $\exists m \in \mathbb{Z}$, tal que $f^{m}\left(z_{0}\right)=z_{0}$, onde $m \in \mathbb{Z}$ e $z_{0}$ é o ponto inicial da órbita.

Definição 3.1.8 Um Ciclo Limite é uma trajetória fechada no retrato de fase, isolada no sentido de que trajetórias vizinhas não fechadas espiralam ou em direção ou para fora dessa.

Definição 3.1.9 Dado um sistema dinâmico de equações diferenciais $\dot{x}=f(x)$, uma Seção de Poincaré é uma discretização das soluções desse sistema, sendo apresentadas pontualmente num plano bidimensional que consiste numa redução do espaço multidimensional que caracteriza a dinâmica de tal sistema.

Com tal exposição conceitual relatada anteriormente, veremos na próxima subseção, a sua aplicabilidade, ao menos em partes, em um tipo de RNA, a saber, Redes de Hopfield.

\subsection{REDES DE HOPFIELD: CONCEITOS E APLICAÇÕES}

Resumidamente, uma rede de Hopfield é uma RNA em que seus neurônios constituintes realimentam os outros, por meio de operadores de atraso de unidade, sem ocorrências de autorrealimentação. Na Figura 4, encontra-se um esboço deste modelo de rede neural: 


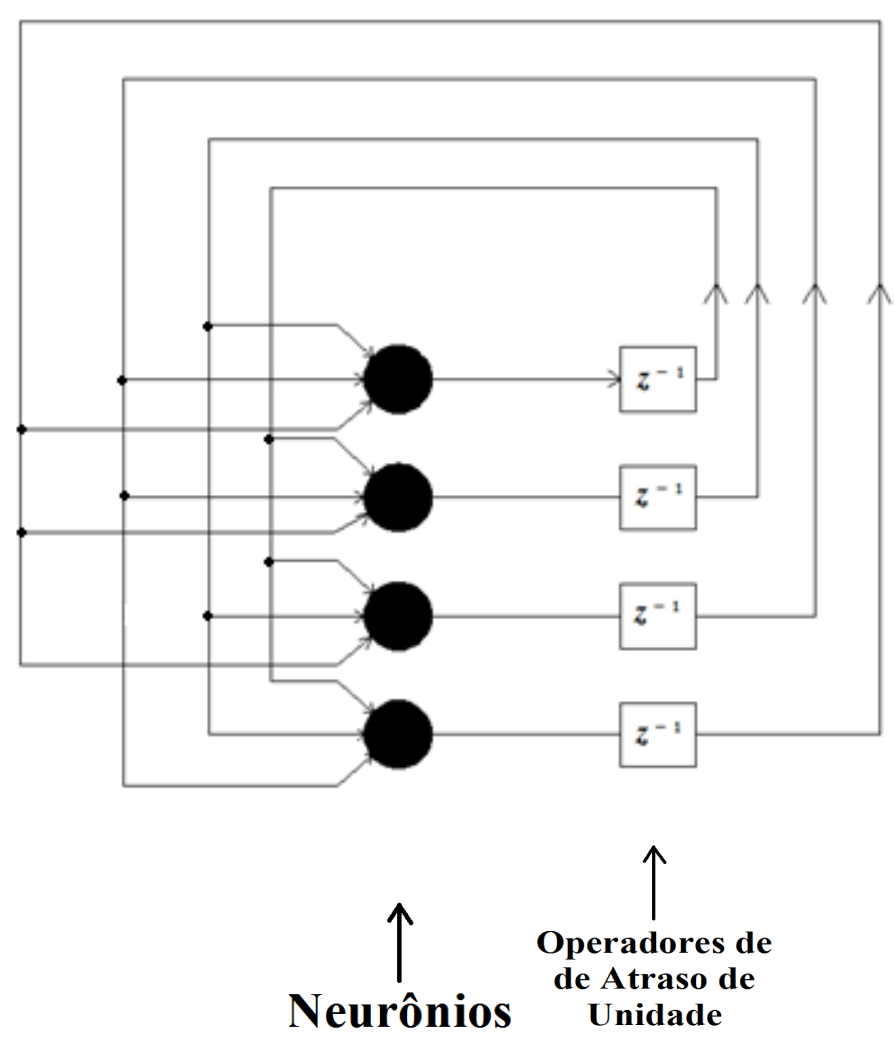

Figura 4 - Esquema de uma Rede de Hopfield formada por 4 neurônios. Adaptado de: Haykin, S. ${ }^{8}$

As redes de Hopfield são modeladas por um sistema de equações descrito por:

$$
C_{j} \frac{d}{d t} v_{j}(t)=-\frac{v_{j}(t)}{R_{j}}+\sum_{i=1}^{N} w_{i j} \varphi_{i}\left(v_{i}(t)\right)+I_{j}, j=1, \ldots, N
$$

onde $x_{i}(t)=\varphi_{i}\left(v_{i}(t)\right)$ é o sinal de saída do neurônio $i$ por meio de uma função de ativação $\varphi_{i}$ aplicada no estado $v_{i}(t)$ desse neurônio em um dado instante $t$.

Os valores $w_{i j}$ representam os pesos sinápticos (forças de acoplamento) entre os neurônios $i$ e $j$. Como nesta rede não há autorrealimentação, temos que $w_{i j}=0, \forall i=j$.

O estudo da dinâmica de tal rede, no que se refere à estabilidade, envolve conceitos de funções de energia que permitem analisar quantitativa e qualitativamente os seus pontos fixos e assim, o seu retrato de fase. Essa estrutura neural artificial possui a propriedade de armazenamento e recuperação de memória e isto é útil em tarefas de reconhecimento de 
padrões que são incompletos ou ruidosos. Os pontos fixos são como memórias das características peculiares dos padrões aprendidos. Uma vez que é apresentado à rede um padrão com informação parcial ou confusa (com ruídos), pode-se verificar o quanto o mesmo está próximo dessas memórias, tornando, por fim, possível o reconhecimento.

Como exemplos de trabalhos que utilizaram as redes de Hopfield podemos citar o de Maurer, A., Hersch, M. e Billard, A. G. que desenvolveram estas redes para o armazenamento de sequências múltiplas de duração variável a fim de aplica-las em tarefas de aprendizado, reconhecimento e codificação de um conjunto de gestos humanos. ${ }^{9}$

Young, S.S., Scott, P. D. e Nasrabadi, N. M., utilizaram uma rede de Hopfield multicamada para classificação de objetos em relação às suas espessuras (grosso ou fino). Cada camada, neste caso, era formada por essas redes e codificava cada característica de um objeto em uma resolução distinta. Assim, as camadas eram interligadas em cascata e cada interconexão entre camadas adjacentes era de forma bidirecional. ${ }^{10}$

Ainda, recentemente, as redes de Hopfield servem como modelos de aplicação em trabalhos como o de Ahn, K. C. que explorou critérios de estabilidade em um tipo de rede de Hopfield. ${ }^{11}$ Como ferramentas de modelagem, tais redes foram utilizadas em estudos de padrões de grupos de opiniões sociais sob influências não-positivas. ${ }^{12}$

Assim, resumimos, nesta seção, os conceitos básicos da Neurodinâmica e algumas definições de elementos de Sistemas Dinâmicos que serão essenciais para toda a tese; fizemos também, uma síntese de uma RNA e algumas aplicações que a utilizam como fonte de inspiração.

A seguir será abordado outro elemento de estudo dinâmico e algumas de suas formas de contribuições em aplicações computacionais: fractais. 


\section{TEORIA FRACTAL E APLICAÇÕES} COMPUTACIONAIS

Fractais são conjuntos no plano cuja forma é extremamente irregular ou fragmentada e que apresentam essencialmente o mesmo padrão em todas as escalas. ${ }^{13,14}$

A geometria dos fractais permite uma estimativa muito mais precisa da dimensão de objetos naturais, que são muito distintos das formas euclidianas. Este tipo de geometria possui muitas aplicações, como por exemplo, em botânica e classificação de imagens de satélite ou de caracteres impressos. ${ }^{15,16,17,18}$

De acordo com Miranda, as figuras fractais foram nomeadas nos anos 1980 por Benoît Mandelbrot, na classificação de objetos que não possuíam dimensão inteira, mas fracionária. Daí o termo fractais (do latim fractus, o que significa fração, quebrado). ${ }^{19}$

A geometria fractal é o ramo da matemática que estuda propriedades e o comportamento dos fractais. O surgimento da teoria dos fractais ocorreu em trabalhos de cientistas entre o final do século XIX e começo do século XX. Porém, esta ciência teve desenvolvimento em sua plenitude a partir dos anos 1960, com o auxílio dos computadores. Mandelbrot foi um dos pioneiros a utilizar computadores para gerar fractais e foi o autor de um dos mais conhecidos, o Conjunto de Mandelbrot. Tal Conjunto no plano complexo é definido pelos pontos $c \in \mathbb{C}$, cuja órbita de $z_{j+1}=z_{j}^{2}+c$, com valor inicial na origem, seja limitada. Na Figura 5 temos este conjunto. 


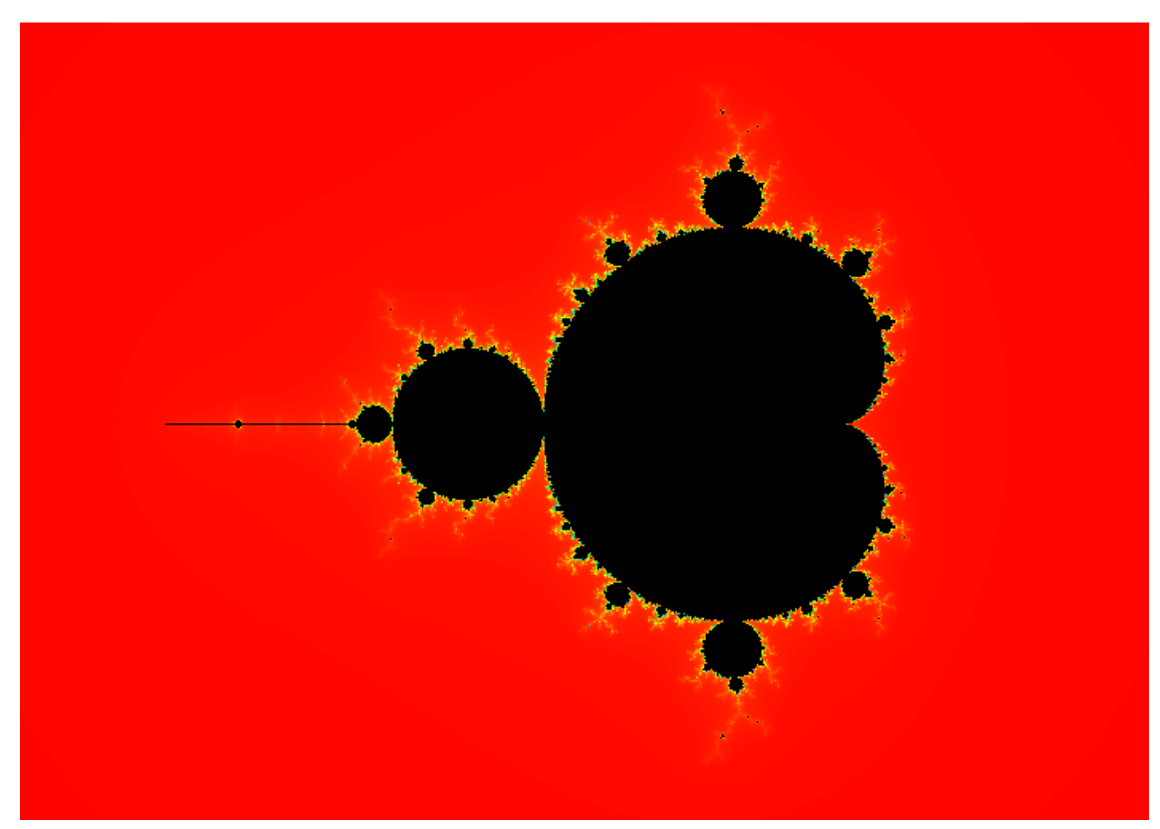

Figura 5 - Conjunto de Mandelbrot. Autoria própria.

Outro tipo de fractal conhecido é o Conjunto de Julia, descoberto pelo matemático Gaston Julia, no século passado. De forma simplificada, esse conjunto é formado por todos os pontos do plano complexo que conduzem a órbitas limitadas. ${ }^{20}$

Esse conjunto pode ser obtido por iterações da função $z_{j+1}=z_{j}^{2}+c, \operatorname{com} c$ sendo um número complexo, para cada ponto $z_{0}$ no plano complexo. Com isso, será gerada uma sequência de números complexos (órbita de $z_{0}$ ):

$$
z_{0} \rightarrow z_{1}=z_{0}^{2}+c \rightarrow z_{2}=z_{1}^{2}+c \rightarrow \ldots
$$

Se a órbita de $z_{0}$ tende ao infinito, então $z_{0}$ não pertence a nenhum Conjunto de Julia. Se a órbita de $z_{0}$ tende a algum círculo na origem, então $z_{0}$ pertence a algum Conjunto de Julia. Ambos os conjuntos complementam-se preenchendo alguma região do plano complexo. Dessa forma, a fronteira do primeiro conjunto citado é a fronteira do segundo, e nesta, tem-se o Conjunto de Julia que está associado a $c$.

Nas Figuras 6 há um destes conjuntos com seus respectivos parâmetros $c$. 


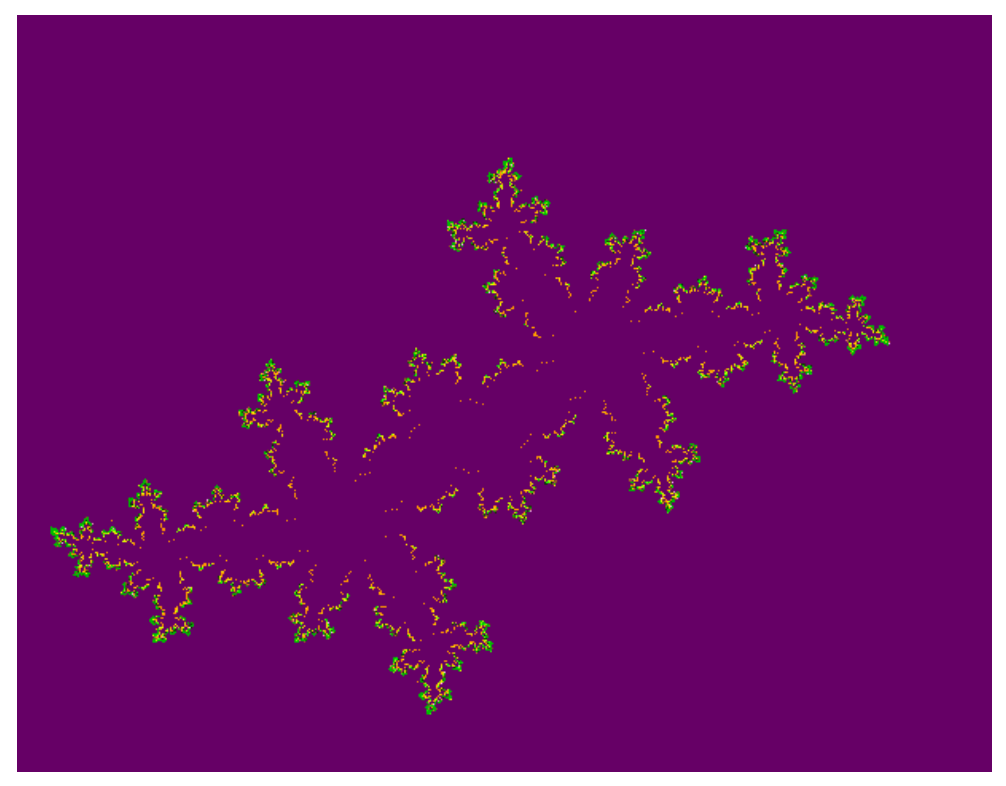

Figura 6 - Conjunto de Julia para c=-0,55+0,6i. Autoria própria.

É interessante observar que o algoritmo que constrói os Conjuntos de Julia considera um ponto $c$ do plano complexo fixo, enquanto que, nos Conjuntos de Mandelbrot, variam-se os pontos $c$ dentro de um reticulado definido pelo seu respectivo algoritmo.

Algumas das atividades computacionais que fazem uso da teoria fractal se resumem basicamente em problemas de classificação de padrões. As técnicas oriundas dessas atividades são caracterizadas como híbridas: as etapas que utilizam os fractais servem para extrair características e, o processamento restante, fica por conta de alguma RNA (Rede Neural Artificial), ou para correção de erros de classificação feitos por uma rede neural.

As figuras 7 e 8 apresentam duas ideias esquemáticas que ilustram em qual fase do processamento os fractais são empregados para a extração de características e otimização de classificações feitas por alguma RNA, respectivamente. 


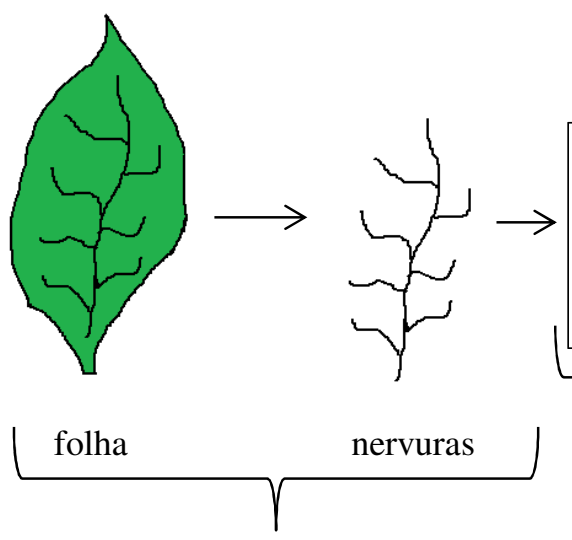

Processamento

Figura 7 - Classificação de espécies de plantas da Mata Atlântica e do Cerrado por meio de processamento das imagens de nervuras dos órgãos foliares. Adaptado de: Plotzer et al. ${ }^{21}$

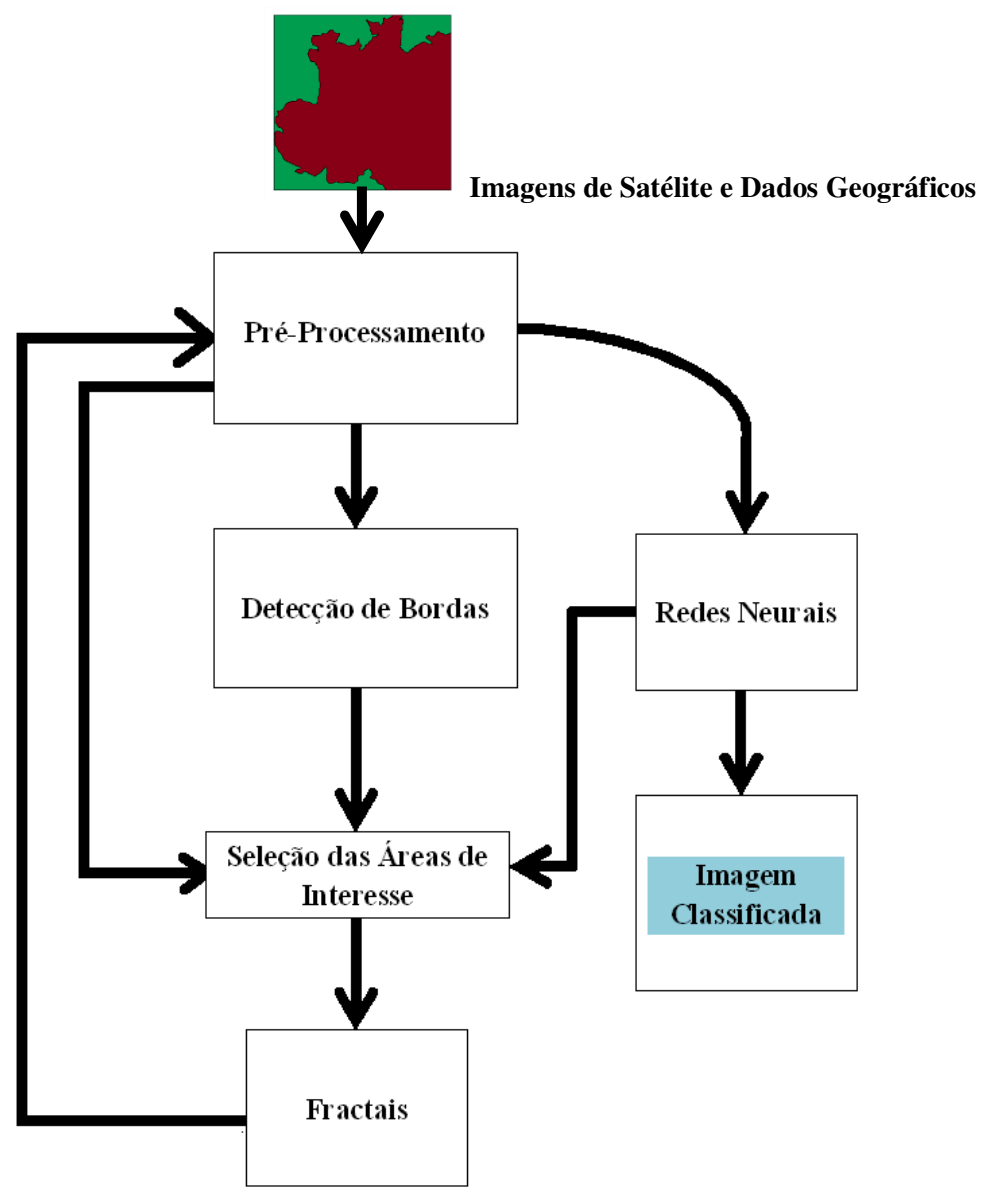

Figura 8 - Esquema do uso de fractais para corrigir erros de classificação em RNA's. Adaptado de: Gómes et al. ${ }^{22}$ 
No primeiro algoritmo ilustrado pela Figura 7, as nervuras das folhas servem de base para a construção do vetor de características por meio de conceitos da teoria fractal. Dessa forma, este vetor será a entrada para uma RNA executar a tarefa de classificar de qual espécie aquela folha faz parte.

No segundo exemplo de algoritmo ilustrado pela Figura 8, para classificar imagens de satélite, os fractais são utilizados para corrigir erros no processo de seleção das áreas geográficas feita por uma RNA, realimentando assim o pré-processamento para a mesma rede neural.

Por conseguinte, mostramos, resumidamente, o conceito de fractal e, de forma indireta, a importância do desenvolvimento dos computadores para o estudo dessa teoria, bem como o emprego de suas propriedades em problemas de classificação de padrões.

No próximo capítulo apresentaremos os principais conceitos e aplicações computacionais de reconhecimento de padrões estáveis de redes neurais modeladas com osciladores de CL de Stuart-Landau. 


\section{Osciladores de CiClo Limite DE STUART-LANDAU}

O objeto de estudo que faz parte desse trabalho consiste em osciladores de Ciclo Limite de Stuart-Landau, onde se interpreta cada oscilador como um neurônio e os mesmos são interligados, formando um anel. Aqui será abordado o tipo de oscilador descrito pelo sistema de equações diferenciais:

$$
\dot{z}_{j}(t)=(\alpha+i \beta) z_{j}(t)-z_{j}(t)\left|z_{j}(t)\right|^{2}+K_{j} z_{j+1}\left(t-\tau_{j}\right)
$$

Cada $K_{j}$ e $\tau_{j}$ são, respectivamente, os pesos sinápticos (forças de acoplamento) e os atrasos de tempo de sinal entre os neurônios, $j=1, . ., N$, com $N$ sendo o número de neurônios no anel; $\alpha$ e $\beta$ são constantes reais arbitrárias.

Na Figura 10, há um esboço de como seria esse sistema dinâmico, bem como a propagação de sinal de forma unilateral:
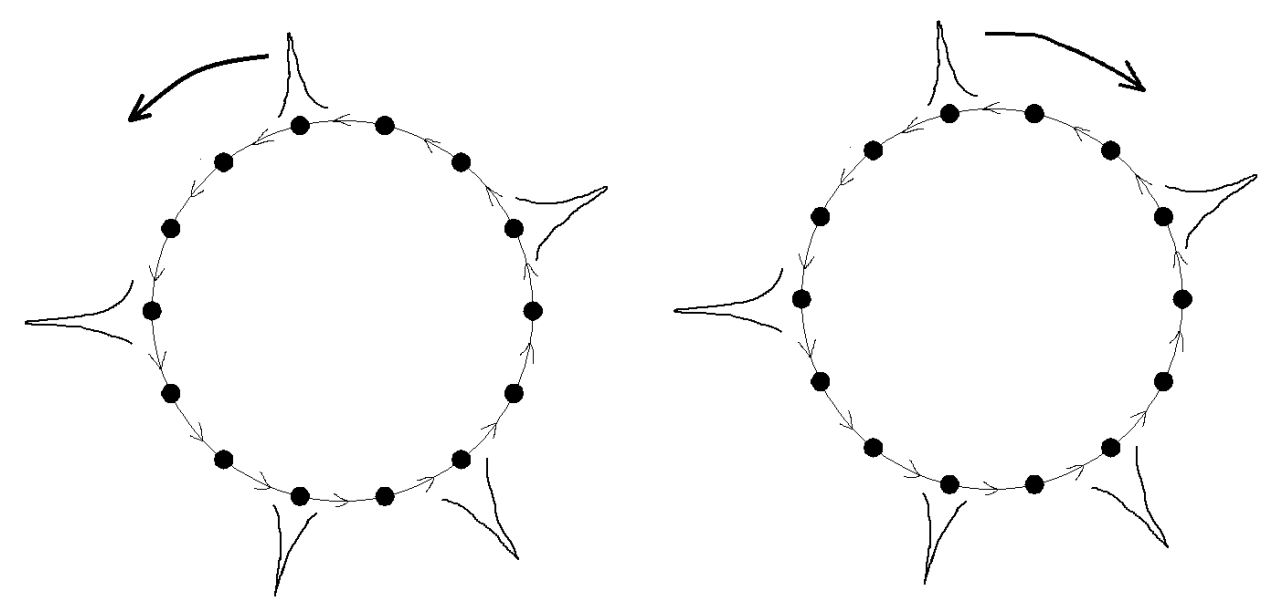

Figura 10 - Esboço de um anel de neurônios acoplados. À esquerda, trens de pulsos percorrendo no sentido do anel. À direita, trens de pulsos percorrendo no sentido contrário do anel. Adaptado de: Yanchuk et al. ${ }^{21}$

Conforme Yanchuk et al., os estudos envolvendo anéis neurais como osciladores de Stuart-Landau, na forma não homogênea (isto é, na equação (3), os $K_{j}$ são diferentes entre si), as soluções periódicas podem ser vistas como: 


$$
z_{j}(t)=\rho_{j} e^{i \omega t+i \psi_{j}}
$$

Com amplitudes $\rho_{j}$, frequência $\omega$ e mudanças de fase $\psi_{j} .{ }^{23}$ Substituindo (4) em (3), os pesos sinápticos $K_{j}$ e as amplitudes $\rho_{j}$, para um padrão de fase $\left\{\psi_{j}\right\}_{J=1}^{N}$, serão iguais, respectivamente às equações seguintes:

$$
\begin{gathered}
K_{j}=\frac{\rho_{j}}{\rho_{j+1}} \frac{\omega-\beta}{\sin \left(\psi_{j+1}-\psi_{j}-\omega \tau_{j}\right)} \\
\rho_{j}=\sqrt{\alpha+(\omega-\beta) \cot \left(\psi_{j+1}-\psi_{j}-\omega \tau_{j}\right)}
\end{gathered}
$$

As expressões (5) e (6) serão demonstradas no Apêndice, ao final desse trabalho.

Existem, no mínimo, três vantagens não triviais desses anéis de osciladores em relação às redes neurais dinâmicas tradicionais, como a de Hopfield, descrita no antepenúltimo capítulo: primeira, cada padrão de entrada pode ser codificado por um vetor em vez de uma matriz; segunda, os pesos sinápticos podem ser determinados analiticamente e terceira, devida a sua natureza dinâmica, são hábeis para capturar padrões temporais.

Existem outros trabalhos que abordam sistemas como o descrito em (3), analisando os seus aspectos dinâmicos, como critérios de estabilidade, caoticidade ou como modelos de RNA's, utilizando estes mesmos aspectos em tarefas de classificação ou reconhecimento de padrões. Como estudos sobre a dinâmica desse tipo de rede neural, podemos citar e expor sucintamente que Zou, W. et al. analisaram a dinâmica desses osciladores, via estudo dos seus pontos fixos no retrato de fase. Para isso, eles utilizaram, inicialmente, dois osciladores, fazendo suas análises para cada um separadamente e destituídos de conexões $(K=0)$ entre eles. Para ambos os osciladores com amplitudes constantes $\left(\rho_{1}=r_{1}\right.$ e $\left.\rho_{2}=r_{2} ; r_{1}=r_{2}=1\right)$, suas soluções são periódicas com mesmo período $T=\frac{1}{\omega}$ e estáveis (Ciclos Limites) o que 
também foram estáveis no caso em que $\rho_{1} \neq 1$ e $\rho_{2} \neq 1$ e $\rho_{1} \neq \rho_{2}{ }^{24}$. Na Figura 11 está um esboço para este último caso comentado.

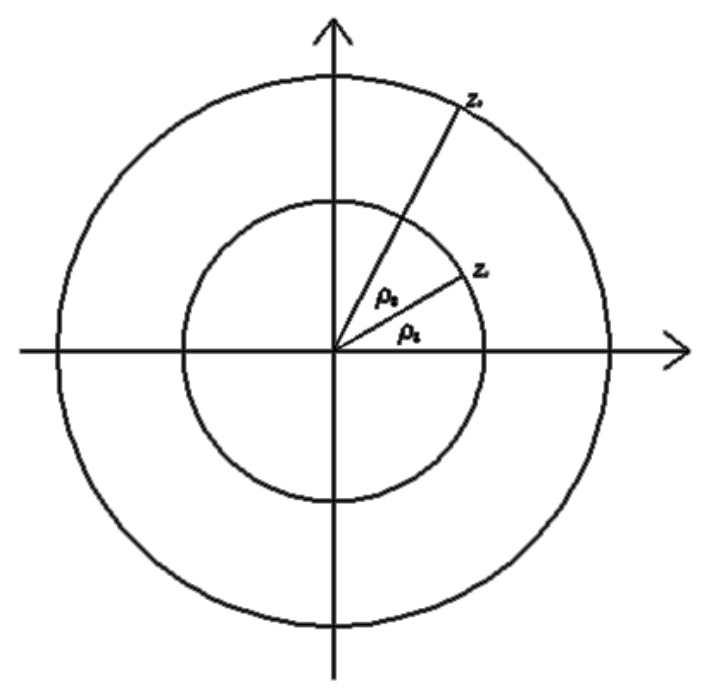

Figura 11 - Trajetórias de duas soluções periódicas no retrato de fase $\operatorname{com} \boldsymbol{\rho}_{\mathbf{1}} \neq \boldsymbol{\rho}_{2}$. Círculos concêntricos (Ciclos Limites). Autoria própria.

No ponto $z_{j}(t)=0, \forall t \in \mathbb{R}_{+}$, com $K_{l} \neq 0$, Reddy, D. V. et al. estudaram analiticamente, em mais detalhes, a instabilidade desta região. Quando (3) não possui atrasos de tempo $\left(\tau_{j}=0, \forall j \in\{1,2\}\right)$ a origem mantem as soluções periódicas. Para o caso em que $\tau_{j}$ $\neq 0, \forall j \in\{1,2\}$, com o uso de cálculos algébricos em (3), há o surgimento de múltiplas frequências de oscilação em (4). Eles esboçaram gráficos com tais frequências e as amplitudes associadas, versus pesos sinápticos. Eles perceberam que, com valores baixos de amplitudes, há regiões instáveis e com isso, soluções instáveis. ${ }^{25}$

Quando a quantidade de neurônios é maior do que 2, iremos analisar o aspecto dinâmico das soluções periódicas por meio de simulações do seu espectro, variando as condições iniciais temporais $t$, por considerarmos mais intuitivo.

Considerando as soluções periódicas (4), observam-se, por meio das simulações computacionais apresentadas nas Figuras 12, 13 e 14, que, considerando ambas suas partes, reais ou imaginárias, há uma tendência caótica destas, por meio de variações das condições temporais iniciais. Também há de se considerar que os atrasos de tempo estão sendo descritos como por $\tau_{j}=\tau+\eta_{j+1}-\eta_{j}$, com $1 \leq j \leq N$, com $\tau$ sendo o atraso de tempo homogêneo. Os $\eta_{j}$ são obtidos por uma distribuição uniforme sobre o intervalo de tempo [-0,06s; $\left.0,06 \mathrm{~s}\right] \mathrm{e}$ 
suavizados por uma média móvel sobre 25 neurônios. Na Figura 12, percebe-se um acréscimo de perturbação nos espectros, com aumento de condições iniciais de tempo nas partes reais $(\operatorname{Re}(z))$ e imaginárias $(\operatorname{Im}(z))$ de (4) com $\mathrm{n}=50$ neurônios.

$\mathrm{t}=0 \mathrm{~s}$ e $\mathrm{N}=50$

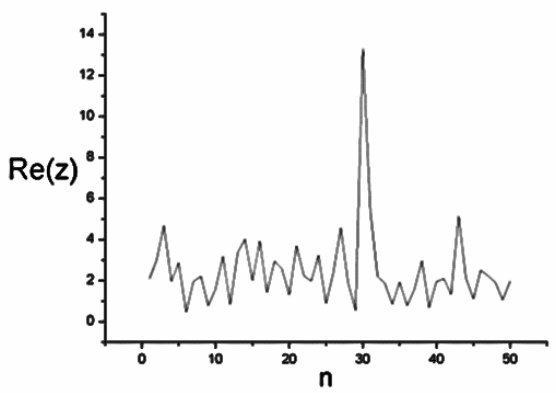

(a)

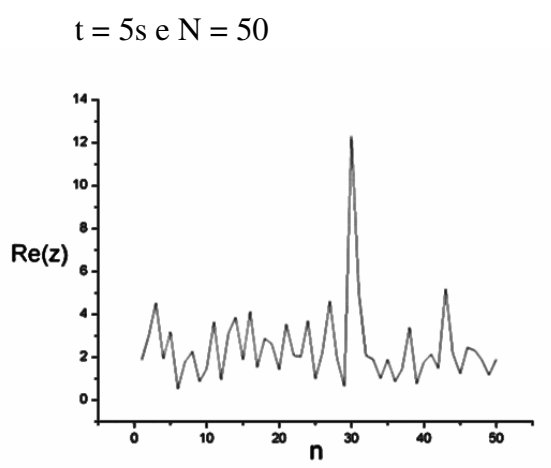

(c)

$\mathrm{t}=10$ s e $\mathrm{N}=50$

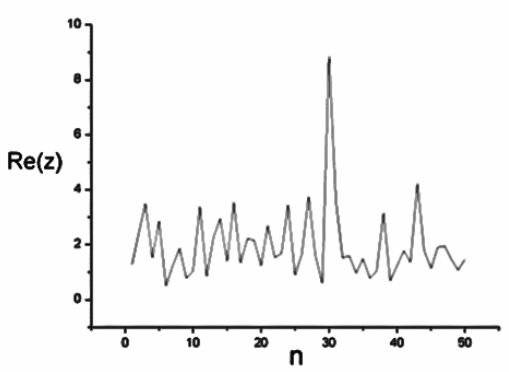

(e)

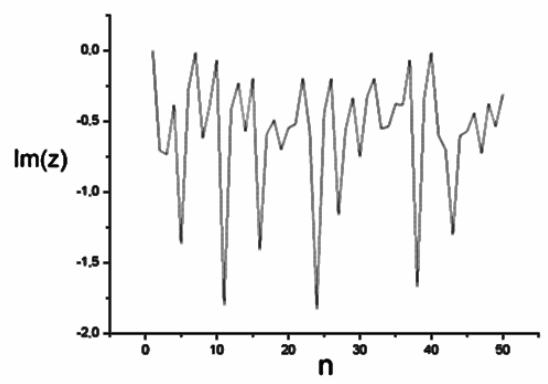

(b)

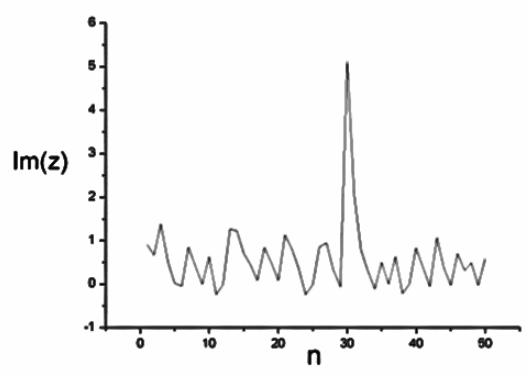

(d)

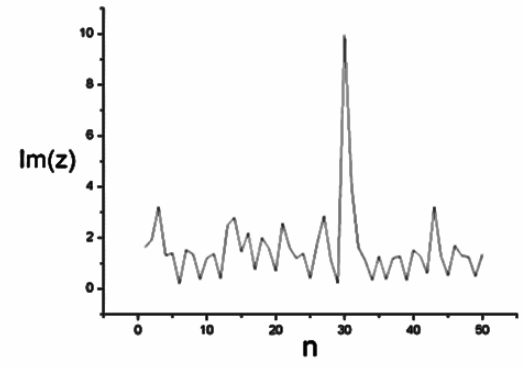

(f)

Fim da primeira parte da Figura 12 
Início e fim da segunda parte da Figura 12

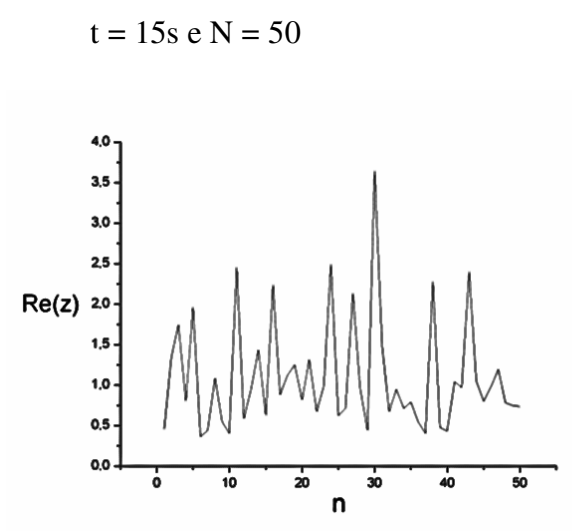

(g)

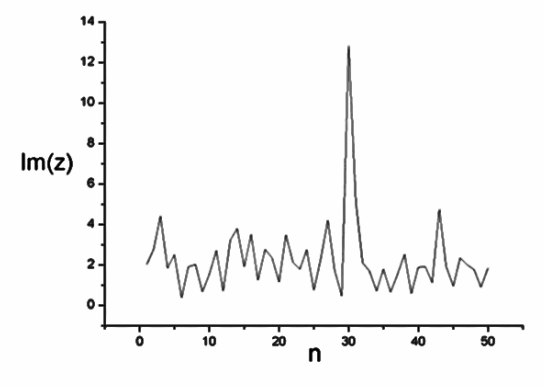

(h)

Figura 12 - Aumento das perturbações ora nas partes reais, ora nas partes imaginárias no espectro das soluções com 50 neurônios. Variação temporal inicial observada de (a) a (h).

Há também um aumento nas perturbações dos espectros para os anéis com 100 e 150 neurônios, respectivamente, variando as condições iniciais temporais, da mesma forma como do conjunto de figuras anterior. Isto pode ser constatado nas Figuras 13 e 14 .

$\mathrm{t}=0$ s e $\mathrm{N}=100$

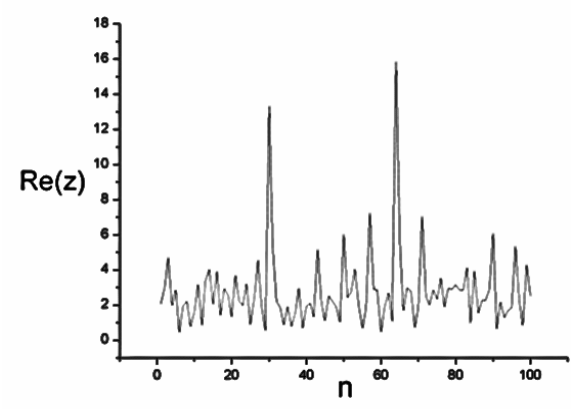

(i)

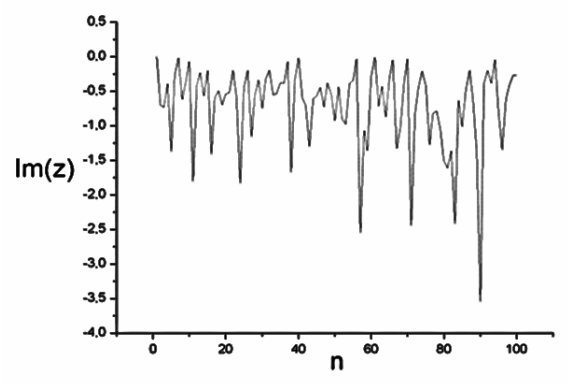

(j)

Fim da primeira parte da Figura 13 
Início e fim da segunda parte da Figura 13

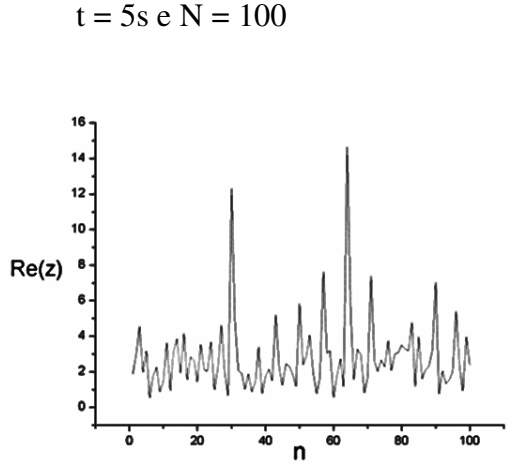

(k)

$\mathrm{t}=10$ s e $\mathrm{N}=100$

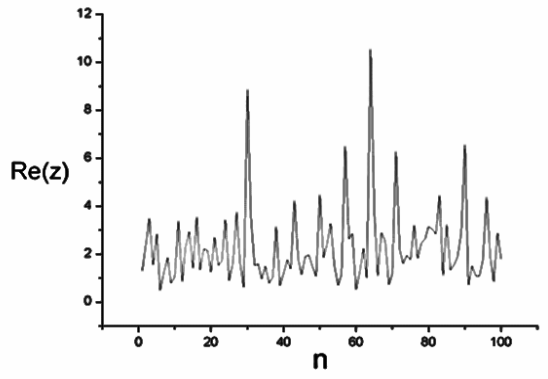

(m)

$$
\mathrm{t}=15 \mathrm{~s} \text { e } \mathrm{N}=100
$$

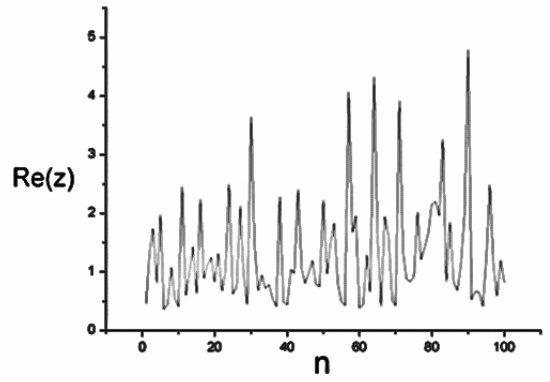

(o)

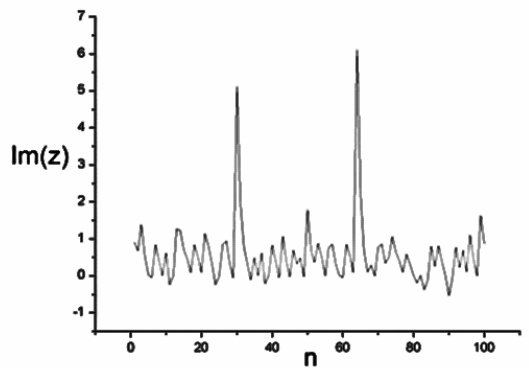

(1)

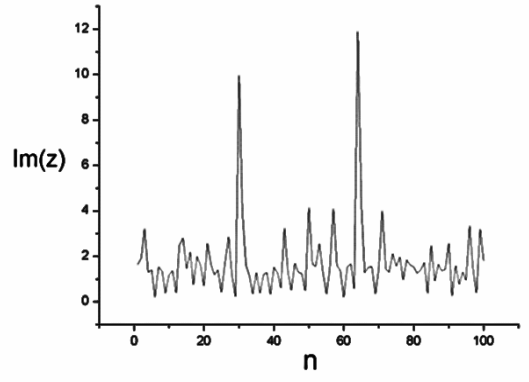

(n)

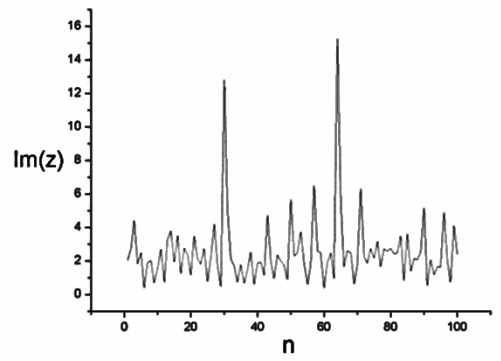

(p)

Figura 13 - Aumento das perturbações do espectro das soluções de (i) a (p). Simulações feitas com 100 neurônios. 
$t=0$ s e $N=150$

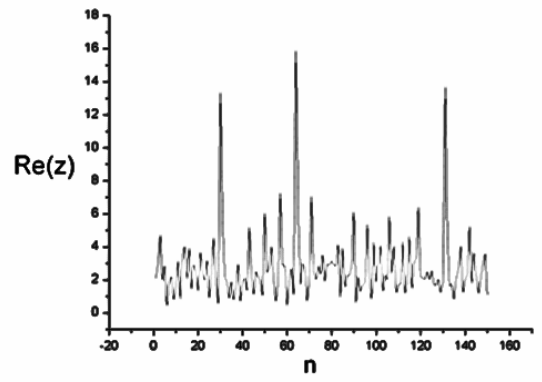

(q)

$t=5 s$ e $N=150$

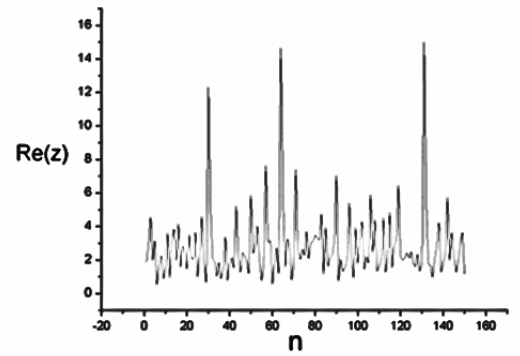

(s)

$$
\mathrm{t}=10 \mathrm{~s} \text { e } \mathrm{N}=150
$$

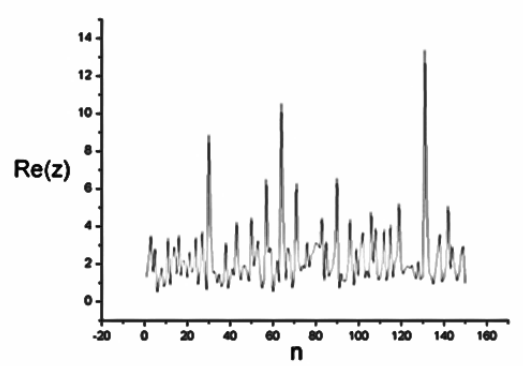

(u)

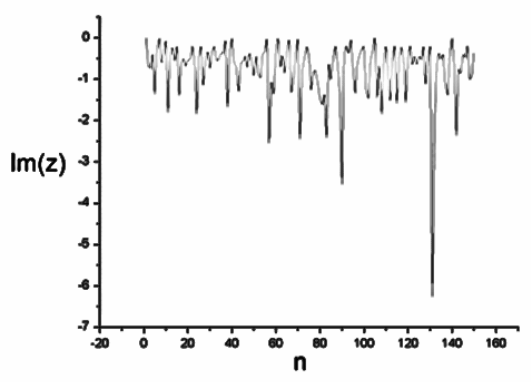

(r)

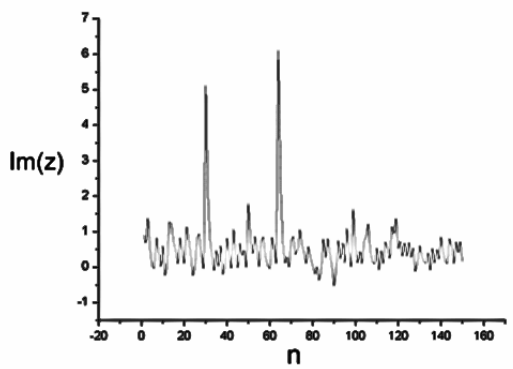

(t)

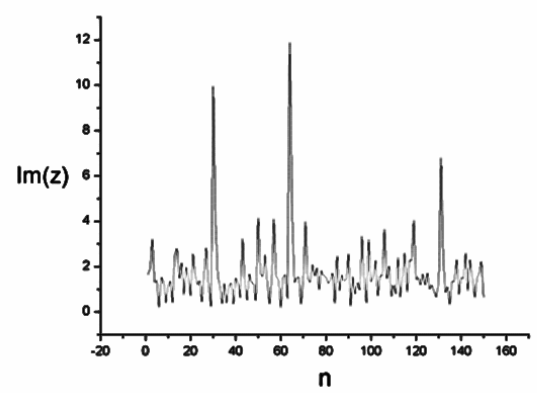

(v) 
Início e fim da segunda parte da Figura 14

$$
\mathrm{t}=15 \mathrm{~s} \text { e } \mathrm{N}=150
$$

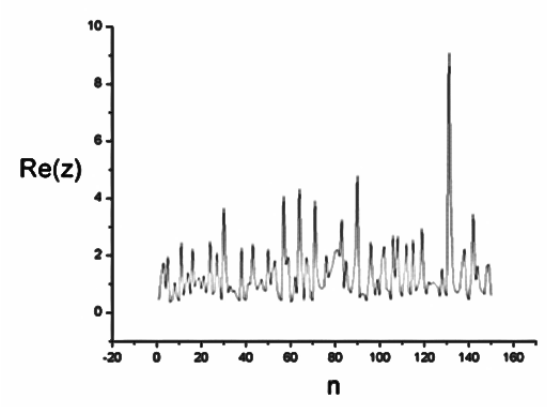

(w)

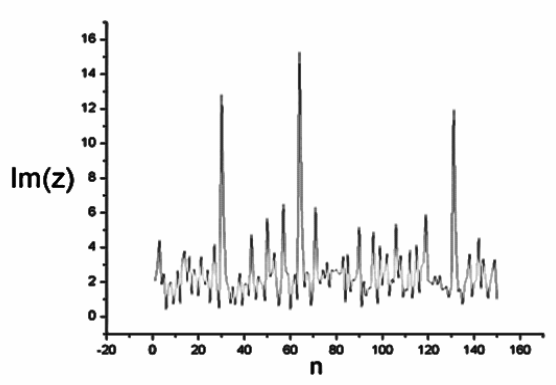

$(\mathrm{x})$

Figura 14 - Aumento das perturbações do espectro das soluções de (q) à (x). Simulações feitas com 150 neurônios.

Portanto, conforme o que foi presenciado nos trabalhos resumidos anteriormente e nas simulações feitas, verifica-se uma tendência do anel neural modelado via osciladores de Ciclo Limite de Stuart-Landau em obter um comportamento caótico, variando numericamente as condições iniciais temporais. Quando este sistema neural é estável, o mesmo reconhece padrões estáveis gerados aleatoriamente.

Para um padrão de fase $\left\{\psi_{j}\right\}_{J=1}^{N}$, frequência $\omega$ e os atrasos homogêneos dados são possíveis encontrar, de forma única, os termos em (4) que geram tal padrão espaço-temporal em (3). O valor de $\omega$ é obtido considerando (3) homogêneo, no sentido de que os atrasos de tempos são de mesmo valor entre si, assim como todos os pesos sinápticos e tal frequência é encontrada por uma equação transcendental (equação cuja solução é encontrada apenas por métodos de cálculo numérico) obtida pela resolução de (3). Diante destas considerações, cada $\psi_{j}=-2 \pi \eta_{j} / T$, onde $\eta_{j}$ são os tempos de disparo para cada neurônio do anel e $T=1 / \omega$, isto é, o período de referência do padrão sincronizado na fase. Levando-se em conta que as soluções periódicas descritas por (4), atravessam a seção de Poincaré $\{x=0, y \geq 0\}$, a Figura 15 (y) é obtida por esse cruzamento aleatório, com $\omega \approx 1,25 \mathrm{~ms}^{-1}, \mathrm{n}=100$ neurônios e $t$ variável. Na Figura 15(z) ilustra que, por meio de simulações numéricas em (3), com os pesos sinápticos encontrados, o mesmo padrão é encontrado. 


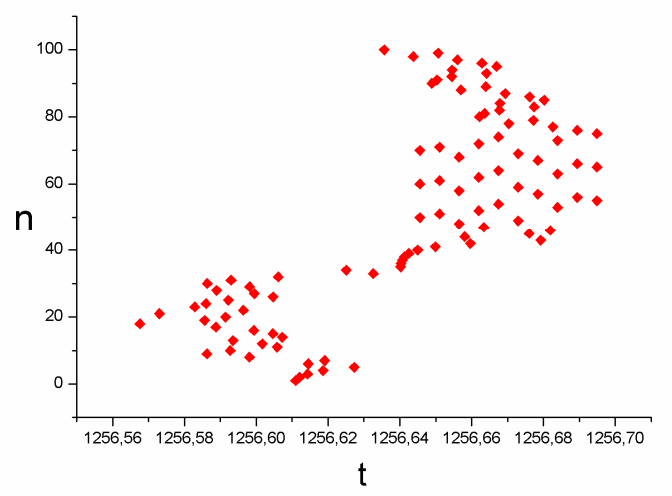

(y)

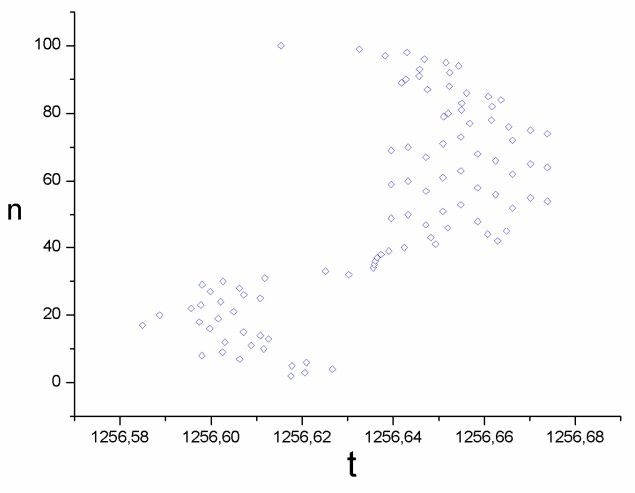

(z)

Figura 15 - Padrão estável gerado aleatoriamente (em vermelho) mediante os pontos $(\mathrm{t}, \mathrm{n})$ dos quais as soluções periódicas atravessam a Seção de Poincaré $\{x=0, y \geq 0\}$. Simulações (em azul) reconhecem o padrão gerado.

O programa em Fortran 77 criado a partir do algoritmo descrito no parágrafo anterior que permite esboços de padrões estáveis como os da Figura 15 se encontra no Apêndice, no final deste trabalho.

Diante das considerações do comportamento dinâmico que o sistema descrito em (3) nos forneceu, a questão a ser possivelmente levantada seria a seguinte:

- O mesmo sistema, com perturbações, reconheceria padrões caóticos gerados ao acaso?

A resposta é afirmativa, como será abordado a seguir, mediante a apresentação de um algoritmo que possibilita a este tipo de anel neural identificar figuras fractais. 


\section{RECONHECIMENTOS DE PADRÕES FRACTAIS AlEATórios POR OSCILAdORES DE CIClo LIMITE DE STUART-LANDAU}

Nesta seção será apresentado um algoritmo que permite o anel neural estudado reconhecer figuras fractais geradas de forma aleatória. Também serão apresentadas as simulações estatísticas que corroboram com o desempenho que esta tarefa encarrega para este tipo de rede neural.

Nas simulações computacionais com o uso do algoritmo proposto, manteve-se a mesmas características numéricas da seção anterior para as constantes $\alpha$ e $\beta$, ou seja, a primeira foi fixada no valor unitário e a segunda, foi realizada uma distribuição normal em torno desta variável com desvio igual a 0,01 e esta servindo como média igual a 1 .

Para o cálculo das amplitudes e pesos sinápticos, foram usadas as equações (5) e (6) do capítulo anterior.

Para as simulações, usamos, no cálculo das órbitas, as partes reais, $x_{j}(t+h)$, e imaginárias, $y_{j}(t+h)$, onde $h$ é o incremento, fornecidas pelas equações (7) e (8):

$$
\begin{aligned}
& x_{j}(t+h) \approx\left(\alpha h-h \rho_{j}^{2}+1\right) \rho_{j} \cos \left(\omega t+\psi_{j}\right)-h \beta \rho_{j} \operatorname{sen}\left(\omega t+\psi_{j}\right)+h K_{j} \rho_{j+1} \cos (\omega t+ \\
& \left.\psi_{j+1}-\omega \tau_{j}\right) \\
& y_{j}(t+h) \approx\left(\alpha h-h \rho_{j}^{2}+1\right) \rho_{j} \operatorname{sen}\left(\omega t+\psi_{j}\right)+h \beta \rho_{j} \cos \left(\omega t+\psi_{j}\right)+h K_{j} \rho_{j+1} \operatorname{sen}(\omega t+ \\
& \left.\psi_{j+1}-\omega \tau_{j}\right)
\end{aligned}
$$

Estas equações serão demonstradas no Apêndice, no final deste trabalho. A seguir, são apresentados nas Figuras 16 e 17, os fluxogramas do algoritmo desenvolvido. O programa em Fortran 77 do mesmo encontra-se no final da tese. 


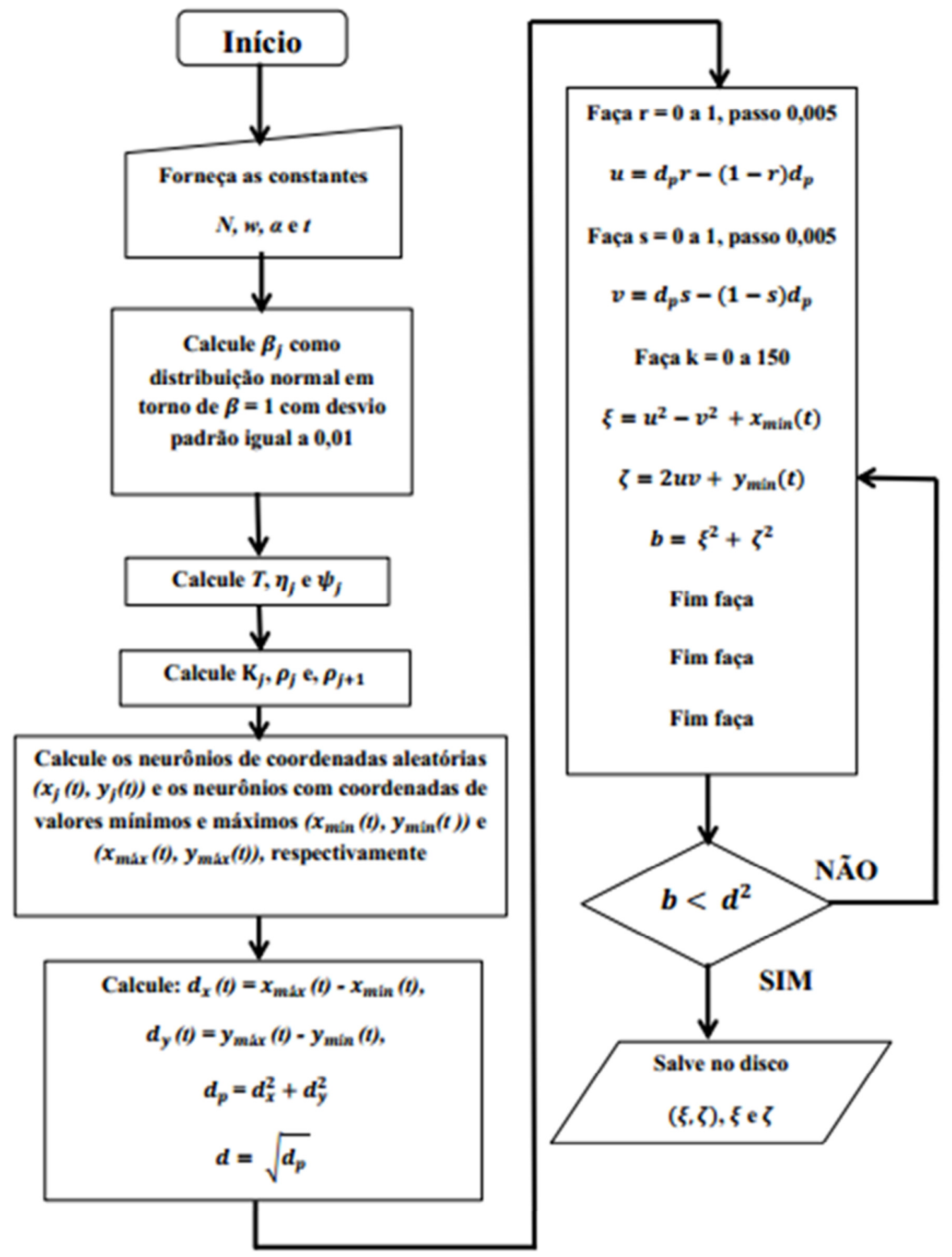

Figura 16 - Parte do programa em fluxograma responsável por gerar e armazenar o fractal aleatório por meio das funções de iterações $\xi=Q^{k}\left(u, v, x_{m i n}(t)\right)=u^{2}-v^{2}+x_{m i ́ n}(t)$ e $\zeta=Z^{k}\left(u, v, y_{m i ́ n}(t)\right)=2 u v+y_{m i ́ n}(t)$. 
Calcule os neurônios simulados $(x \operatorname{simu}(t), y \operatorname{simu}(t))$ e os neurônios com coordenadas de valores mínimos e máximos $\left(x \operatorname{sim} u_{\min }(t), y \operatorname{sim} u_{\min }(t)\right)$ e $\left(x \operatorname{sim} u_{\operatorname{mix}}(t), y \operatorname{sim} u_{\max }(t)\right)$, respectivamente

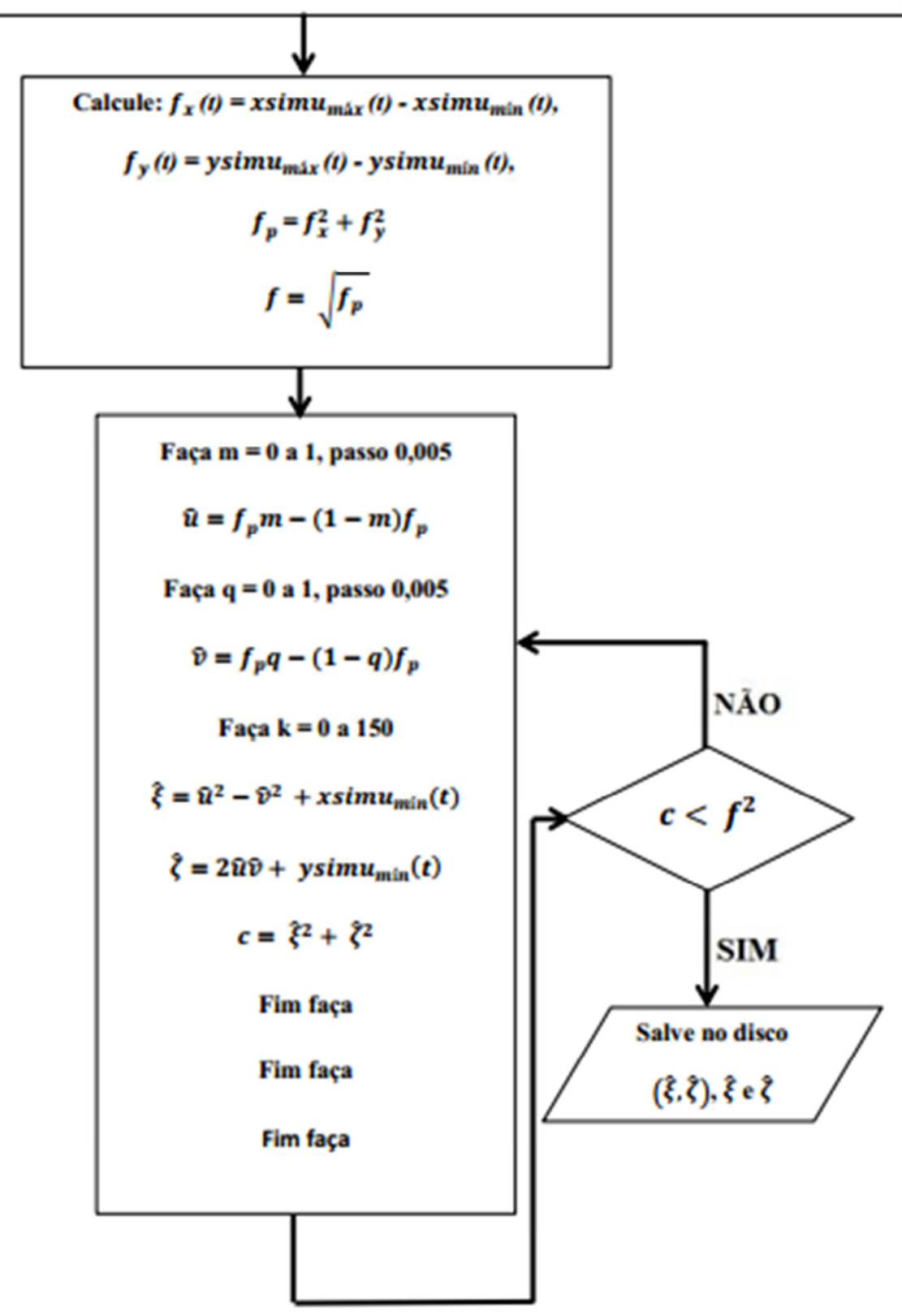

Figura 17 - Parte do programa em fluxograma responsável pelo reconhecimento e armazenamento do padrão fractal gerado por meio das equações (7) e (8) (neurônios simulados). Foram utilizadas as mesmas funções de iterações descritas na Figura 16. 
Com o programa criado e usando amostras de 50, 100, 150 e 200 neurônios respectivamente, nota-se um reconhecimento progressivo do anel neural frente aos fractais gerados de forma aleatória (figuras em vermelho); em 200 neurônios, praticamente esse tipo de rede reproduz fielmente tais figuras (Figura 21(m1) e Figura 21(n1)). Isto é confirmado por meio dos gráficos de correlações (Figura 21(o1) e Figura 21 (p1)).

Nas Figuras 18, 19, 20 e 21, são apresentadas as evoluções das órbitas geradas com base nos neurônios do anel e as comparações das figuras geradas aleatoriamente (em vermelho) com as obtidas por meio de simulações (em azul). Os respectivos diagramas de correlação são apresentados com o objetivo de expor o aprendizado progressivo do anel nas tarefas de reconhecimento das figuras construídas. Comparando-se os eixos dos gráficos das figuras com os fluxogramas apresentados anteriormente, $\operatorname{Re}(z)=\xi$ (qsi) e $\operatorname{Im}(z)=\zeta$ (zeta), $\operatorname{RSimu}(z)=\widehat{\xi}$ (qsichap) e $\operatorname{ImSimu}(z)=\hat{\zeta}$ (zetachap).

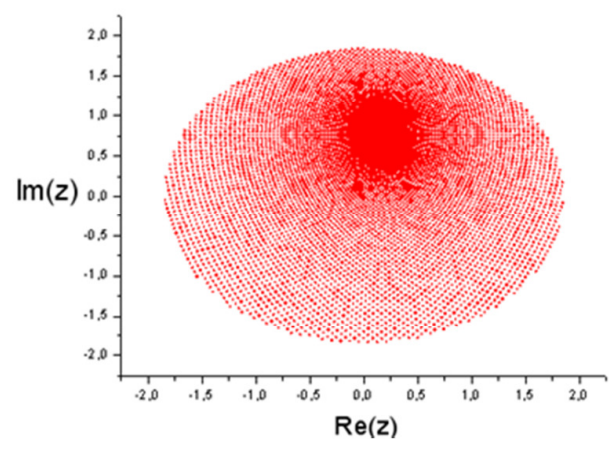

(a1)

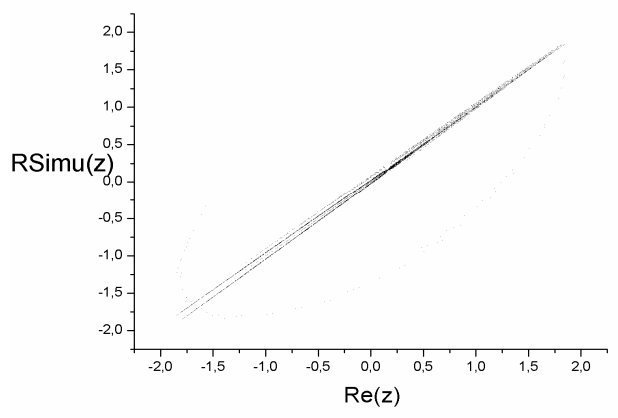

(c1)

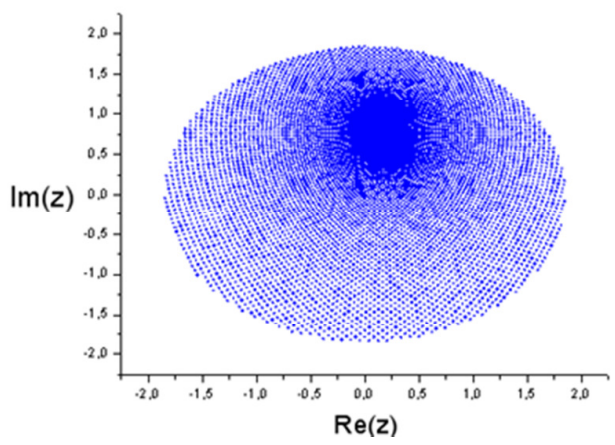

(b1)

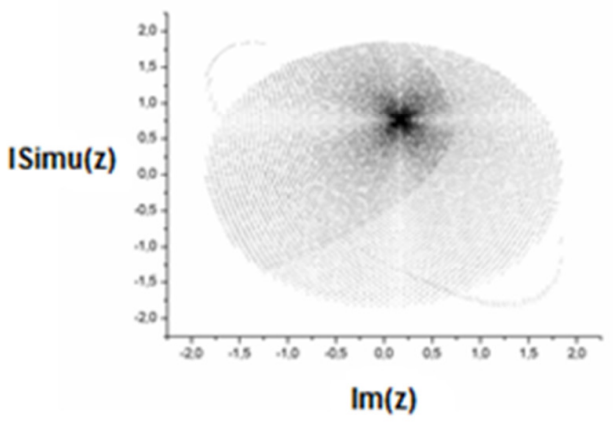

(d1)

Figura 18- Simulação realizada com 50 neurônios. O gráfico em vermelho e sua região caótica (fractal) obtida aleatoriamente em (a1). O gráfico em azul e sua região caótica (fractal) são obtidos por meio de simulações em (b1) e (c1-d1) são os gráficos de correlações entre as partes reais e imaginárias das órbitas. 


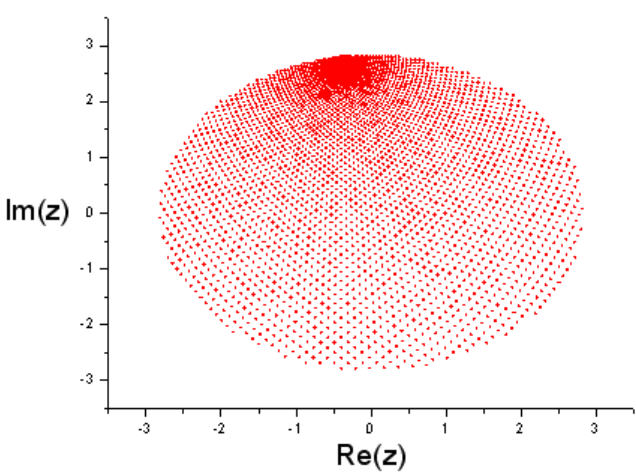

(e1)

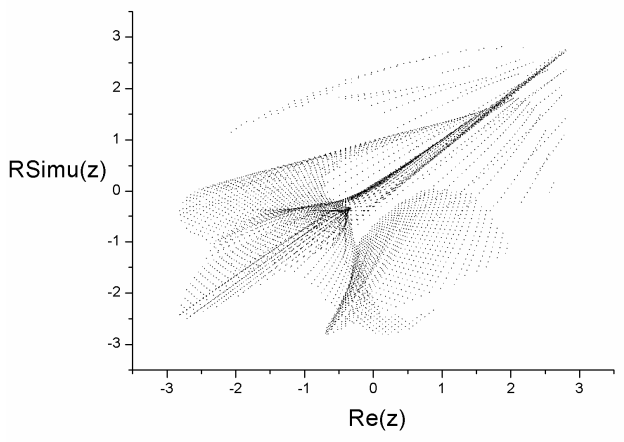

(g1)

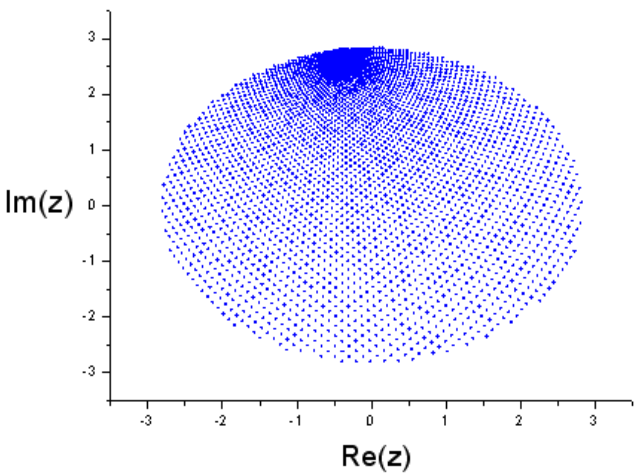

(f1)

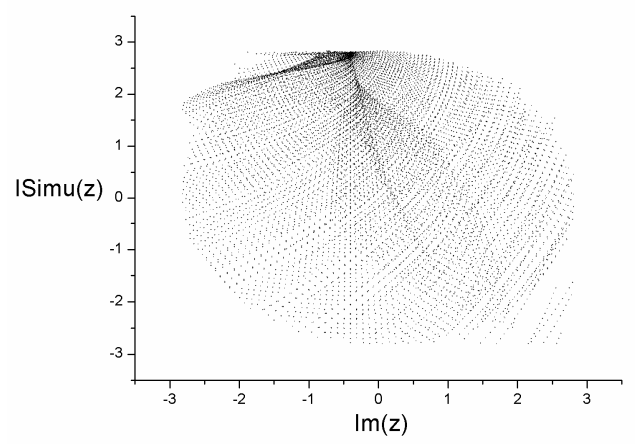

(h1)

Figura 19 - Geração aleatória do fractal em (e1), utilizando 100 neurônios (região caótica em vermelho). A região caótica em azul (f1) é o fractal gerado por meio de simulações com 100 neurônios. Em (g1) e (h1), gráficos de correlações entre partes reais e imaginárias das órbitas.

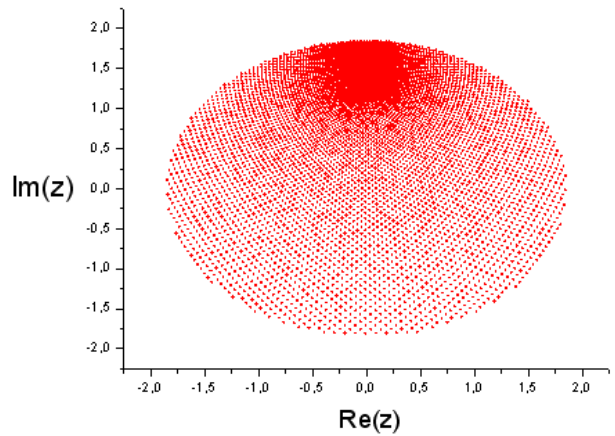

(i1)

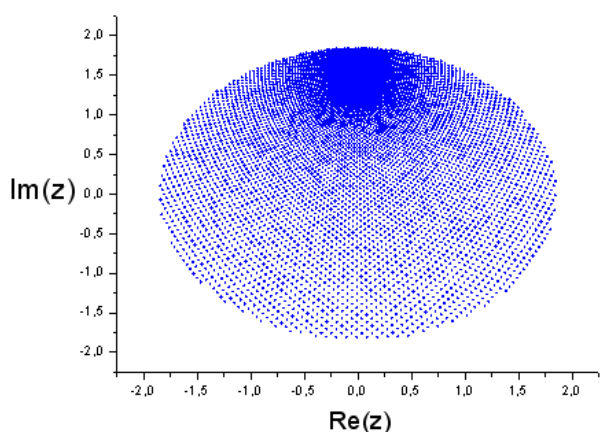

(j1) 
Início e fim da segunda parte da Figura 20

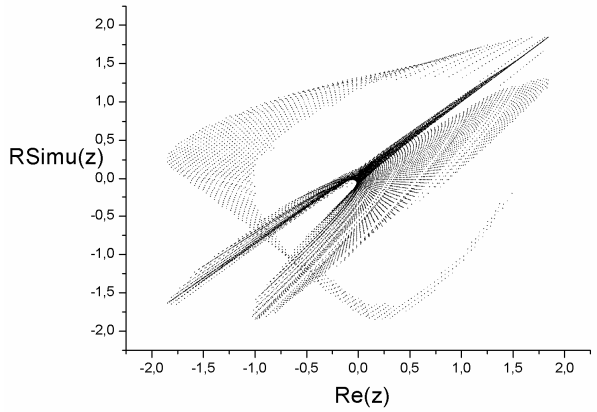

(k1)

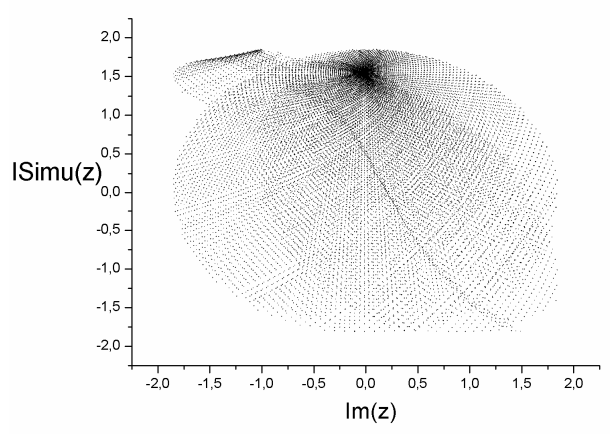

(11)

Figura 20 - Fractal aleatório (região caótica em vermelho) e o de simulação (região caótica em azul). Os testes foram realizados com 150 neurônios. Em (k1) e (11) ocorreu uma dispersão menor.

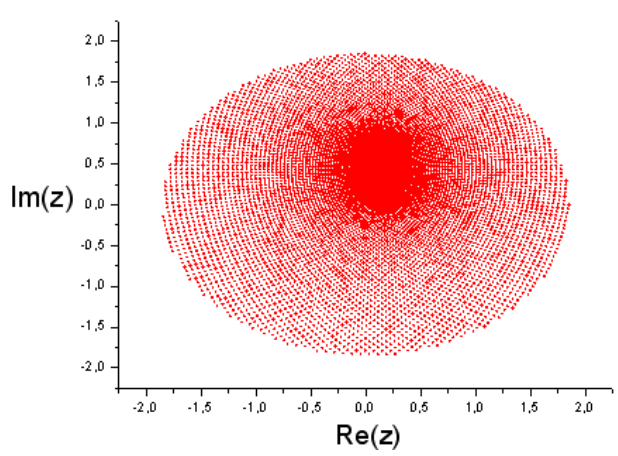

(m1)

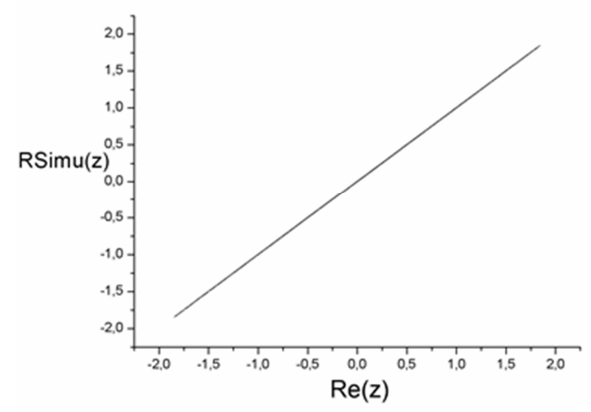

(o1)

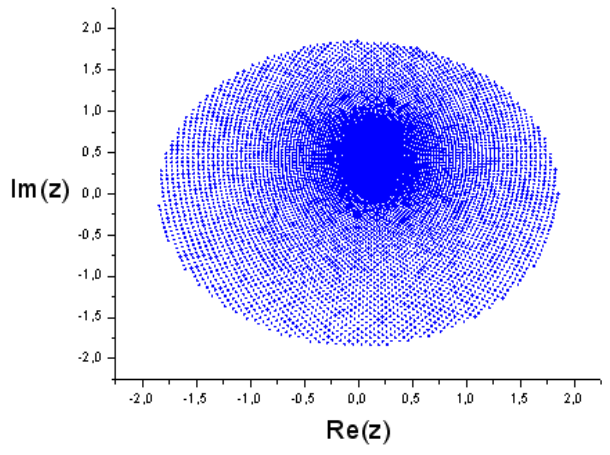

(n1)

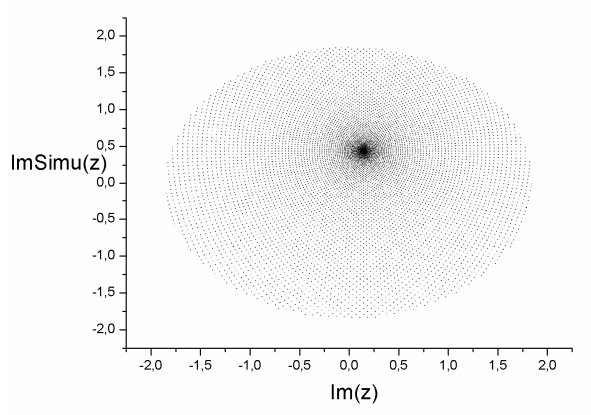

(p1)

Figura 21 - Regiões caóticas aleatórias (m1) e simuladas (n1), usando-se 200 neurônios. Gráficos de correlações das partes reais (o1) e imaginárias (p1) das órbitas. 
Fixando $\mathrm{N}=50$ e variando $\mathrm{t}=0,5$ e $10 \mathrm{~s}$, ocorre um aprendizado gradual para as simulações de (q1) à (b2) que utilizam o mesmo tipo de figura. A seguir, têm-se as simulações que comprovam tais afirmações.

$\mathrm{N}=50, \mathrm{t}=0 \mathrm{~s}$

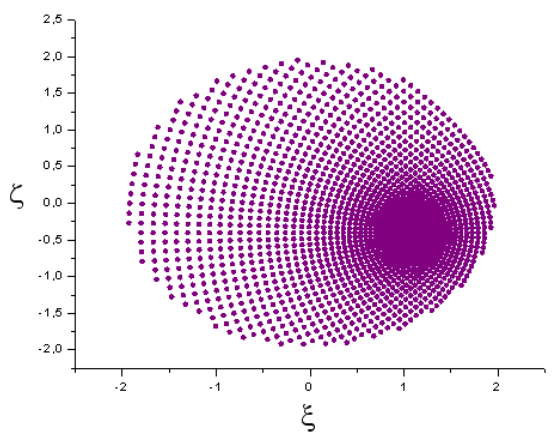

(q1)

Gráficos de correlações $(\mathrm{N}=50, \mathrm{t}=0 \mathrm{~s})$

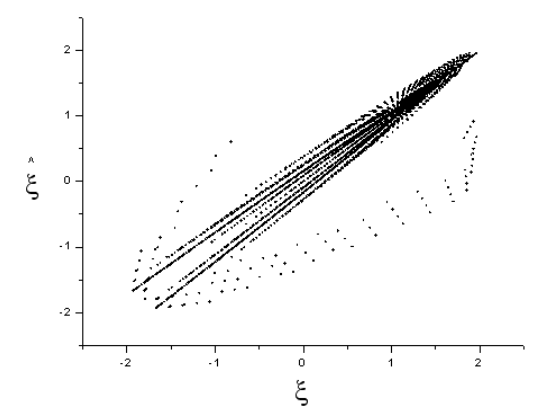

(s1)

$\mathrm{N}=50, \mathrm{t}=5 \mathrm{~s}$

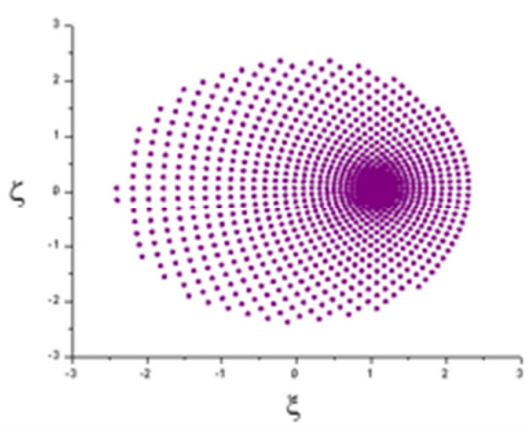

(u1)

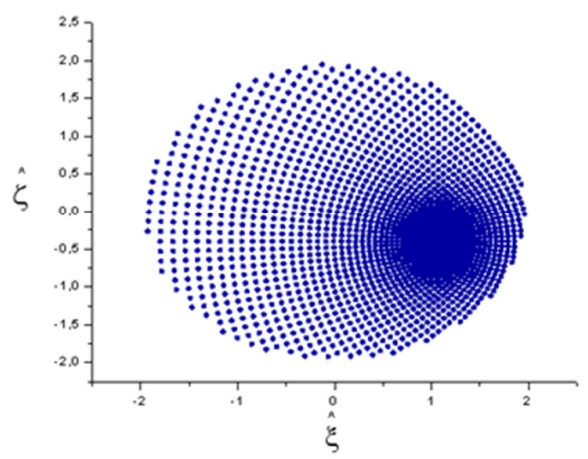

(r1)

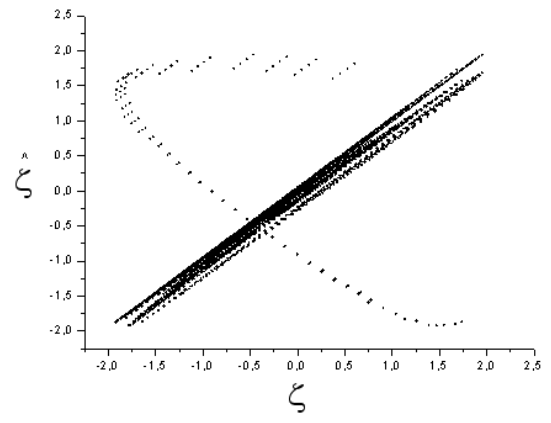

(t1)

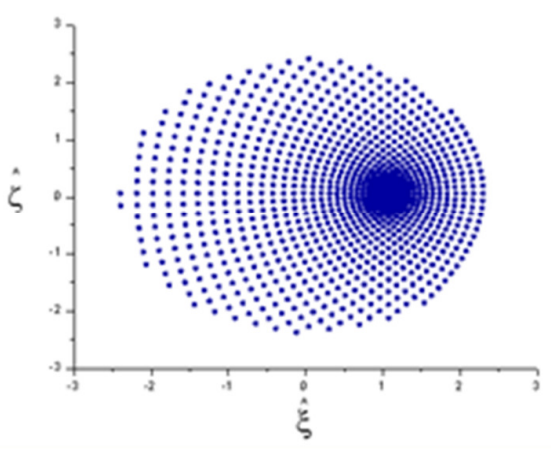

(v1)

Fim da primeira parte da Figura 22 
Início e fim da segunda parte da Figura 22

Gráficos de correlações $(\mathrm{N}=50, \mathrm{t}=5 \mathrm{~s})$

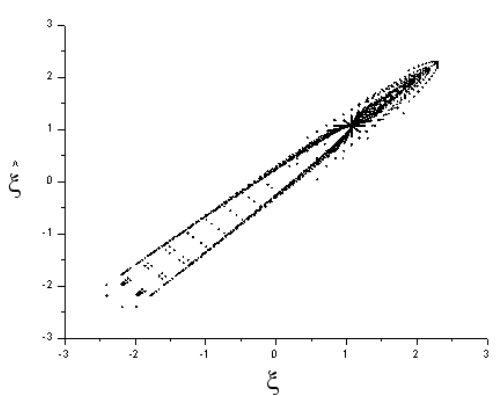

(w1)

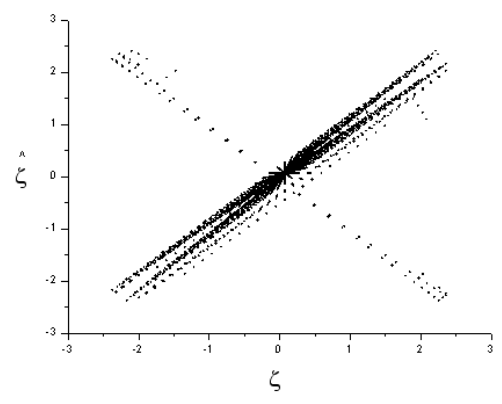

(x1)

$\mathrm{N}=50 \mathrm{~s}, \mathrm{t}=10 \mathrm{~s}$

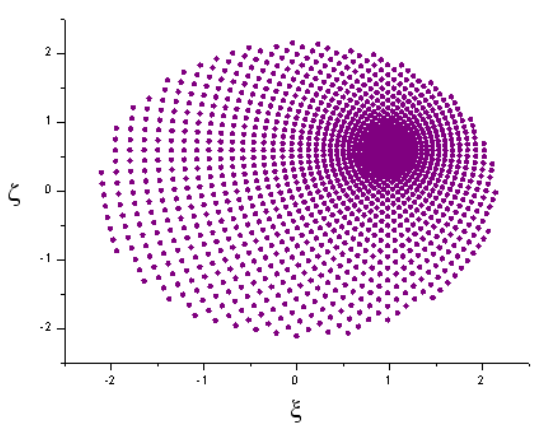

(y1)

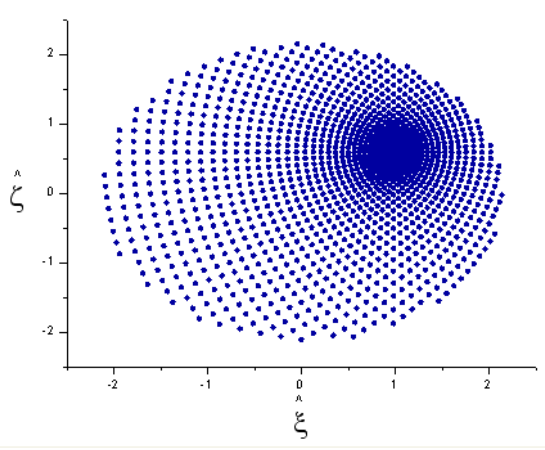

(z1)

Gráficos de correlações $(\mathrm{N}=50, \mathrm{t}=10 \mathrm{~s})$

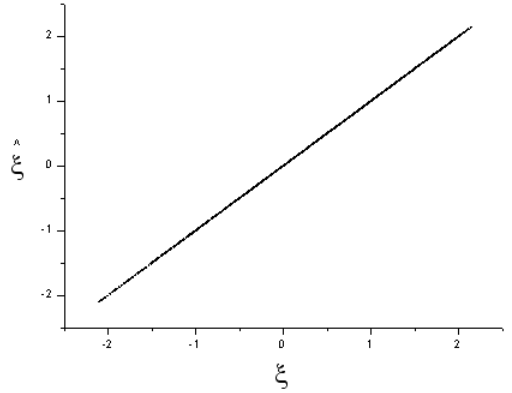

(a2)

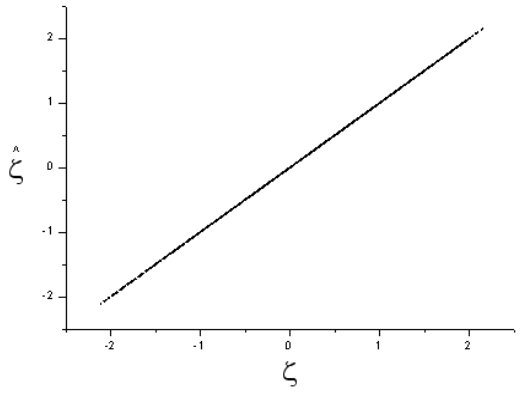

(b2)

Figuras 22 - Simulações de (q1) à (b2) apresentam aprendizado progressivo (gráficos de correlações) do anel com $\mathrm{N}=50$ neurônios. Para cada subconjunto de quatro figuras, há as respectivas variações das condições temporais $(\mathrm{t}=0,5$ e $10 \mathrm{~s})$. 
O que foi verificado também, em termos de reconhecimento que, aumentando a quantidade de neurônios, de 100 em 100, ocorre aprendizado da tarefa proposta à rede, para tamanhos amostrais $\mathrm{N}=50,150,250,350$ e 450, com $\mathrm{t}=5$ s fixo. Abaixo estão os gráficos que corroboram com esta afirmação:

$\mathrm{N}=50, \mathrm{t}=5 \mathrm{~s}$

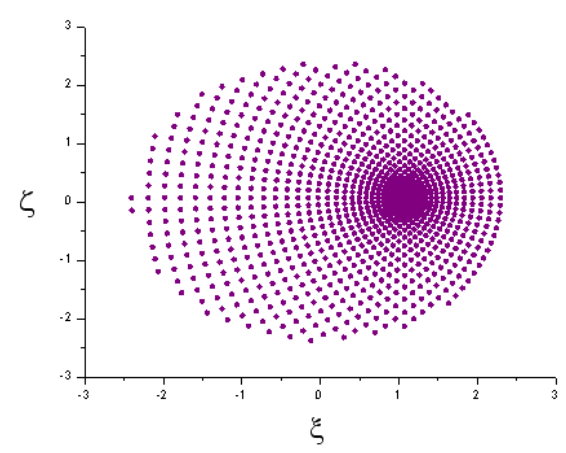

(c2)

Gráfico de correlações $(\mathrm{N}=50, \mathrm{t}=5 \mathrm{~s})$

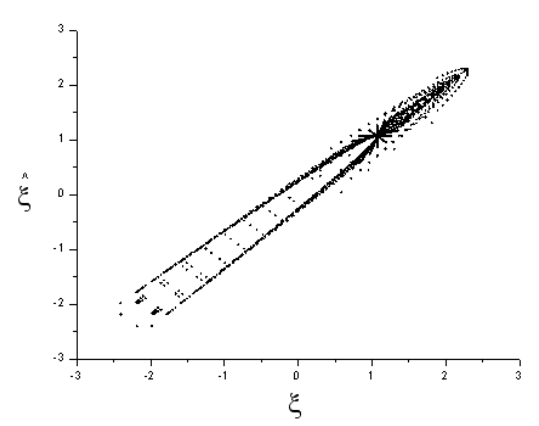

(e2)

$\mathrm{N}=150, \mathrm{t}=5 \mathrm{~s}$

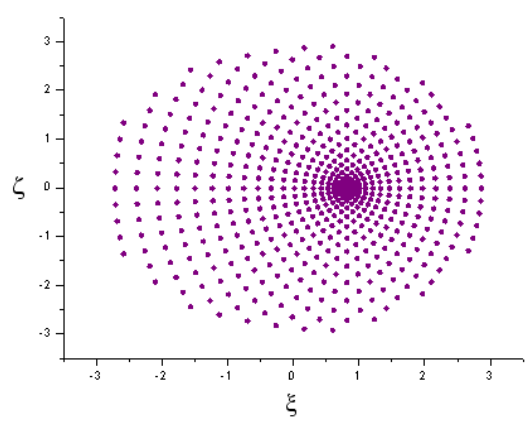

(g2)

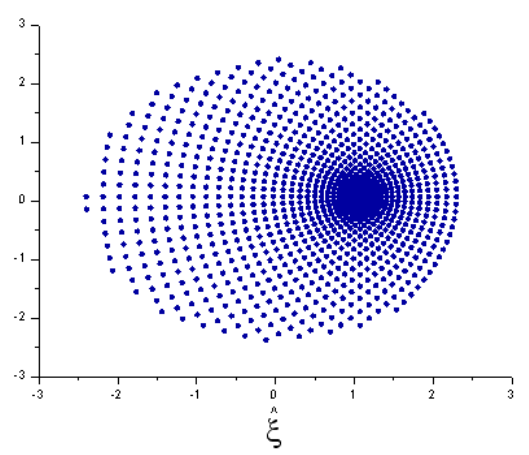

(d2)

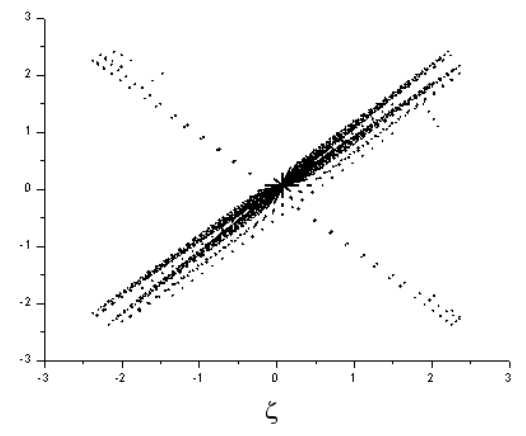

(f2)

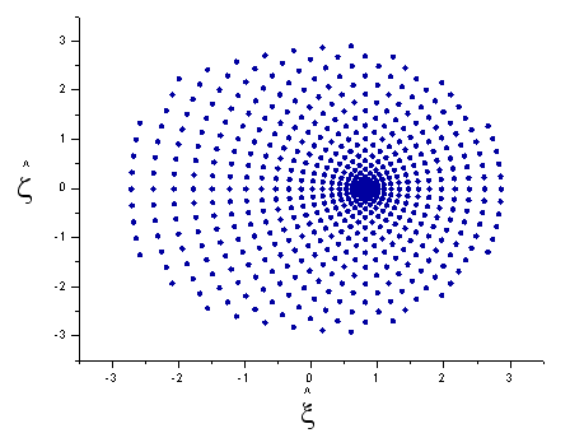

(h2)

Fim da primeira parte da Figura 23 
Início da segunda parte da Figura 23

Gráfico de correlações $(\mathrm{N}=150, \mathrm{t}=5 \mathrm{~s})$

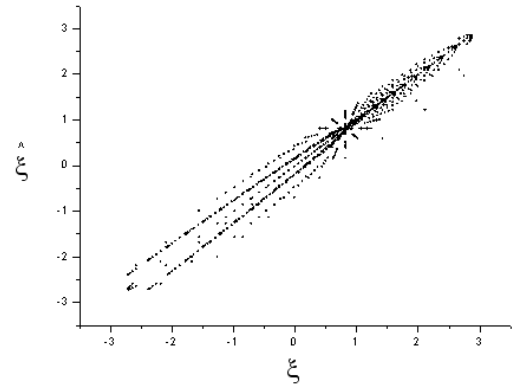

(i2)

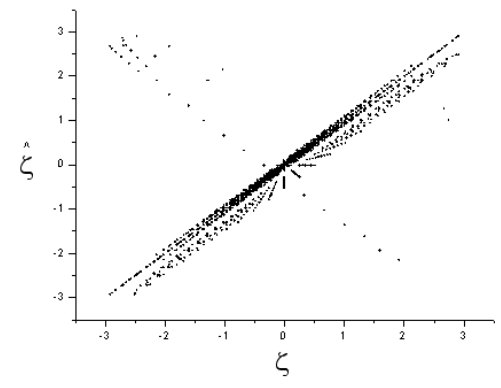

(j2)

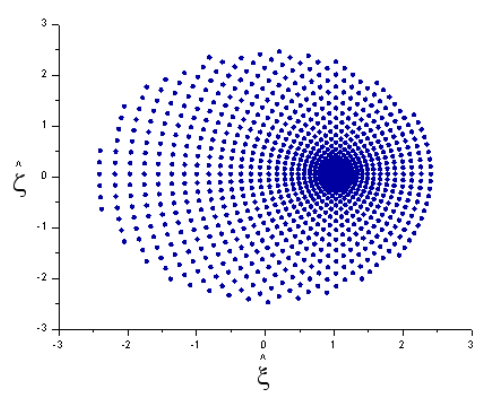

(12)

Gráfico de correlações $(\mathrm{N}=250, \mathrm{t}=5 \mathrm{~s})$
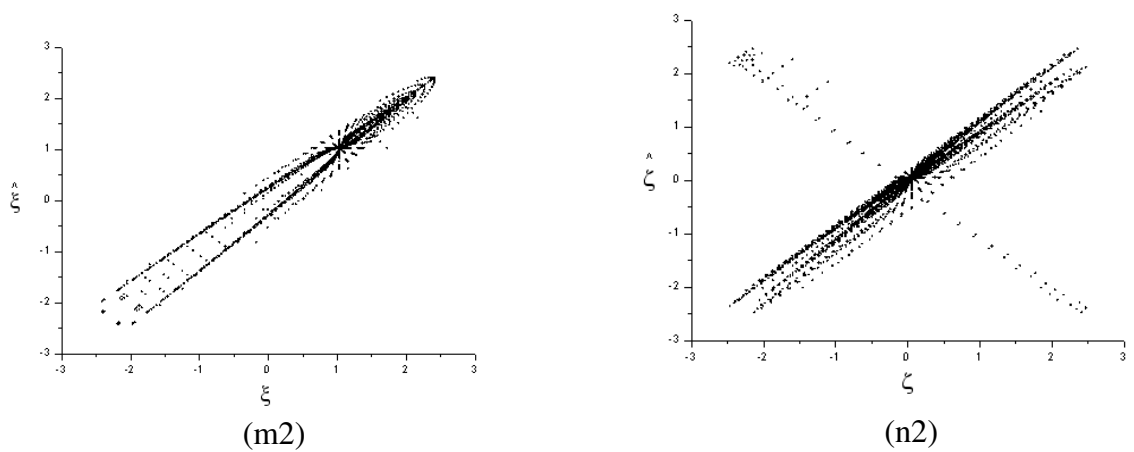

(n2)

Fim da segunda parte da Figura 23 
Início da terceira parte da Figura 23

$\mathrm{N}=350, \mathrm{t}=5 \mathrm{~s}$

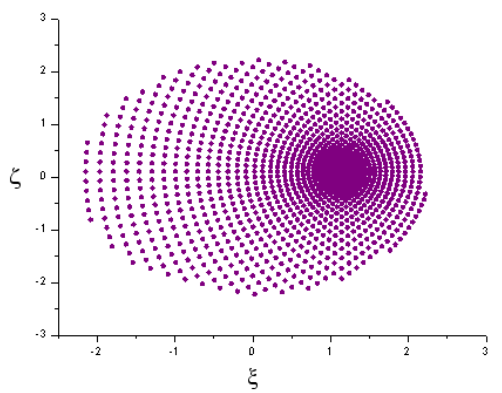

(o2)

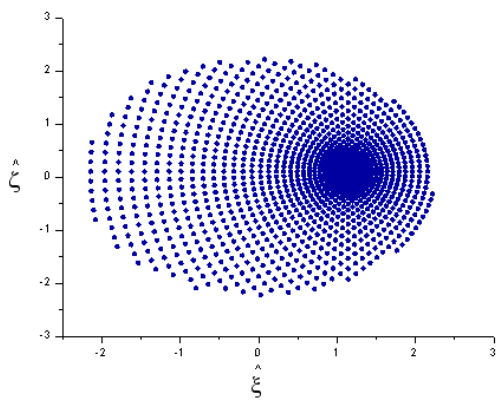

(p2)

Gráfico de correlações $(\mathrm{N}=350, \mathrm{t}=5 \mathrm{~s})$

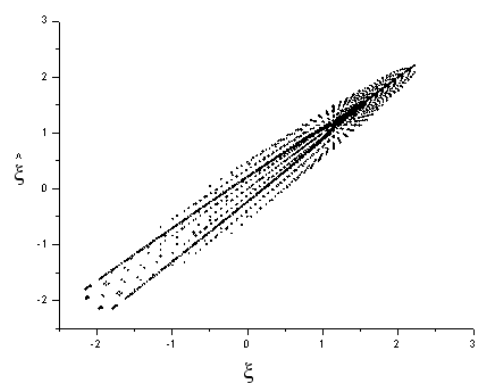

(q2)

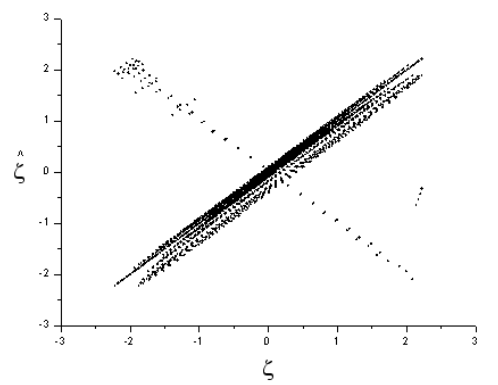

(r2)

$\mathrm{N}=450, \mathrm{t}=5 \mathrm{~s}$

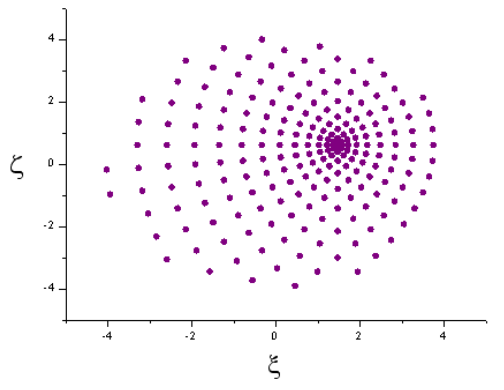

(s2)

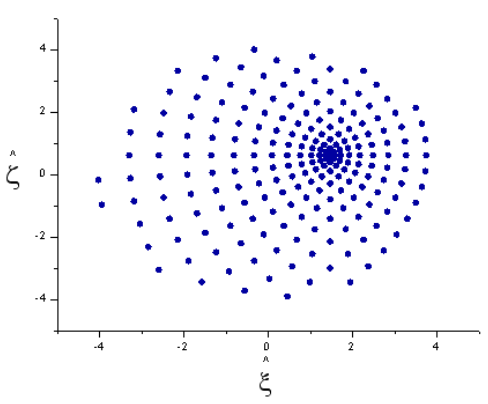

(t2) 
Início e fim da quarta parte da Figura 23

Gráfico de correlações $(\mathrm{N}=450, \mathrm{t}=5 \mathrm{~s})$

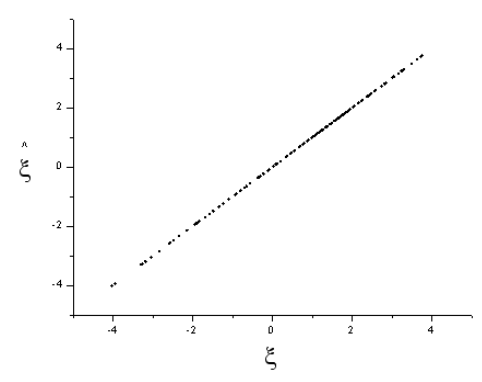

(u2)

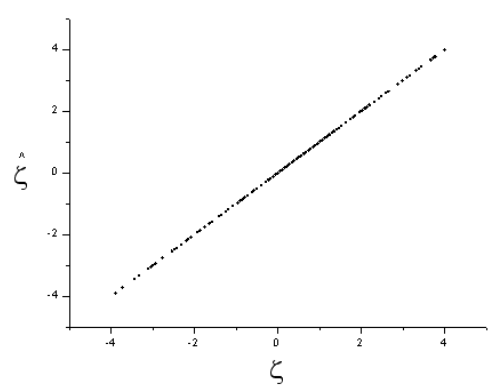

(v2)

Figuras 23 - Simulações de (c2) à (v2) feitas com aumento graduais da quantidade de neurônios ( $\mathrm{N}=50,150,250,350$ e 450), com $t=5$ s fixado. Pelos gráficos de correlações das variáveis, houve ocorrência de aprendizado do anel ao reconhecimento das respectivas regiões fractais.

Também foi observado aprendizado em simulações com o programa baseado nos fluxogramas expostos nas Figuras 16 e 17, utilizando figuras fractais geradas por meio de iterações descritas pelas funções abaixo:

$$
\begin{gathered}
\xi=Q^{k}\left(u, v, x_{\min }(t)\right)=\frac{u+x_{\min }(t)}{\left[u+x_{\min }(t)\right]^{2}+\left[v+y_{\min }(t)\right]^{2}} \\
\zeta=Z^{k}\left(u, v, y_{\min }(t)\right)=\frac{-v-y_{\min }(t)}{\left[u+x_{\min }(t)\right]^{2}+\left[v+y_{\min }(t)\right]^{2}}
\end{gathered}
$$

Aplicando as funções (9) e (10), para $\mathrm{N}=50$ neurônios e $\mathrm{t}=0$ e $5 \mathrm{~s}$, ocorre reconhecimento das figuras geradas (Figura 24: (w2) à (d3)). Formas similares de reconhecimento (observando-se os gráficos de correlações) são observadas com $\mathrm{N}=250$ neurônios e t $=0$ e 5s (Figura 25: (e3) à (13)). 
$\mathrm{N}=50, \mathrm{t}=0 \mathrm{~s}$

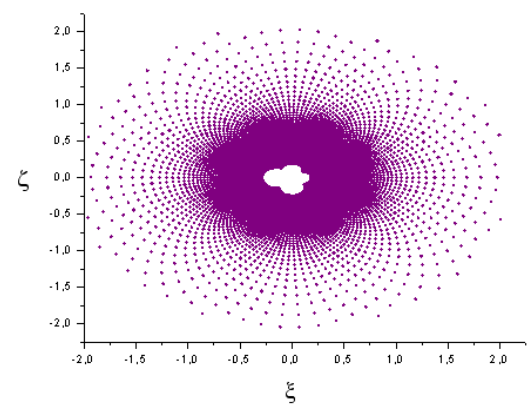

(w2)

Gráfico de correlações $(\mathrm{N}=50, \mathrm{t}=0 \mathrm{~s})$

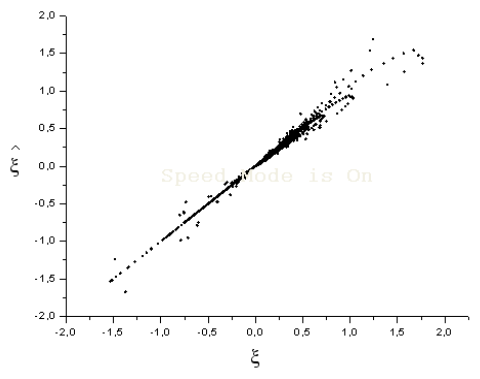

(y2)

$\mathrm{N}=50, \mathrm{t}=5 \mathrm{~s}$

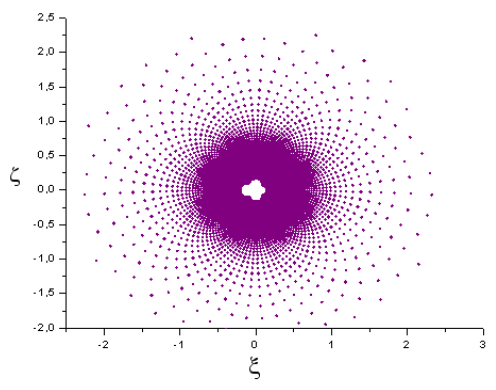

(a3)

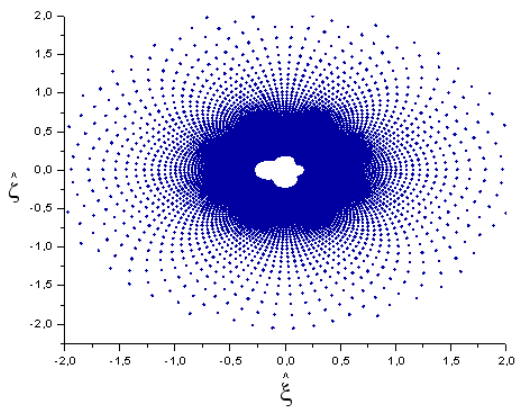

(x2)

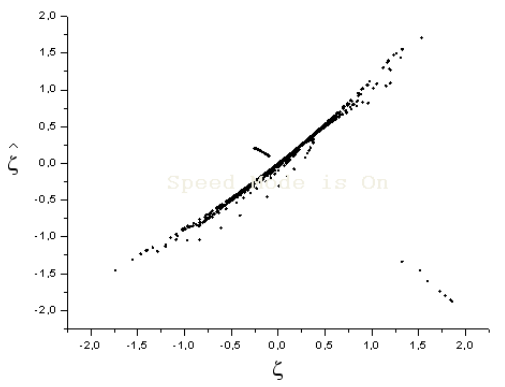

(z2)

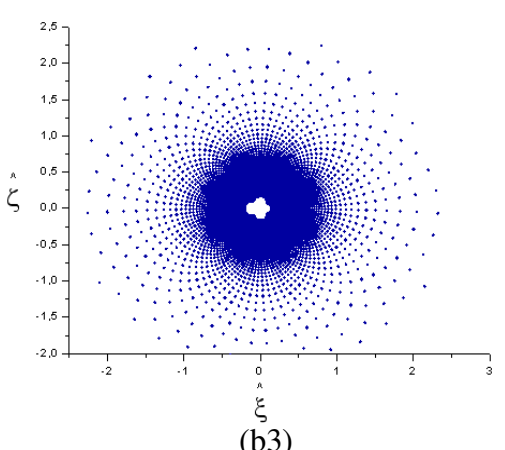

Fim da primeira parte da Figura 24 
Início e fim da segunda da Figura 24

Gráfico de correlações $(\mathrm{N}=50, \mathrm{t}=5 \mathrm{~s})$

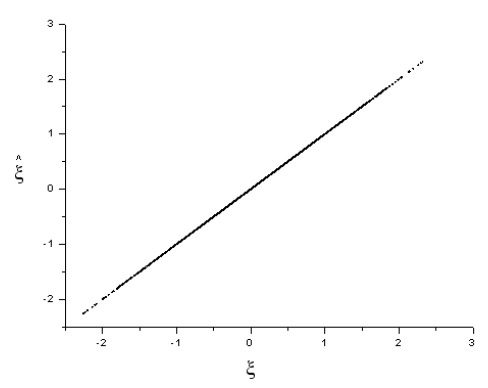

(c3)

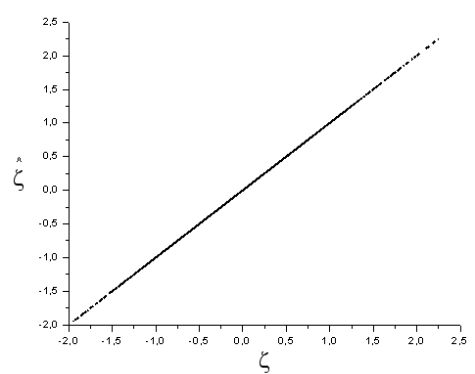

(d3)

Figura 24 - Reconhecimento gradual dos fractais em vermelho com anel de 50 neurônios, variando a condição inicial $\mathrm{t}=0$ e $5 \mathrm{~s}$.

$\mathrm{N}=250, \mathrm{t}=0 \mathrm{~s}$

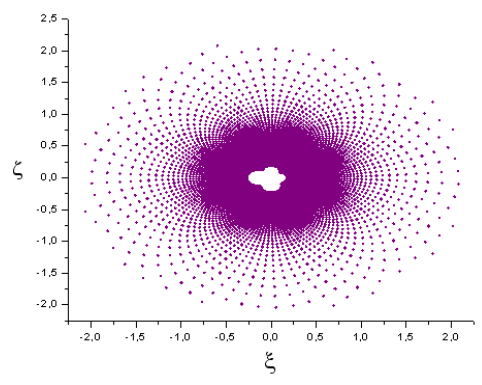

'(e3)

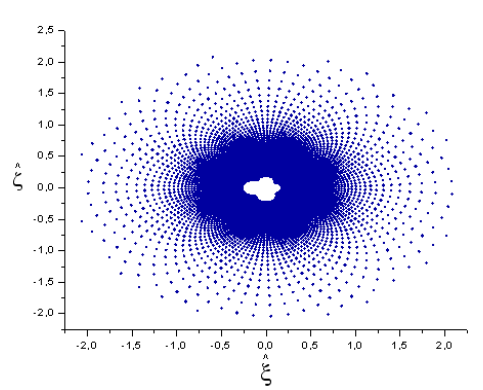

(f3)

Gráfico de correlações $(\mathrm{N}=250, \mathrm{t}=0 \mathrm{~s})$

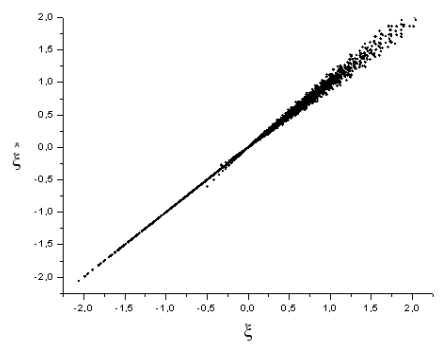

(g3)

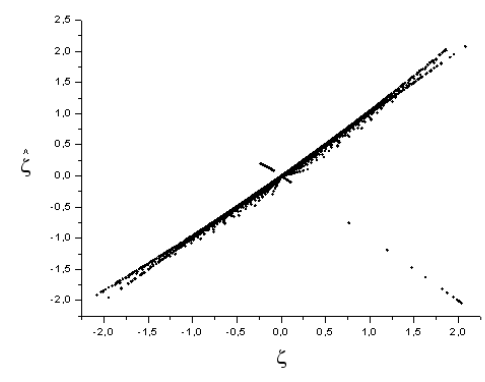

(h3)

Fim da primeira parte da Figura 25 
Início e fim da segunda parte da Figura 25

$\mathrm{N}=250, \mathrm{t}=5 \mathrm{~s}$

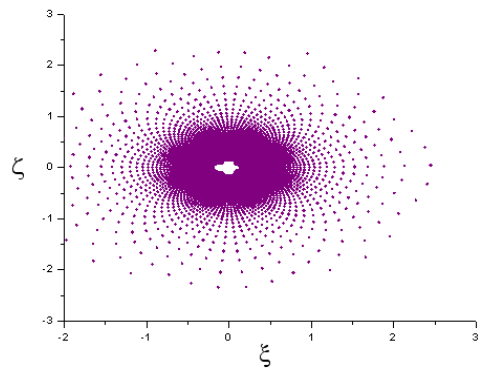

(i3)

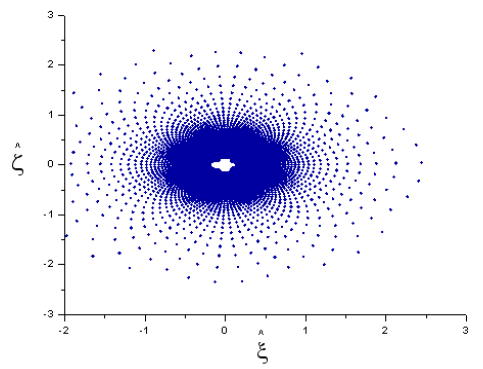

(j3)

Gráfico de correlações $(\mathrm{N}=250, \mathrm{t}=5 \mathrm{~s})$

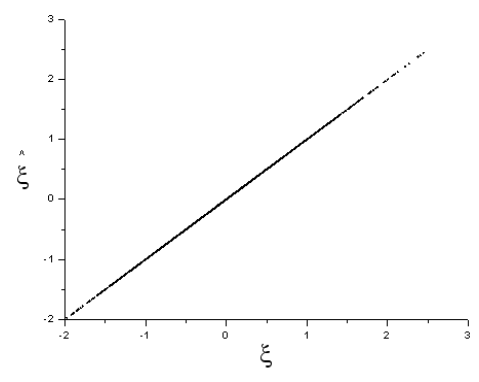

(k3)

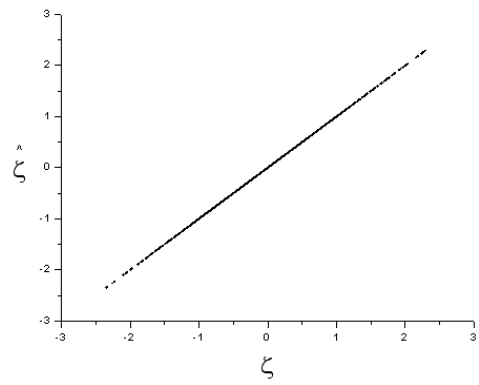

(13)

Figura 25 - Reconhecimento gradual dos fractais em vermelho com anel de 250 neurônios, variando a condição inicial $\mathrm{t}=0$ e $5 \mathrm{~s}$.

Outra simulação que apresentou também resultados interessantes foi realizada fixando $\mathrm{N}=450$, e variando $\mathrm{t}=0,5,10$ e $15 \mathrm{~s}$. Dessa forma, o anel neural sempre reconhecia os padrões fractais gerados (figuras em vinho), o que é confirmado pelos respectivos gráficos de correlações (correlações lineares) para cada condição inicial temporal. Isto pode ser conferido observando a Figura 26 a seguir: 
$\mathrm{N}=450, \mathrm{t}=0 \mathrm{~s}$

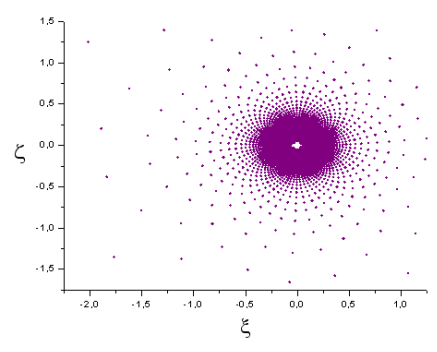

(m3)

Gráficos de correlações $(\mathrm{N}=450, \mathrm{t}=0 \mathrm{~s})$

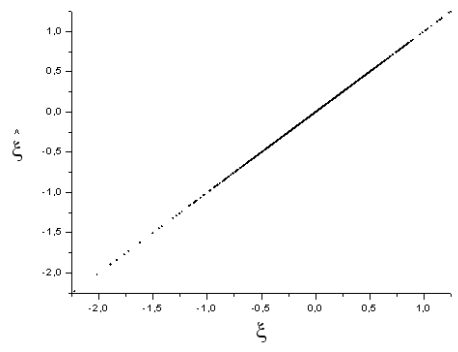

(o3)

$\mathrm{N}=450, \mathrm{t}=5 \mathrm{~s}$

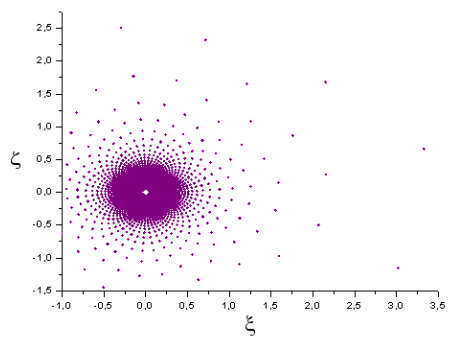

(q3)

Gráfico de correlação $(N=450, t=5 s)$

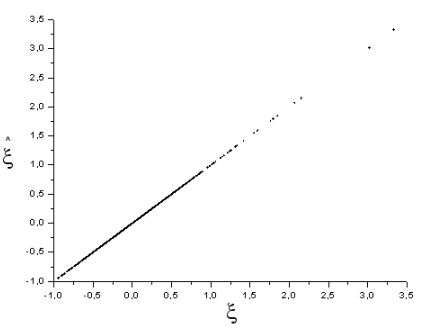

(s3)

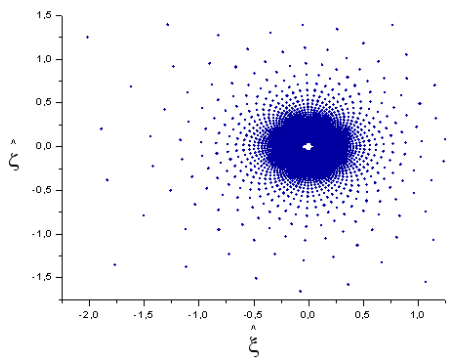

(n3)

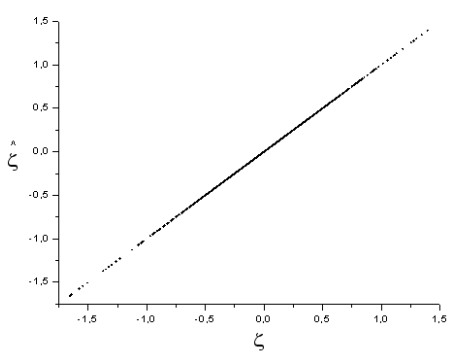

(p3)

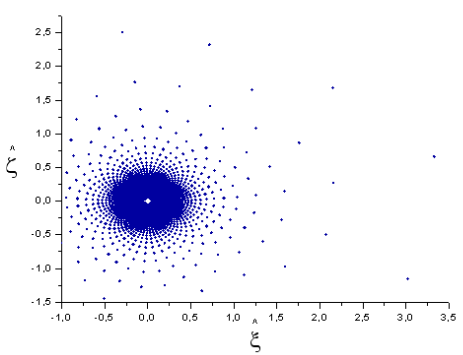

(r3)

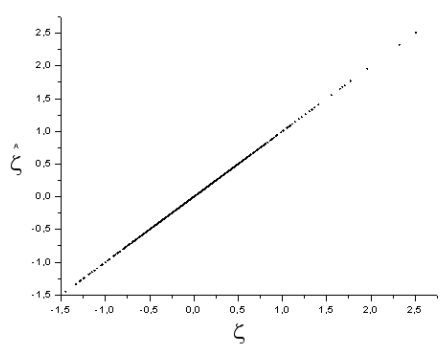

(t3) 
Início da segunda parte da Figura 26

$\mathrm{N}=450, \mathrm{t}=10 \mathrm{~s}$

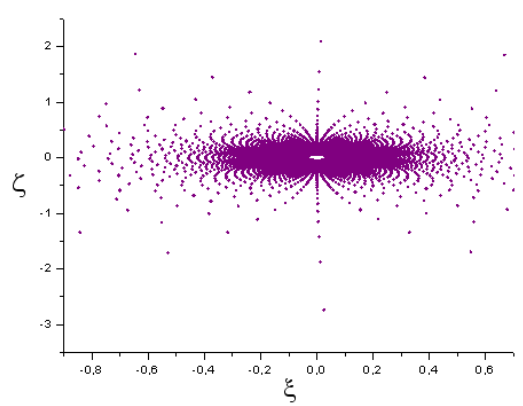

(u3)

Gráficos de correlação $(\mathrm{N}=450, \mathrm{t}=10 \mathrm{~s})$

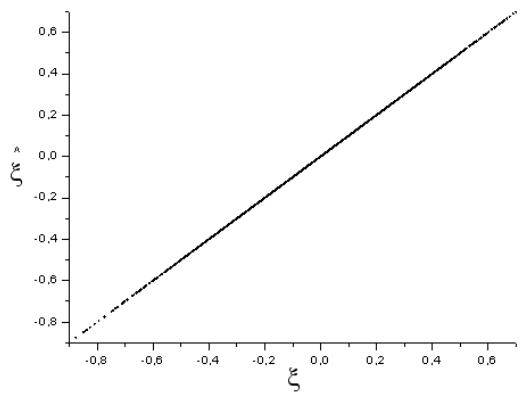

(w3)

$\mathrm{N}=450, \mathrm{t}=15 \mathrm{~s}$

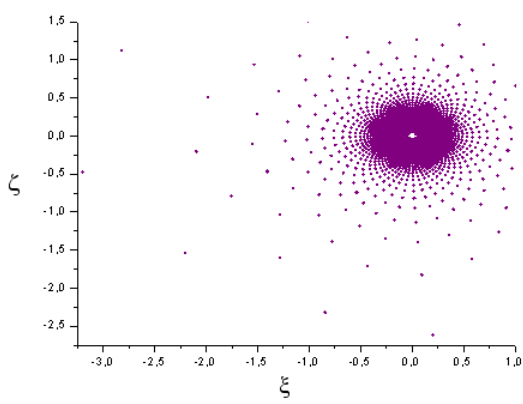

(y3)

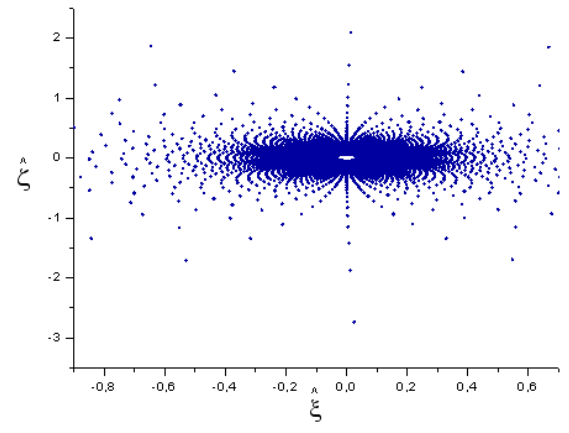

(v3)

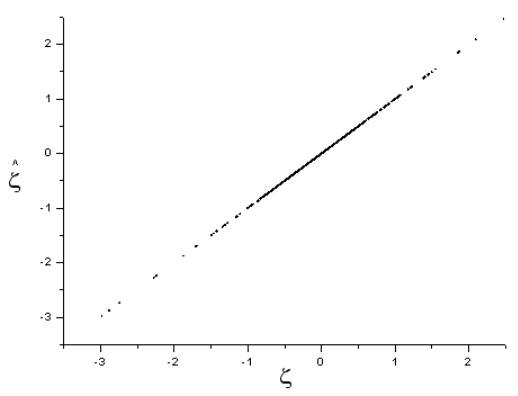

(x3)

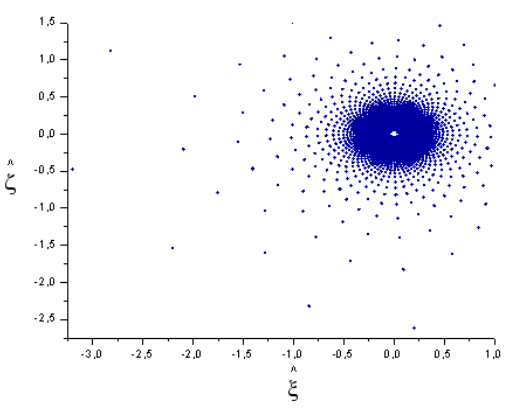

(z3)

Fim da segunda parte da Figura 26 
Início e fim da terceira parte da Figura 26

Gráficos de correlação: $\mathrm{N}=450, \mathrm{t}=15 \mathrm{~s}$

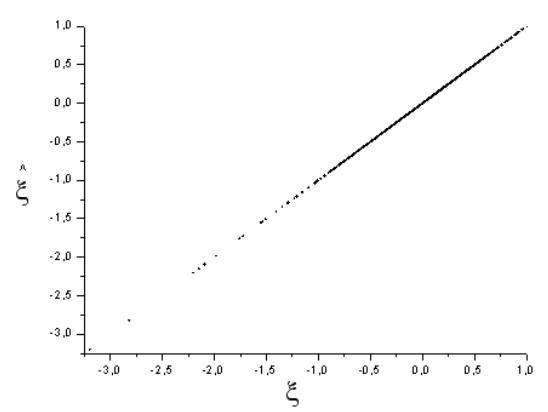

(w3)

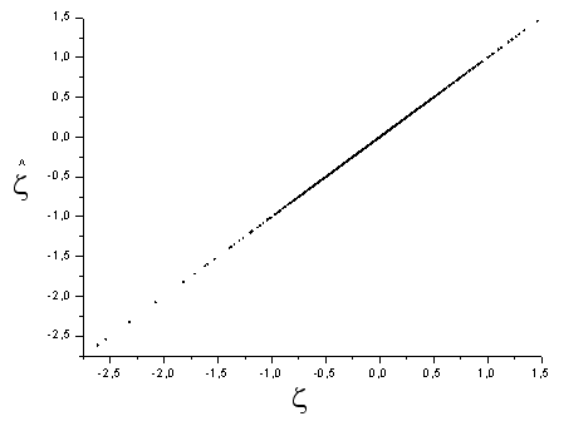

(x3)

Figuras 26 - Variação das condições temporais $t=0,5,10$ e 15s, com N = 450 neurônios. Em cada instante, ocorre reconhecimento total das figuras fractais.

Quando fixamos $t=5 \mathrm{~s}$ e variamos $\mathrm{N}=50,150,250,350$ e 450, o anel também tem um reconhecimento total (correlações lineares) para as figuras fractais apresentadas (em vinho). Na Figura 27, podemos confirmar estas afirmações:

$\mathrm{N}=50, \mathrm{t}=5 \mathrm{~s}$

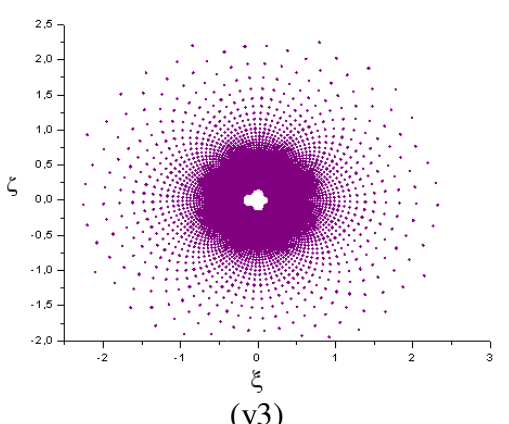

(y3)

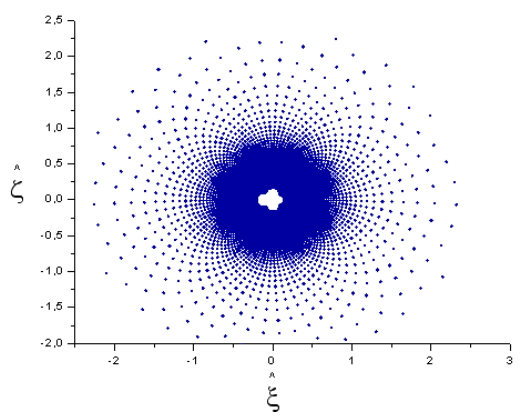

(z3) 
Início da segunda parte da Figura 27

Gráficos de correlações $(\mathrm{N}=50, \mathrm{t}=5 \mathrm{~s})$

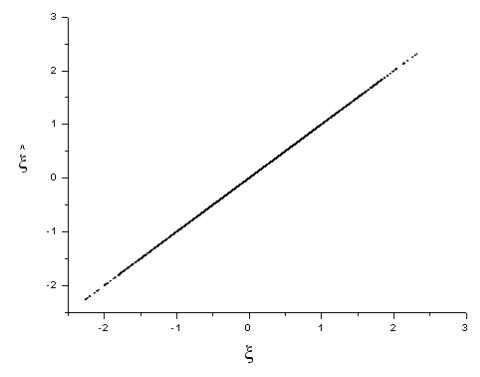

(a4)

$\mathrm{N}=150, \mathrm{t}=5 \mathrm{~s}$

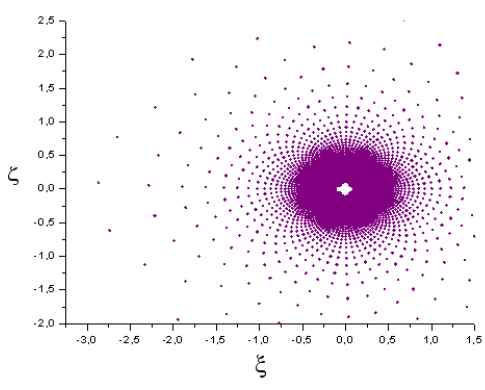

(c4)

Gráficos de correlações $(\mathrm{N}=150, \mathrm{t}=5 \mathrm{~s})$

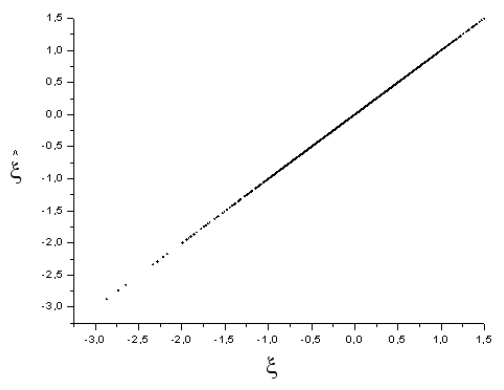

(e4)

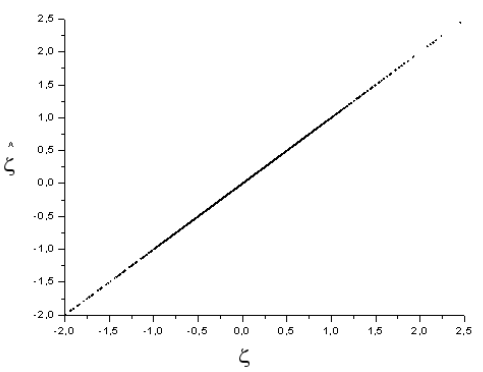

(b4)

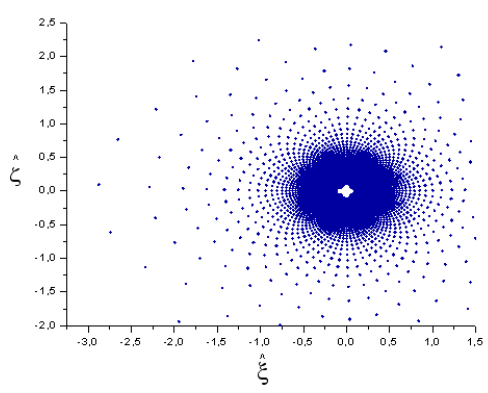

(d4)

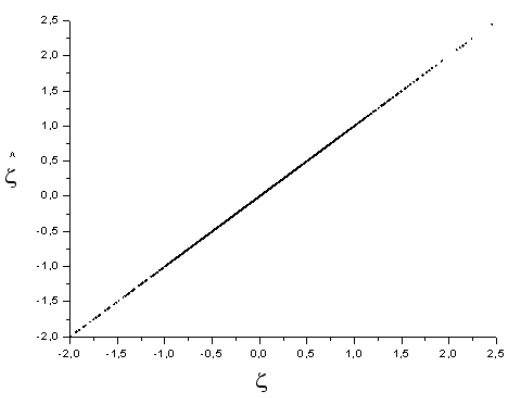

(f4)

Fim da segunda parte da Figura 27 
Início da terceira parte da Figura 27

$\mathrm{N}=250, \mathrm{t}=5 \mathrm{~s}$

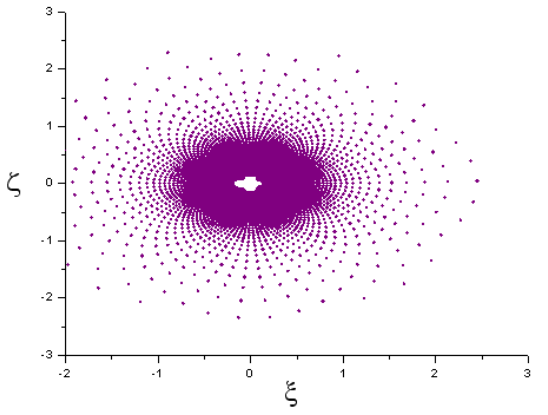

(g4)

Gráficos de correlações $(\mathrm{N}=250, \mathrm{t}=5 \mathrm{~s})$

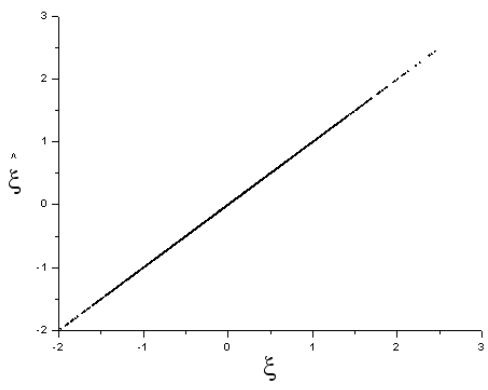

(i4)

$\mathrm{N}=350, \mathrm{t}=5 \mathrm{~s}$

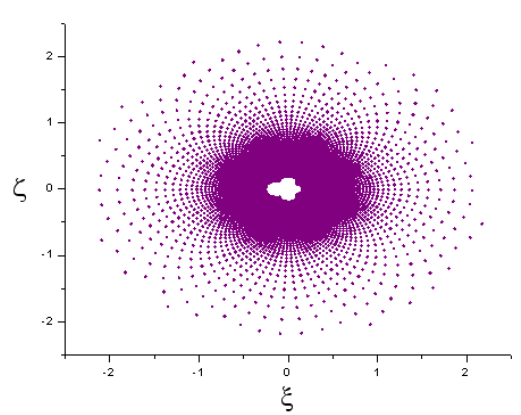

(k4)

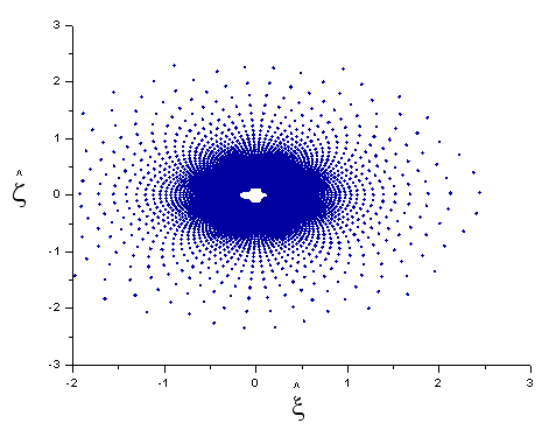

(h4)

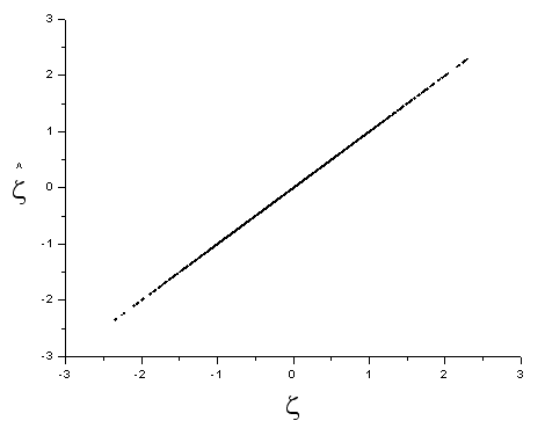

(j4)

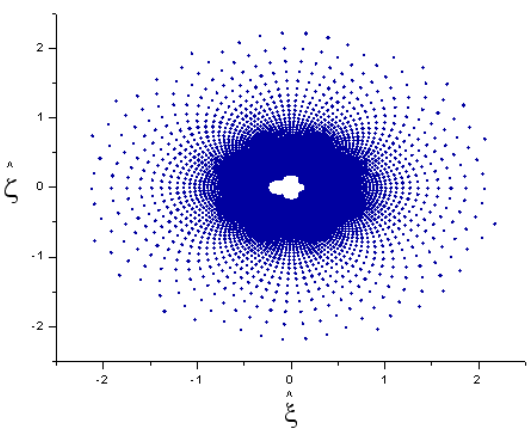

(14)

Fim da terceira parte da Figura 27 
Início e fim da quarta parte da Figura 27

Gráficos de correlações $(\mathrm{N}=350, \mathrm{t}=5 \mathrm{~s})$

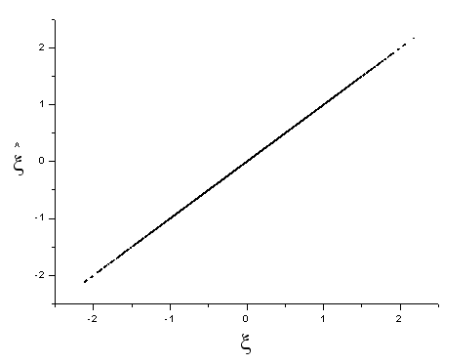

(m4)

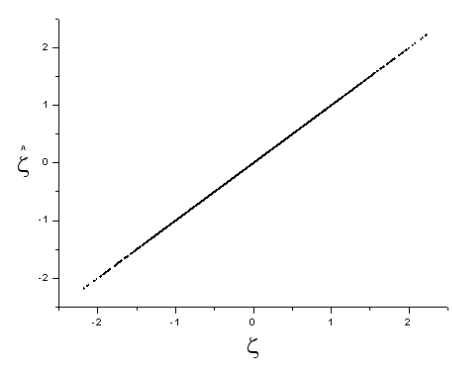

(n4)

$\mathrm{N}=450, \mathrm{t}=5 \mathrm{~s}$

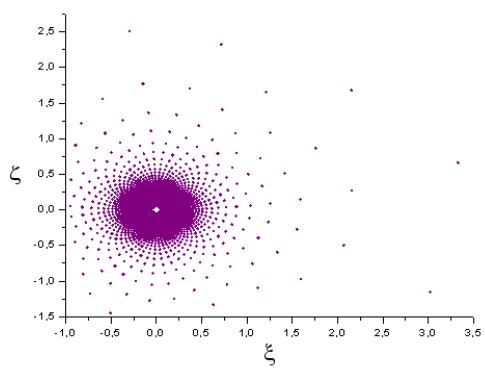

(o4)

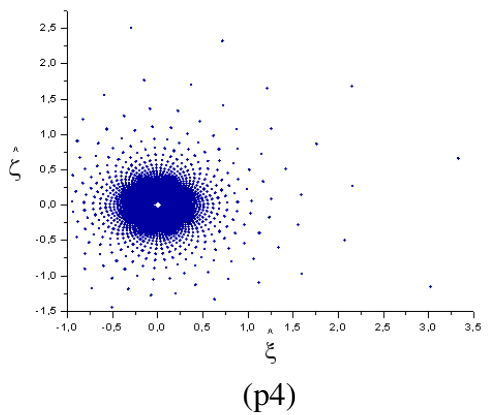

Gráficos de correlações $(\mathrm{N}=450, \mathrm{t}=5 \mathrm{~s})$

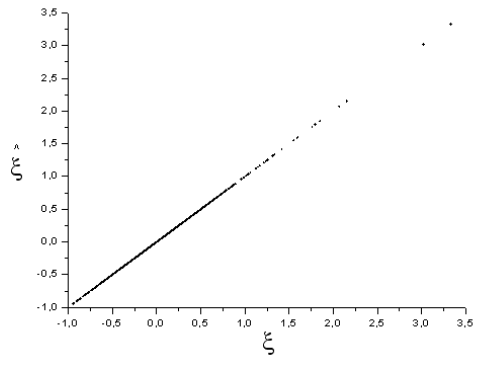

(q4)

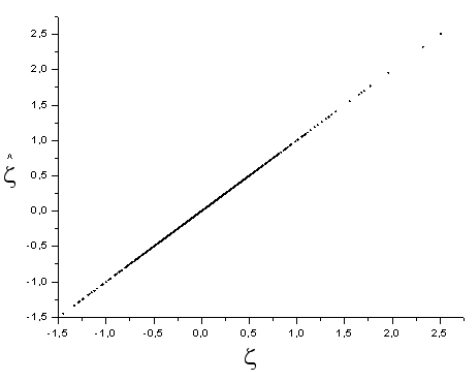

(r4)

Figuras 27 - Reconhecimento total (correlações lineares) é visto em simulações de (y3) a (r4), para $\mathrm{t}=5 \mathrm{~s}$ fixo e $\mathrm{N}=50,150,250,350$ e 450 neurônios. 
Usando as funções iteradas (9) e (10), para $\mathrm{t}=10$ s fixo e variando $\mathrm{N}=50$ e 150 , há uma correlação linear entre as variáveis envolvidas, mostrando que, aumentando em mais 100 a quantidade inicial de neurônios $(\mathrm{N}=50)$, o anel reconhece a figura fractal gerada. Na Figura 28, encontram-se o reconhecimento gradual para estas afirmações:

$\mathrm{N}=50, \mathrm{t}=10 \mathrm{~s}$

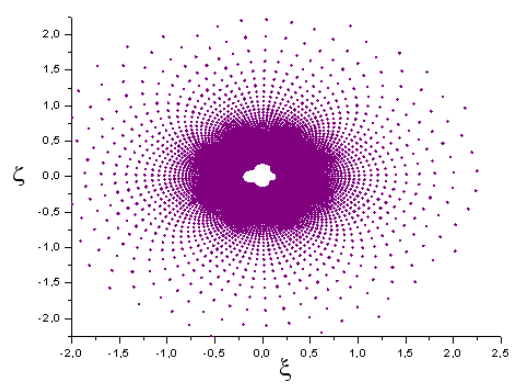

(s4)

Gráficos de correlações $(\mathrm{N}=50, \mathrm{t}=10 \mathrm{~s})$

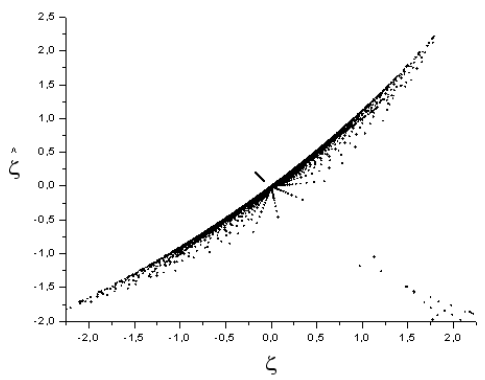

(u4)

$$
\mathrm{N}=150, \mathrm{t}=10 \mathrm{~s}
$$

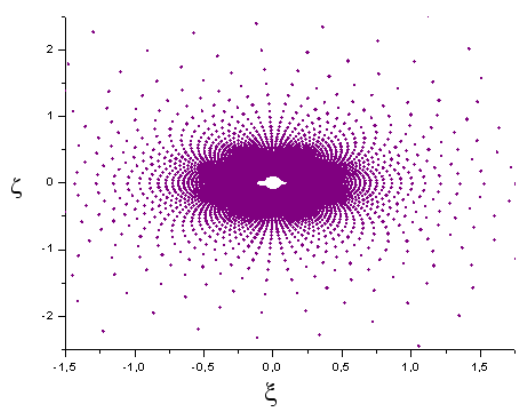

(w4)

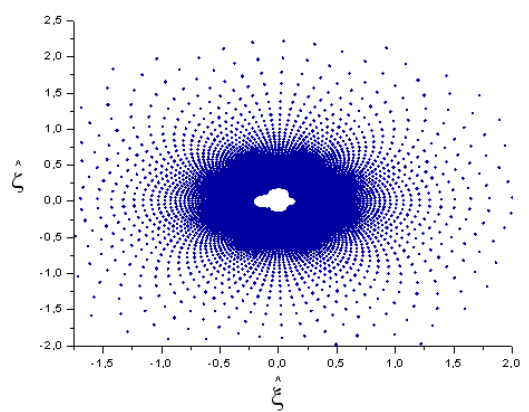

(t4)

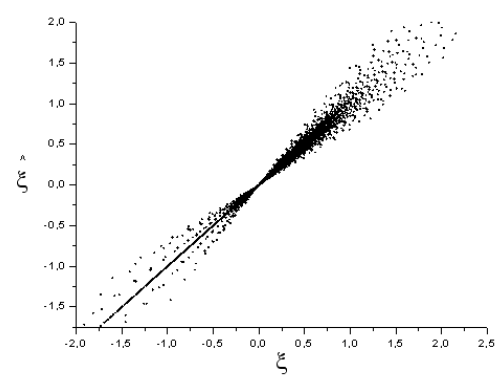

(v4)

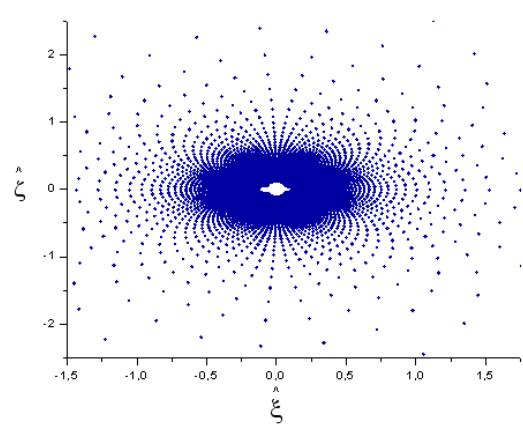

(x4)

Fim da primeira parte da Figura 28 
Início e fim da segunda parte da Figura 28

Gráficos de correlações $(\mathrm{N}=150, \mathrm{t}=10 \mathrm{~s})$

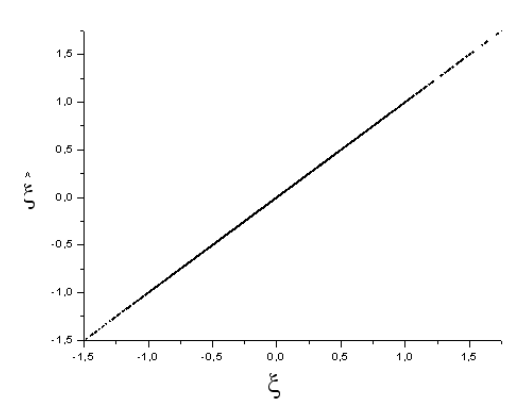

(y4)

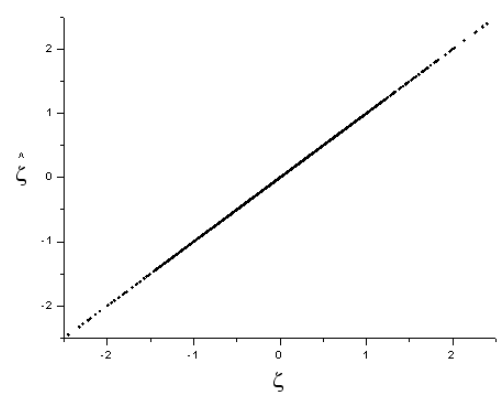

(z4)

Figuras 28 - Reconhecimento das figuras geradas (em vinho) para a condição inicial $\mathrm{t}=10 \mathrm{~s}$ do anel neural com $\mathrm{N}=50$ e 150 neurônios

Foram realizadas simulações computacionais com novas funções de iterações para geração de outra figura fractal, onde foram utilizadas as seguintes equações:

$$
\begin{gathered}
\xi=Q^{k}\left(u, v, x_{\min }(t)\right)=\left\{0,4-\left[\frac{6,0}{1,0+\left(u^{2}+v^{2}\right)}\right]\right\} \tan \left(u^{2}+v^{2}\right) \\
\zeta=Z^{k}\left(u, v, y_{\min }(t)\right)=\tan \left(\frac{u v}{0,4-\left[\frac{6,0}{1,0+\left(u^{2}+v^{2}\right)}\right] 0,009}\right)
\end{gathered}
$$

Inicialmente, fixando $t=0$ s e variando $N=50,150,250,350$ e 450 , a rede reconhece progressivamente o padrão dado aleatoriamente. Este reconhecimento pode ser visto a seguir:

$\mathrm{N}=50, \mathrm{t}=0 \mathrm{~s}$

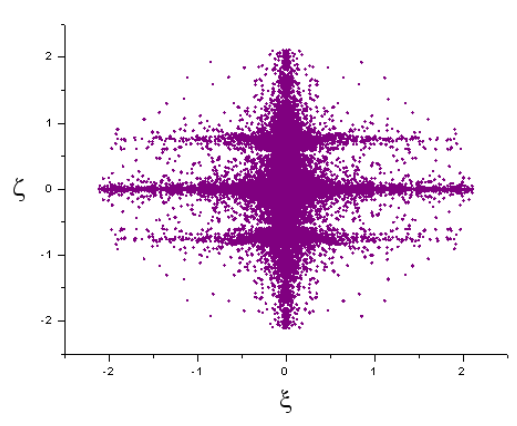

(a5)

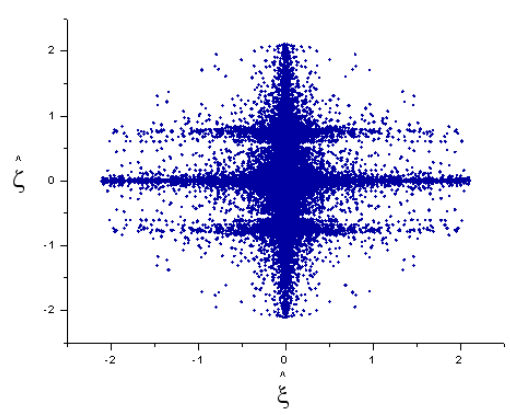

(b5)

Fim da primeira parte da Figura 29 
Início da segunda parte da Figura 29

Gráficos de correlações $(\mathrm{N}=50, \mathrm{t}=0 \mathrm{~s})$

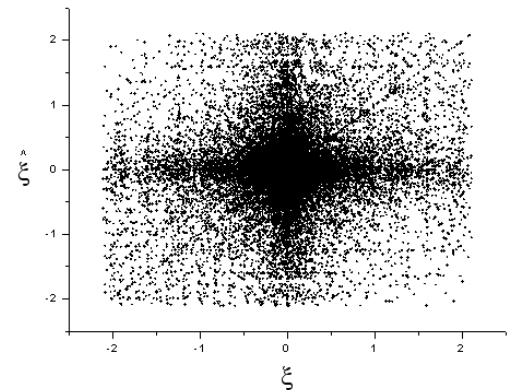

(c5)

$\mathrm{N}=150, \mathrm{t}=0 \mathrm{~s}$

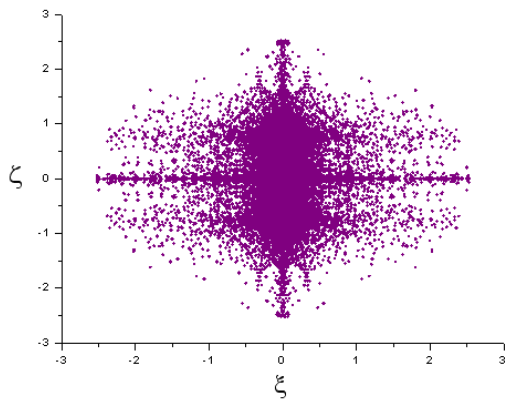

(e5)

Gráficos de correlações $(\mathrm{N}=150, \mathrm{t}=0 \mathrm{~s})$

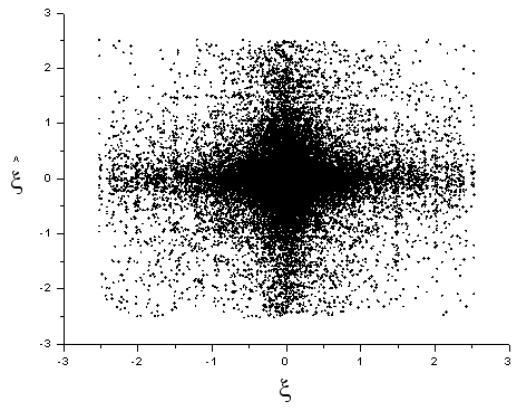

(g5)

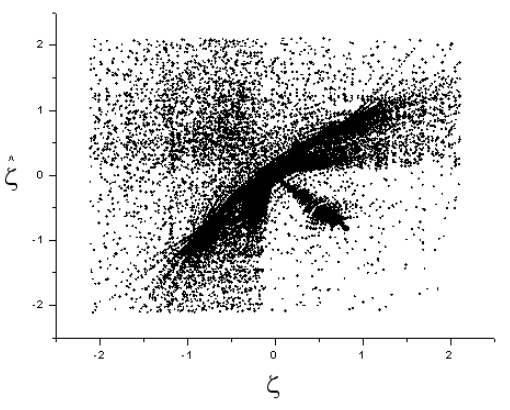

(d5)

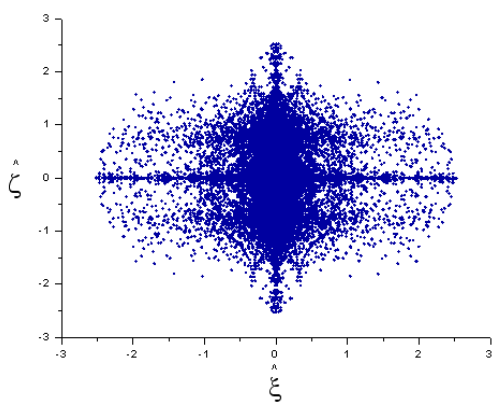

(f5)

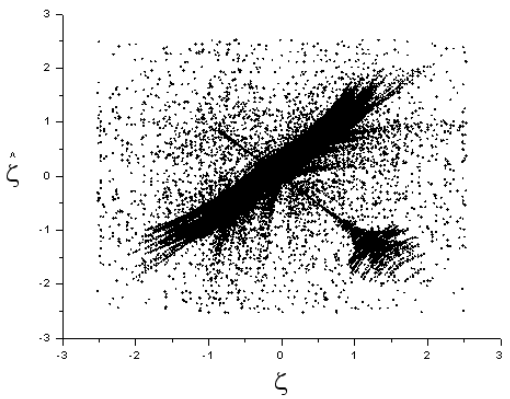

(h5) 
Início da terceira parte da Figura 29

$\mathrm{N}=250, \mathrm{t}=0 \mathrm{~s}$

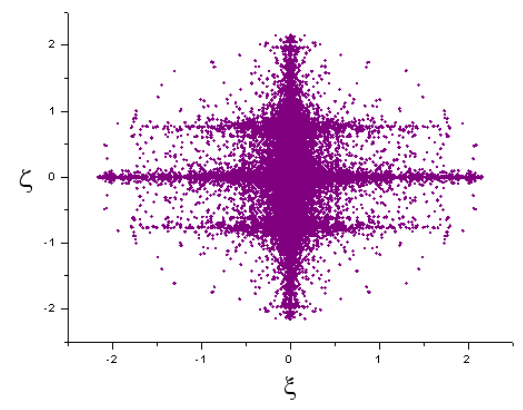

(i5)

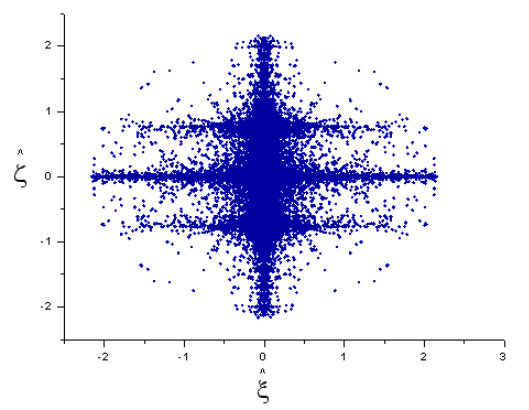

(j5)

Gráficos de correlações $(\mathrm{N}=250, \mathrm{t}=0 \mathrm{~s})$

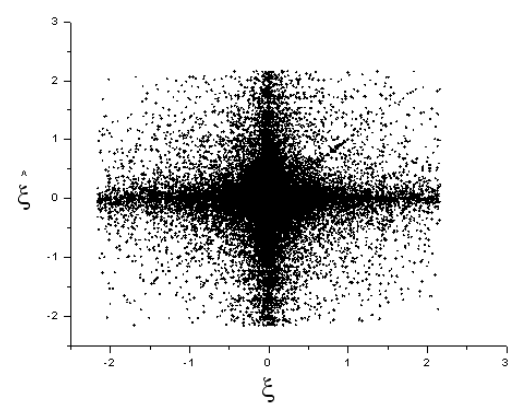

(k5)

$\mathrm{N}=350, \mathrm{t}=0 \mathrm{~s}$

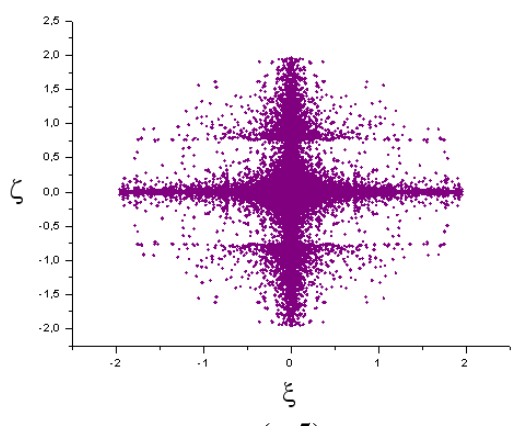

(m5)

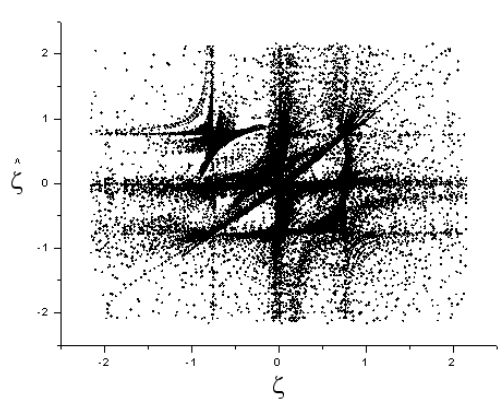

(15)

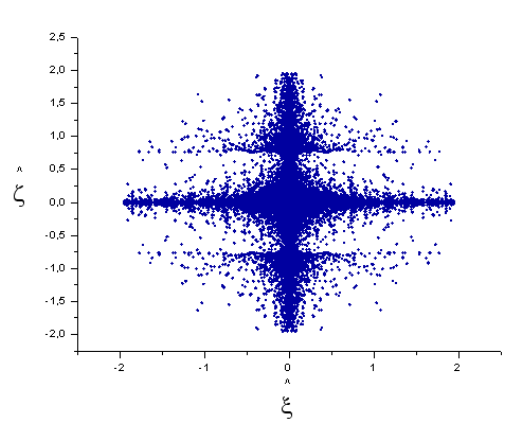

(n5)

Fim da terceira parte da Figura 29 
Início e fim da quarta parte da Figura 29

Gráficos de correlações $(\mathrm{N}=350, \mathrm{t}=0 \mathrm{~s})$

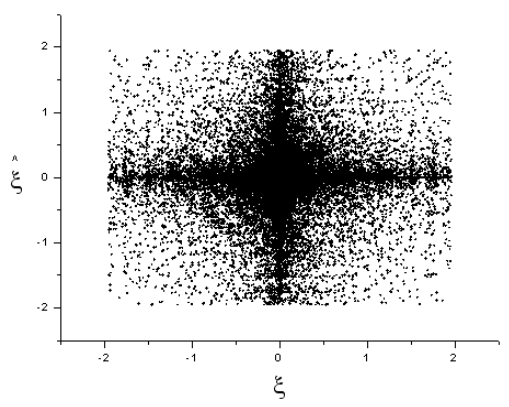

(o5)

$\mathrm{N}=450, \mathrm{t}=0 \mathrm{~s}$

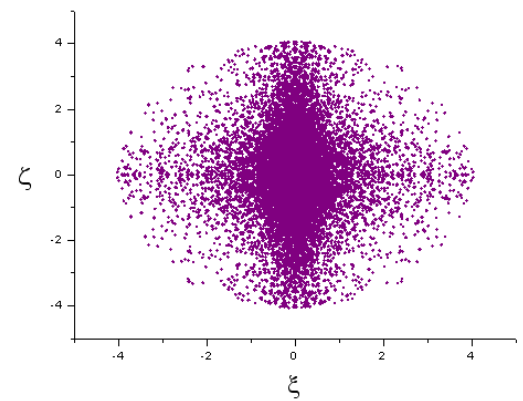

(q5)

Gráficos de correlações $(\mathrm{N}=450, \mathrm{t}=0 \mathrm{~s})$

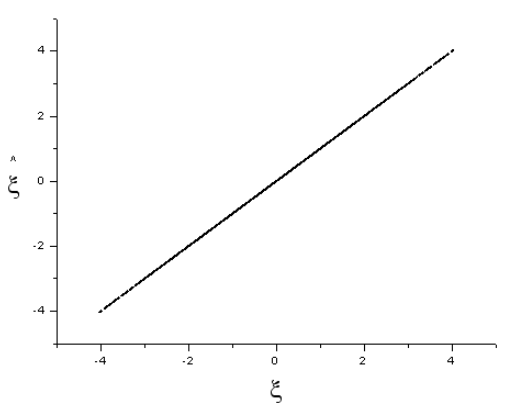

(s5)

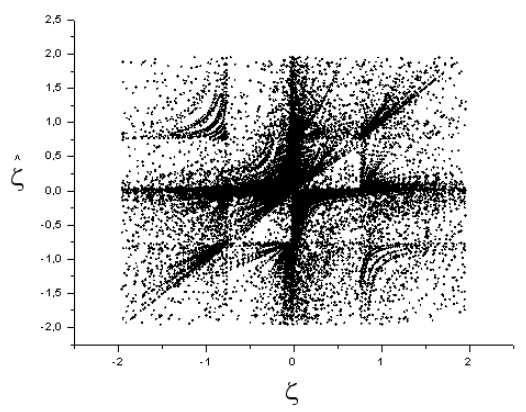

(p5)

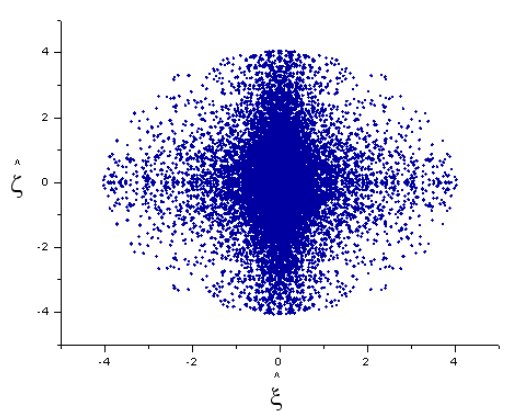

(r5)

G

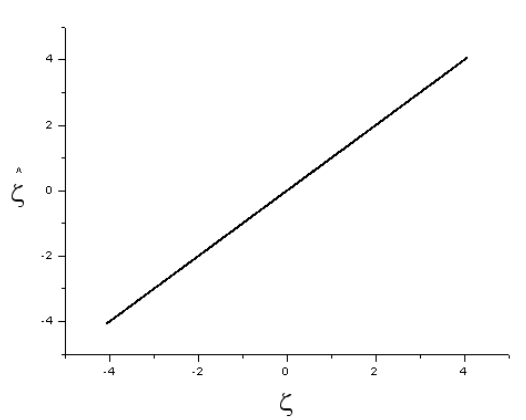

(t5)

Figuras 29 - Reconhecimento progressivo das figuras fractais (em vinho) com $t=0$ s fixo. Ocorrência de reconhecimento total em $\mathrm{N}=450$ neurônios (correlações lineares dos gráficos (a5) e (t5)). 
$\mathrm{O}$ anel neural reconheceu, também, gradativamente, em $\mathrm{t}=10 \mathrm{~s}$, variando, da mesma forma, a quantidade de neurônios de 50 a 450, de 100 em 100. Isso pode ser confirmado pela Figura 30, logo a seguir:

$$
\mathrm{N}=50, \mathrm{t}=10 \mathrm{~s}
$$

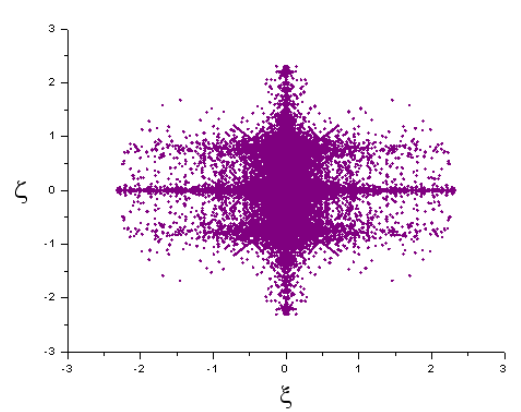

(u5)

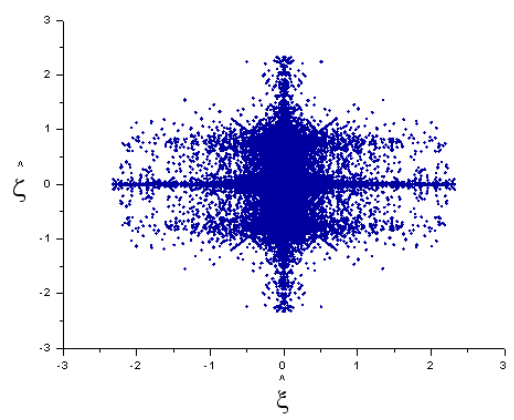

(v5)

Gráfico de correlação $(\mathrm{N}=50, \mathrm{t}=10 \mathrm{~s})$

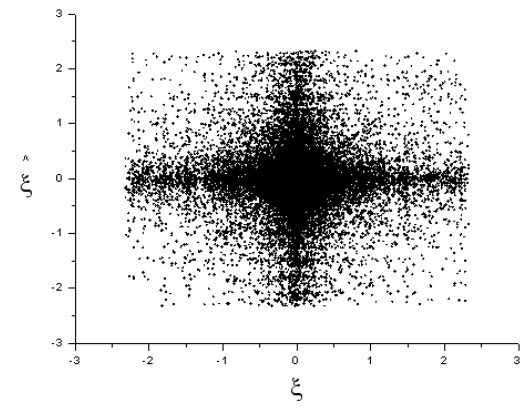

(w5)

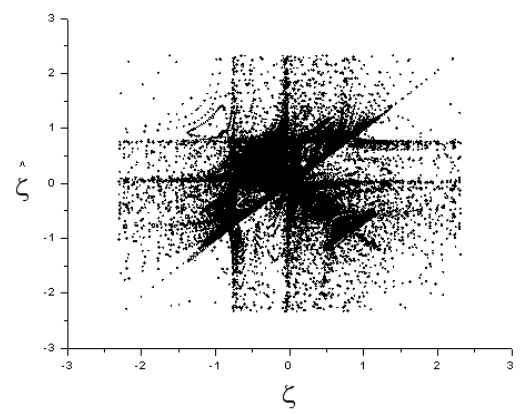

(x5)

$\mathrm{N}=150, \mathrm{t}=10 \mathrm{~s}$

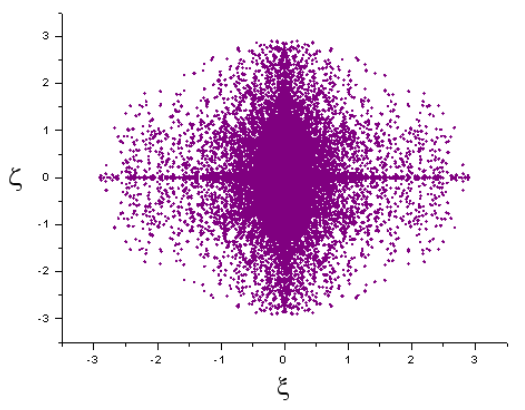

(y5)

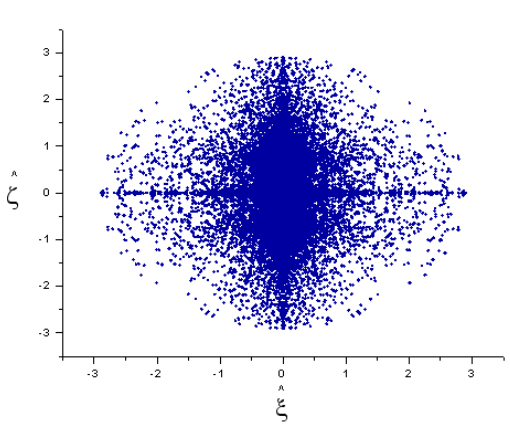

(z5)

Fim da primeira parte da Figura 30 
Início da segunda parte da Figura 30

Gráfico de correlação $(\mathrm{N}=150, \mathrm{t}=10 \mathrm{~s})$

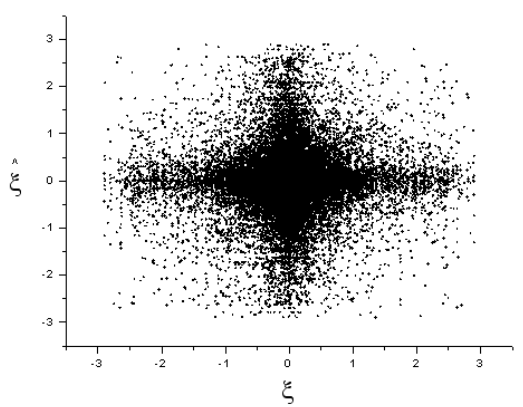

(a6)

$\mathrm{N}=250, \mathrm{t}=10 \mathrm{~s}$

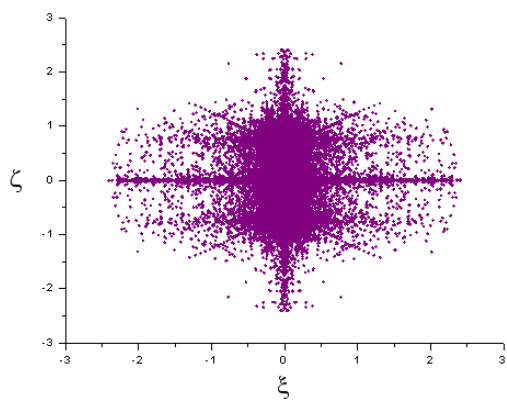

(c6)

Gráfico de correlação $(\mathrm{N}=250, \mathrm{t}=10 \mathrm{~s})$

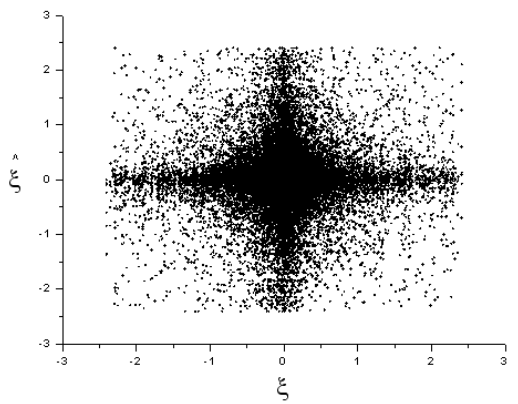

(e6)

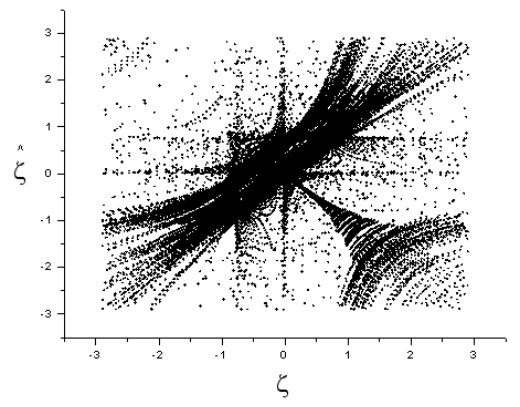

(b6)

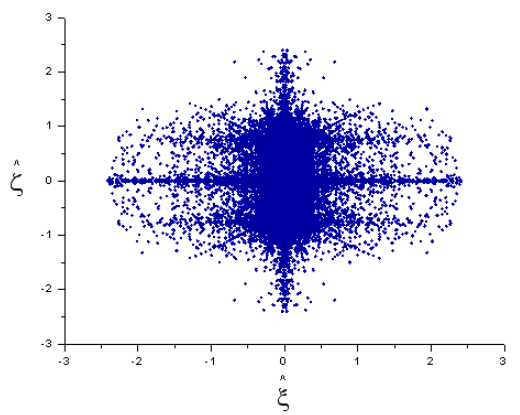

(d6)

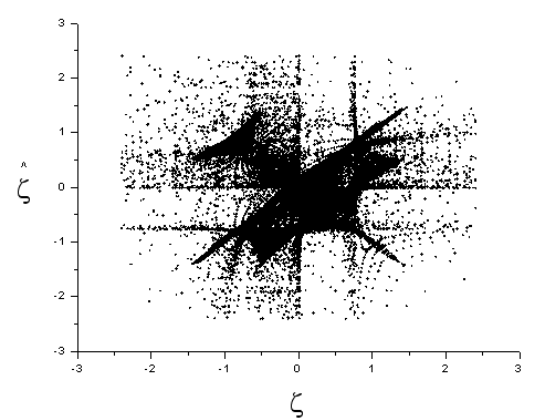

(f6)

Fim da segunda parte da Figura 30 
Início da terceira parte da Figura 30

$\mathrm{N}=350, \mathrm{t}=10 \mathrm{~s}$
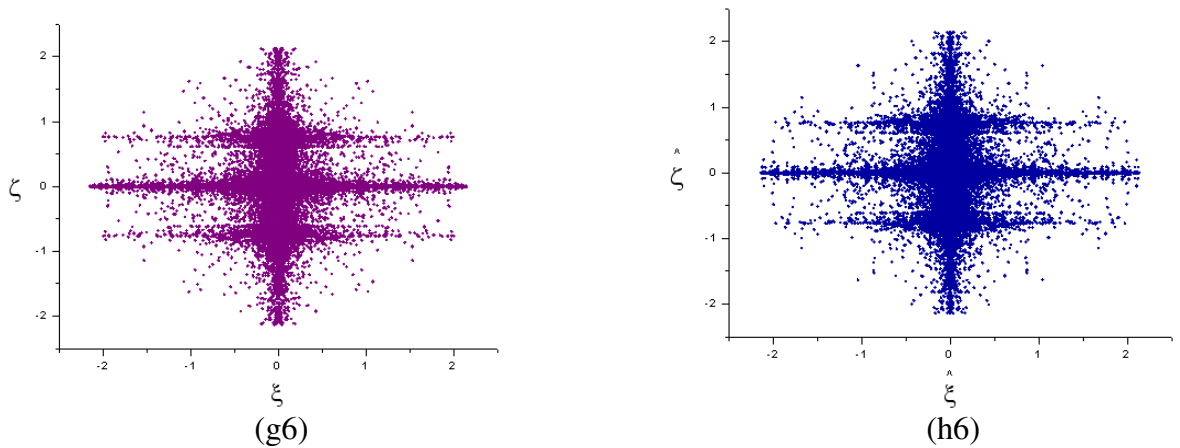

Gráfico de correlação $(\mathrm{N}=350, \mathrm{t}=10 \mathrm{~s})$

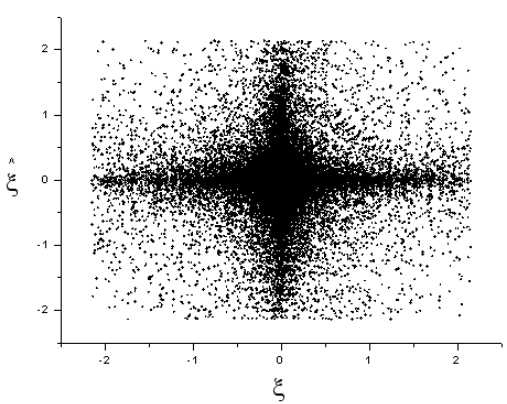

(i6)

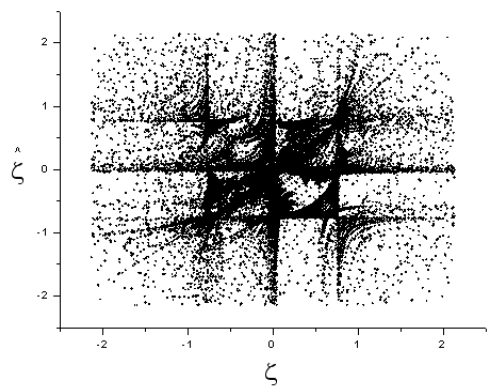

(j6)

$\mathrm{N}=450, \mathrm{t}=10 \mathrm{~s}$

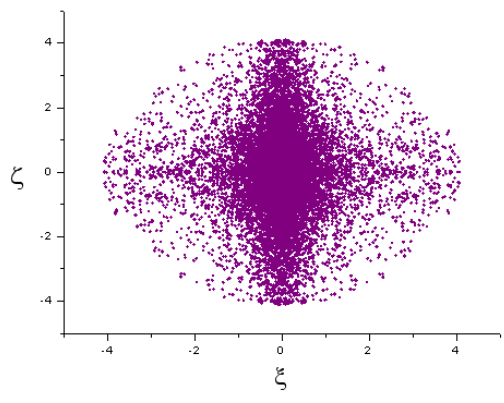

(k6)

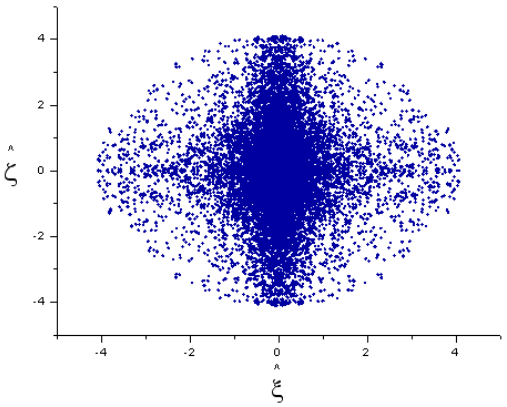

(16)

Fim da terceira parte da Figura 30 
Início e fim da quarta parte da Figura 30

Gráfico de correlação $(\mathrm{N}=450, \mathrm{t}=10 \mathrm{~s})$
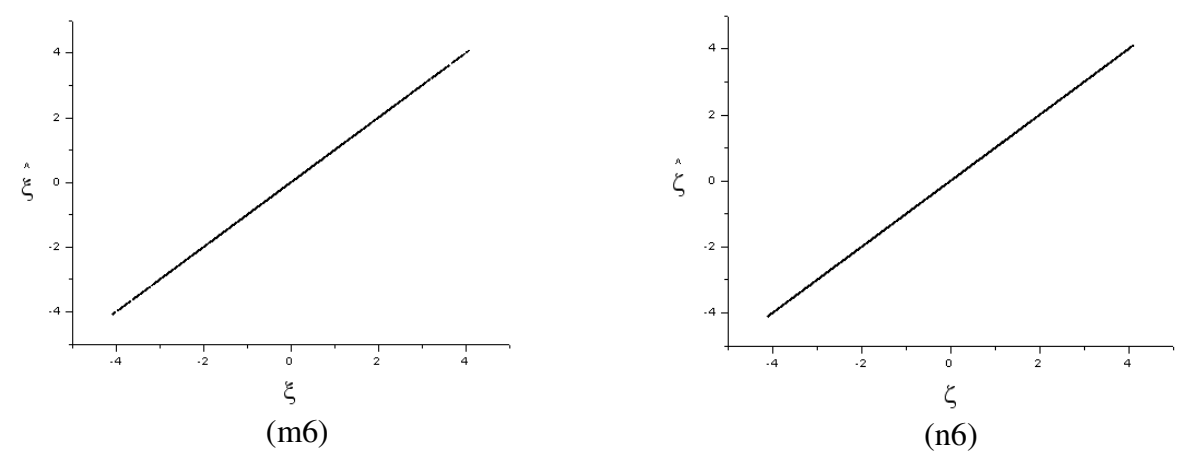

Figuras $30-$ Reconhecimento gradual para $\mathrm{t}=10 \mathrm{~s}$ e $\mathrm{N}=50,150,250,350$ e 450 neurônios.

Outra forma de reconhecimento das figuras fractais usando as funções iteradas (11) e (12), constituiu em variar a quantidade de neurônios $\mathrm{N}$ de 250 a 450 (de 100 em 100 neurônios) e concomitantemente a condição inicial temporal t de 0 a $10 \mathrm{~s}$ (de 5 em $5 \mathrm{~s}$ ). As simulações que confirmam estas afirmações são explicitadas na Figura 31:

$\mathrm{N}=250, \mathrm{t}=0 \mathrm{~s}$

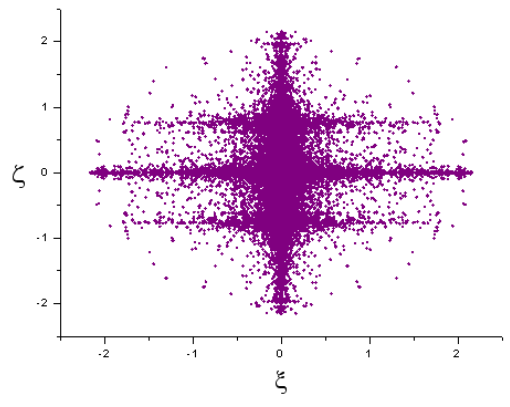

(o6)

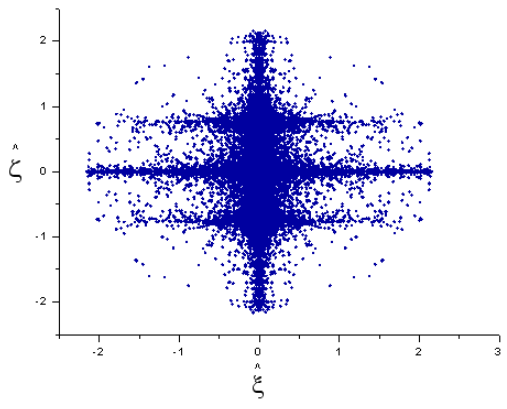

(p6)

Fim da primeira parte da Figura 31 
Início da segunda parte da Figura 31

Gráfico de correlação $(\mathrm{N}=250, \mathrm{t}=0 \mathrm{~s})$

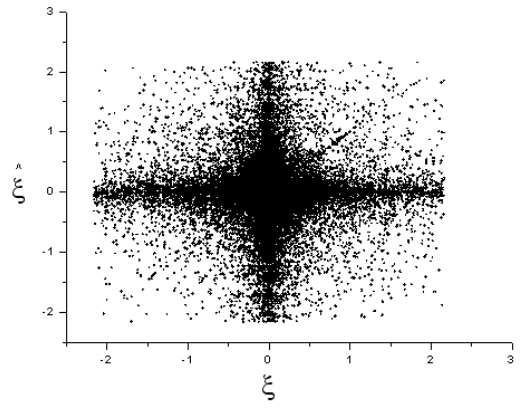

(q6)

$\mathrm{N}=350, \mathrm{t}=5 \mathrm{~s}$

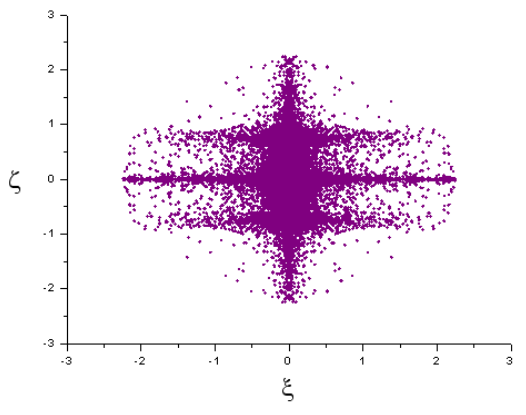

(s6)

Gráfico de correlação $(\mathrm{N}=350, \mathrm{t}=5 \mathrm{~s})$

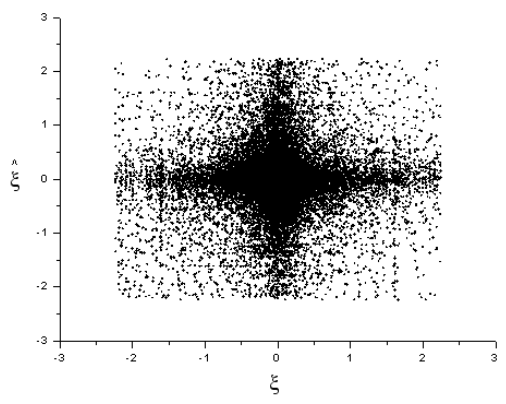

(u6)

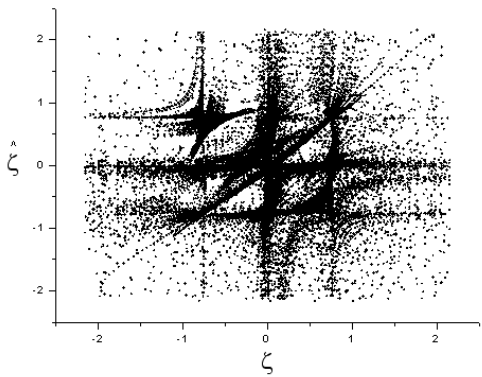

(r6)

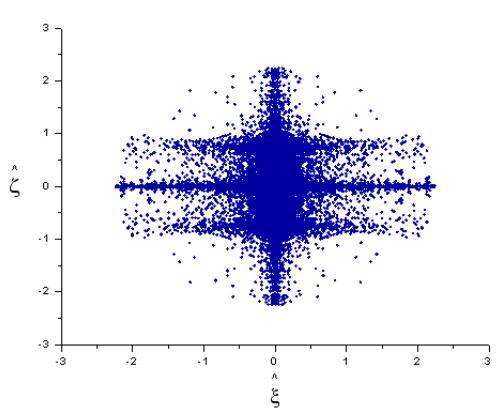

(t6)

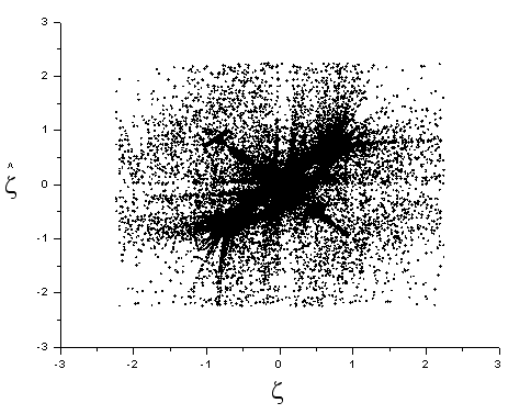

(v6)

Fim da segunda parte da Figura 31 
Início e fim da terceira parte da Figura 31

$\mathrm{N}=450, \mathrm{t}=10 \mathrm{~s}$

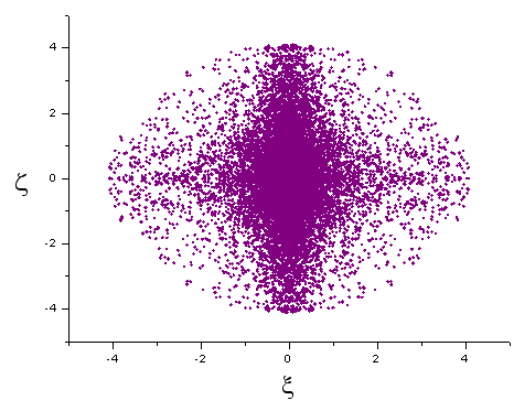

(w6)

Gráfico de correlação $(N=450, t=10 s)$

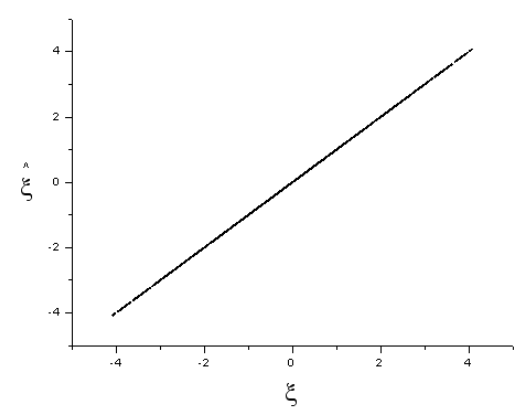

(y6)

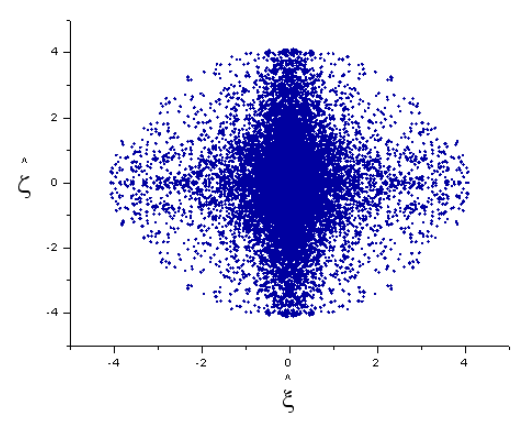

(x6)

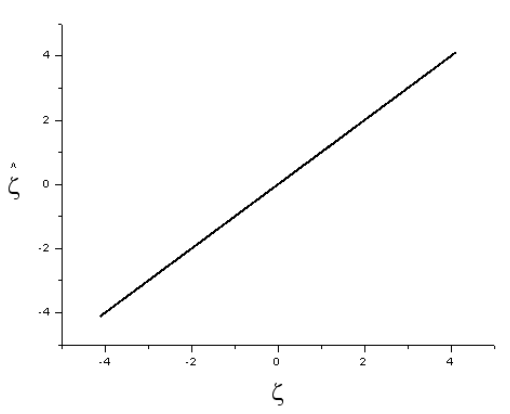

(z6)

Figura 31 - Reconhecimento gradual das figuras fractais (em vinho) por meio de variações numéricas concomitantes das variáveis $N$ e $t$.

Assim, por meio das simulações realizadas, constatamos que o algoritmo proposto possui potencial para identificar fractais aleatórios. Vemos também que, nas tarefas de reconhecimento das figuras, existem relações entre a identificação e as variáveis que tal estrutura de osciladores possui como a quantidade de neurônios $N$ e as condições temporais iniciais $t$; em cada exemplo de funções de iterações, nota-se que da forma como variamos $N$ ou $t$ ou de forma concomitante, ambas as variáveis, o anel torna-se hábil para aprender e identificar tais figuras geométricas caóticas. 
Estes resultados foram publicados ${ }^{26,27}$, sendo revisto e considerado um trabalho original, pela forma que associamos este tipo de rede neural com tarefas de reconhecimento de figuras que não são descritas por meio da geometria euclidiana, tendo como consequência, o algoritmo descrito pelas Figuras 16 e 17 deste capítulo. Resumidamente, a ideia algorítmica proposta baseou-se em unir o algoritmo de Yanchuk et. al. com o comportamento caótico das soluções periódicas (pela variação numérica da quantidade de neurônios $N$ e condições iniciais temporais $t$ ) e com processo de construção de figuras fractais a partir dos estudos de Mandelbrot.

Na próxima seção será exposta a conclusão deste trabalho, bem como propostas de aplicações para o algoritmo desenvolvido. 


\section{CONCLUSÃO}

Nesta tese apresentamos, como proposta, um algoritmo para armazenamento de padrões fractais e reconhecimento destes tipos de figuras geométricas no plano. A rede neural utilizada neste trabalho consistiu de sua modelagem utilizando os osciladores de Ciclo Limite de Stuart-Landau; cada neurônio, neste caso, é considerado um oscilador e a topologia da rede neural construída tem formato anelar. Tal proposta teve como fundamento o comportamento caótico das soluções periódicas (4) do Capítulo 5. É sabido que os trabalhos de Popovych et. al. e de Yanchuk et. al., demonstram que este tipo de estrutura neural é capaz de reconhecer

padrões estáveis. ${ }^{23,28}$ Outro incentivo para o desenvolvimento do algoritmo proposto foi o potencial do emprego deste gênero de rede em áreas tecnológicas, como telecomunicações e neurobiologia. $\mathrm{O}$ algoritmo sugerido neste trabalho pode ser dividido em duas partes instrutivas: geração de padrão fractal aleatório e codificação de padrão fractal gerado (armazenamento) e decodificação de padrão fractal gerado (ou reconhecimento).

Mostramos também que a dinâmica caótica é inerente a este tipo de estrutura neural artificial, por meio de simulações do espectro dos osciladores em relação às alterações das condições iniciais temporais. Além disso, as simulações computacionais no Capítulo 6 apresentaram um bom desempenho do algoritmo em tarefas de reconhecimentos das figuras fractais construídas. Os resultados das simulações foram obtidos por meio das alterações numéricas nas condições iniciais $(t)$ e na quantidade de neurônios $(N)$ do anel neural que foi o objeto de estudo para essa tese.

Esperamos que o trabalho desenvolvido aqui se torne um instrumento inspirador para os que pesquisam ou utilizam redes neurais em aplicações de reconhecimento de figuras ou regiões irregulares onde a geometria de Euclides é incapaz de fornecer técnicas para o desenvolvimento de algoritmos de resolução dos problemas apresentados nos estudos que envolvem esta área (RNA's) da Inteligência Artificial. ${ }^{31,32,33}$ 


\section{REFERÊNCIAS BIBLIOGRÁFICAS}

1 JIANG, N.; PAN, W.; YAN, L.; LUO, B.; YANG, L.; XIANG, S.; ZHENG, D. Synchronization preservability of intermittent coupling chaotic semiconductor lasers. J. Opt. Soc. Am. B., vol. 28, n. 5, May 2011.

2 GERSTNER, W.; KEMPTER, R.; HEMMEN, J. L. V.; WAGNER, H. A neuronal learning rule for sub-milisecond temporal coding. Nature 383, 76, 1996.

3 HEBB, D. O. The Organization of Behavior: A Neuropsychological Theory. Wiley, 1949.

4 AHISSAR, E.; KLEINFELD, D. Closed-loop neuronal computations: focus on vibrissa somatosensation in rat. Cer. Cortex 13, 53, 2003.

5 POLIKAR, R. Pattern Recognition, Wiley Encyclopedia of Biomedical Enginnering. John Wiley \& Sons, Inc., 2006.

6 BISHOP, C. M. Pattern Recognition and Machine Learning. Springer, 2006.

7 THEODORIDIS, S.; KOUTROUMBAS, K. Pattern Recognition, 4th ed. Academic Press, 2009.

8 HAYKIN, S. Neural Networks: A Compreensive Foundation. 2nd ed. Pearson Prentice Hall, 1999.

9 MAURER, A.; HERSCH, M.; BILLARD, A. G. Extended Hopfield Network for Sequence Learning Application to Gesture Recognition. Proc. of $\mathbf{1 5}^{\text {th }}$ International Conference on Artificial Neural Network. Warsaw, Poland. ICANN(I), 2005. p. 493-498. 
10 YOUNG, S.S.; SCOTT, P.D.; NASRABADI, N.M. Object recognition using multilayer Hopfield neural Network. IEEE Transactions on Image Processing, vol. 6, n. 3, 1997. p. 357-372.

$11 \mathrm{AHN}$, K. C. $\mathcal{H}_{\infty}$ Stability conditions for fuzzy neural networks, Hindawi Publishing Corporation. Article., 4 p. 2012.

12 LI, Z.; TANG, X. Polarization and non-positive social influence: a Hopfield model of emergent structure. Journal of Knowledge and Systems Science. p. 15-25. July-September 2012. Upload by Tang on Dec 2016.

13 PETTA, J. L. U.; PETTA, J. H. S. Fractais: obras de arte gerada por equações matemáticas. Artigo Pensamento \& Realidade, n. 3, ano I, 1998.

14 MIRANDA, J. A. Fractais: Conjuntos de Julia e Conjuntos de Mandelbrot, Sigmae. Alfenas, v. 1, n. 1, 2012. p. 110-117.

15 SOUZA, G. M.; BUCKIRIDGE, M. S. Sistemas complexos: novas formas de ver a Botânica. Revista Brasil Bot., v. 27, n. 3, 2004. p. 407-419.

16 PLOTZE, R. O.; BRUNO, O. M. Dimensão fractal multiescala e suas aplicações na taxonomia de espécies vegetais. Periódico, ICMC - USP, 2016.

17 GÓMEZ, A. T.; OliveIRA, L. P. L. de; SEVERINO, P. A. R; QUEIROZ, R. B. Desenvolvimento de um sistema híbrido para a classificação de imagens de satélites. XXXVII Simpósio Brasileiro de Pesquisa Operacional, UNISINOS, 2005. p. 259-266.

18 ASSIS, T. P. de; MENDONÇA, A. E. de; AYRES, F. M.; SILVA, E. M. Classificação de caracteres impressos através da Teoria dos Fractais. Instituto Federal de Educação, Ciência e Tecnologia da Paraíba (IFPB). João Pessoa, Paraíba, 2010.

19 NUNES, R. S. R. Geometria Fractal e Aplicações. Tese de Mestrado em Ensino da Matemática. Universidade do Porto, Porto, 2006. 
20 UCEDA, R. A. Propriedades Topológicas do Conjunto de Julia. Tese de Mestrado em Matemática. Universidade Estadual Paulista, São José do Rio Preto, 2008.

21 VILLATE, J. E. Introdução aos sistemas dinâmicos: uma abordagem prática com Maxima. Creative Commons, 2006.

22 STROGATZ, H. S. Nonlinear dynamics and chaos. Perseu Books, 1994.

23 YANCHUK, S.; PERLIKOWSKI, P.; POPOVYCH, O. V.; TASS, P. A. Variability of spatio-temporal patterns in non-homogeneous rings of spiking neurons. Chaos 21, 2011. 047511.

24 ZOU, W.; SENTHILKUMAR, D. V.; NAGAO, R.; KISS, I. Z.; TANG, Y.; KOSESKA, A.; DUAN, J.; KURTHS, J. Restoration of rhythmicity in diffusively coupled dynamical networks. Article. Nature Communications, 2015.

25 REDDY, D. V. R.; SEN, A.; JOHNSTON, G. L. Dynamics of a Limit Cycle Oscillator under Time Delayed Linear and Nonlinear Feedbacks. Physica D: Nonlinear Phenomena. Elsevier, v. 144, October 2000. p. 335-357.

26 SILVA, F. A. O. da; LIANG, Z. A Network of Neural Oscillators for Fractal Pattern Recognition. Neural Processing Letters, 2015. p. 1-11.

27 Recognizing Fractal Patterns Using a Ring of Phase Oscillators, BRACIS, 2014.

28 POPOVYCH, O. V.; YANCHUK, S.; TASS, P. A. Delay and coupling-induced firing patterns in oscillatory neural loops. Physical Review Letters, 2011. 107. 228102.

29 YANCHUK, S.; WORFRUM, M. Desestabilization patterns in chains of coupled oscillators. Physical Review E., 2008. 77. 026212.

30 D' HUYS, O. et al. Amplitude and phase effects on the synchronization of delay-coupled oscillators. Chaos 20, 2010. 043127. 
31 GHONEIM, S. S. M.; ZAINI, H. G.; SHOUSH, K. A. Partial discharge pattern recognition based on artificial neural networks. Journal of Control Automation and Systems, v. 5, n. 2, April 2016.

32 GHOSH, S.; ASWANI, K.; SINGH, S.; SAHU, S.; FUJITA, D.; BANDYOPADHYAY, A. Design and construction of a brain-like computer: a new class of frequency fractal computing using wireless communication in supramolecular organic, inorganic system. Information, 5(1), Jan 2014. p. 28-100.

33 GHEONEA, D. I.; STREBA, C. T.; VERE, C. C.; SERBĂNESCU, M.; PIRICI, D.; COMĂNESCU, M.; STREBA, L. A. M.; CIUREA, M. E.; MOGATANTĂ; ROGOVEANU, I. Diagnosis system for hepatocellular carcinoma based on fractal dimension of morphometric elements integrated in an artificial neural network. Hindawi Publishing Corporation. Biomed Research International. Article. ID 239706. 2014. 10 p. 


\section{APÊNDICE}

Esta seção será responsável por apresentar as demonstrações das fórmulas utilizadas (equações (5) e (6) do Capítulo 5 e as equações (7) e (8) do Capítulo 6, respectivamente) no desenvolvimento deste trabalho, bem como os programas elaborados para o reconhecimento de padrões estáveis e padrões fractais.

Inicialmente serão provadas as fórmulas que calculam as amplitudes $\rho_{j}$ e os pesos sinápticos $K_{j}$, para os atrasos de tempos de disparos $\tau_{j}$, das soluções periódicas $z_{j}(t)$, com $1 \leq j \leq N$.

Seja o sistema dinâmico $\dot{z}_{j}(t)=(\alpha+i \beta) z_{j}(t)-z_{j}(t)\left|z_{j}(t)\right|^{2}+K_{j} z_{j+1}\left(t-\tau_{j}\right)$ que modela o anel neural, onde cada neurônio é considerado um oscilador de Ciclo Limite de Stuart-Landau. Como as soluções periódicas de tal sistema são $Z_{j}(t)=\rho_{j} e^{i\left(\omega t+\psi_{j}\right)}$, onde $\psi_{j}=\frac{2 \pi \eta_{j}}{T}$ são as mudanças de fase, então:

$$
\begin{gathered}
z_{j}(t)=\rho_{j} \cos \left(\omega t+\psi_{j}\right)+i \rho_{j} \operatorname{sen}\left(\omega t+\psi_{j}\right) \\
\dot{z}_{j}(t)=i \omega \rho_{j} e^{i\left(\omega t+\psi_{j}\right)}=-\rho_{j} \omega \operatorname{sen}\left(\omega t+\psi_{j}\right)+i \rho_{j} \omega \cos \left(\omega t+\psi_{j}\right)
\end{gathered}
$$

Substituindo (2) e (3) em (1) segue que: 


$$
\begin{aligned}
& \dot{z}_{j}(t)=(\alpha+i \beta) z_{j}(t)-z_{j}(t)\left|z_{j}(t)\right|^{2}+K_{j} z_{j+1}\left(t-\tau_{j}\right) \\
\Rightarrow & -\rho_{j} \omega \operatorname{sen}\left(\omega t+\psi_{j}\right)+i \rho_{j} \omega \cos \left(\omega t+\psi_{j}\right) \\
= & (\alpha+i \beta)\left[\rho_{j} \cos \left(\omega t+\psi_{j}\right)+i \rho_{j} \operatorname{sen}\left(\omega t+\psi_{j}\right)\right] \\
- & {\left[\rho_{j} \cos \left(\omega t+\psi_{j}\right)+i \rho_{j} \operatorname{sen}\left(\omega t+\psi_{j}\right)\right] \rho_{j}^{2} } \\
+ & K_{j}\left[\rho_{j+1} \cos \left(\omega t-\omega \tau_{j}+\psi_{j}\right)+i \rho_{j+1} \operatorname{sen}\left(\omega t-\omega \tau_{j}+\psi_{j}\right)\right] \\
\Rightarrow & -\rho_{j} \omega \operatorname{sen}\left(\omega t+\psi_{j}\right)+i \rho_{j} \omega \cos \left(\omega t+\psi_{j}\right) \\
= & \alpha \rho_{j} \cos \left(\omega t+\psi_{j}\right)+i \alpha \rho_{j} \operatorname{sen}\left(\omega t+\psi_{j}\right)+i \beta \rho_{j} \cos \left(\omega t+\psi_{j}\right) \\
- & \beta \rho_{j} \operatorname{sen}\left(\omega t+\psi_{j}\right)-\rho_{j}{ }^{3} \cos \left(\omega t+\psi_{j}\right)-i \rho_{j}^{3} \operatorname{sen}\left(\omega t+\psi_{j}\right) \\
+ & K_{j} \rho_{j+1} \cos \left(\omega t-\omega \tau_{j}+\psi_{j}\right)+i K_{j} \rho_{j+1} \operatorname{sen}\left(\omega t-\omega \tau_{j}+\psi_{j}\right) \\
\Rightarrow & -\rho_{j} \omega \operatorname{sen}\left(\omega t+\psi_{j}\right)+i \rho_{j} \omega \cos \left(\omega t+\psi_{j}\right) \\
= & {\left[\alpha \rho_{j} \cos \left(\omega t+\psi_{j}\right)-\beta \rho_{j} \operatorname{sen}\left(\omega t+\psi_{j}\right)-\rho_{j}^{3} \cos \left(\omega t+\psi_{j}\right)\right.} \\
+ & \left.K_{j} \rho_{j+1} \cos \left(\omega t-\omega \tau_{j}+\psi_{j}\right)\right] \\
+ & i\left[\beta \rho_{j} \cos \left(\omega t+\psi_{j}\right)+\alpha \rho_{j} \operatorname{sen}\left(\omega t+\psi_{j}\right)-\rho_{j}^{3} \operatorname{sen}\left(\omega t+\psi_{j}\right)\right. \\
+ & \left.K_{j} \rho_{j+1} \operatorname{sen}\left(\omega t-\omega \tau_{j}+\psi_{j}\right)\right]
\end{aligned}
$$

Usando igualdade de números complexos tem-se o seguinte sistema de equações:

$-\omega \operatorname{sen}\left(\omega t+\psi_{j}\right)=\alpha \cos \left(\omega t+\psi_{j}\right)-\beta \operatorname{sen}\left(\omega t+\psi_{j}\right)-\rho_{j}^{2} \cos \left(\omega t+\psi_{j}\right)+\frac{K_{j} \rho_{j+1}}{\rho_{j}} \cos (\omega t-$ $\left.\omega \tau_{j}+\psi_{j+1}\right)$

$\omega \cos \left(\omega t+\psi_{j}\right)=\alpha \operatorname{sen}\left(\omega t+\psi_{j}\right)+\beta \cos \left(\omega t+\psi_{j}\right)-\rho_{j}{ }^{2} \operatorname{sen}\left(\omega t+\psi_{j}\right)+\frac{K_{j} \rho_{j+1}}{\rho_{j}} \operatorname{sen}\left(\omega t-\omega \tau_{j}+\right.$ $\left.\psi_{j+1}\right) \quad(5)$

Dividindo uma pela outra, as equações (4) e (5), resulta:

$$
\begin{aligned}
& \frac{\cos \left(\omega t-\omega \tau_{j}+\psi_{j+1}\right)}{\operatorname{sen}\left(\omega t-\omega \tau_{j}+\psi_{j+1}\right)}=\frac{-(\omega-\beta) \operatorname{sen}\left(\omega t+\psi_{j}\right)+\left(\rho_{j}{ }^{2}-\alpha\right) \cos \left(\omega t+\psi_{j}\right)}{(\omega-\beta) \cos \left(\omega t+\psi_{j}\right)+\left(\rho_{j}{ }^{2}-\alpha\right) \operatorname{sen}\left(\omega t+\psi_{j}\right)} \Rightarrow(\omega-\beta) \cos \left(\omega t+\psi_{j}\right) \cos (\omega t- \\
& \left.\omega \tau_{j}+\psi_{j+1}\right)+\left(\rho_{j}{ }^{2}-\alpha\right) \operatorname{sen}\left(\omega t+\psi_{j}\right) \cos \left(\omega t-\omega \tau_{j}+\psi_{j+1}\right)= \\
& \left(\rho_{j}{ }^{2}-\alpha\right) \cos \left(\omega t+\psi_{j}\right) \operatorname{sen}\left(\omega t-\omega \tau_{j}+\psi_{j+1}\right)-(\omega-\beta) \operatorname{sen}\left(\omega t+\psi_{j}\right) \operatorname{sen}\left(\omega t-\omega \tau_{j}+\right.
\end{aligned}
$$




$$
\begin{aligned}
& \left.\psi_{j+1}\right) \Rightarrow\left(\rho_{j}^{2}-\alpha\right) \operatorname{sen}\left(\psi_{j+1}-\psi_{j}-\omega \tau_{j}\right)=(\omega-\beta) \cos \left(\psi_{j+1}-\psi_{j}-\omega \tau_{j}\right) \Rightarrow \rho_{j}= \\
& \sqrt{\alpha+(\omega-\beta) \cot \left(\psi_{j+1}-\psi_{j}-\omega \tau_{j}\right)}
\end{aligned}
$$

Multiplicando (4) por $\operatorname{sen}\left(\omega t+\psi_{j}\right)$ e multiplicando (5) por $\cos \left(\omega t+\psi_{j}\right)$, tem-se:

$$
\begin{aligned}
& -\omega \operatorname{sen}\left(\omega t+\psi_{j}\right)^{2}=\alpha \operatorname{sen}\left(\omega t+\psi_{j}\right) \cos \left(\omega t+\psi_{j}\right)-\beta \operatorname{sen}\left(\omega t+\psi_{j}\right)^{2}-\rho_{j}^{2} \operatorname{sen}(\omega t+ \\
& \left.\psi_{j}\right) \cos \left(\omega t+\psi_{j}\right)+\frac{K_{j} \rho_{j+1}}{\rho_{j}} \operatorname{sen}\left(\omega t+\psi_{j}\right) \cos \left(\omega t-\omega \tau_{j}+\psi_{j+1}\right) \\
& \omega \cos \left(\omega t+\psi_{j}\right)^{2}=\alpha \operatorname{sen}\left(\omega t+\psi_{j}\right) \cos \left(\omega t+\psi_{j}\right)+\beta \cos \left(\omega t+\psi_{j}\right)^{2}-\rho_{j}^{2} \operatorname{sen}(\omega t+ \\
& \left.\psi_{j}\right) \cos \left(\omega t+\psi_{j}\right)+\frac{K_{j} \rho_{j+1}}{\rho_{j}} \operatorname{sen}\left(\omega t-\omega \tau_{j}+\psi_{j+1}\right) \cos \left(\omega t+\psi_{j}\right)
\end{aligned}
$$

Multiplicando (7) por -1 e somando o resultado por (8) segue que:

$$
\begin{aligned}
& K_{j} \frac{\rho_{j+1}}{\rho_{j}} \operatorname{sen}(\omega t\left.-\omega \tau_{j}+\psi_{j+1}\right) \cos \left(\omega t+\psi_{j}\right)- \\
&-K_{j} \frac{\rho_{j+1}}{\rho_{j}} \operatorname{sen}\left(\omega t+\psi_{j}\right) \cos \left(\omega t-\omega \tau_{j}+\psi_{j+1}\right)= \\
&=(\omega-\beta) \cos ^{2}\left(\omega t+\psi_{j}\right)+(\omega-\beta) \operatorname{sen}^{2}\left(\omega t+\psi_{j}\right) \\
& K_{j} \frac{\rho_{j+1}}{\rho_{j}} \operatorname{sen}\left(\psi_{j+1}-\psi_{j}-\omega \tau_{j}\right)=(\omega-\beta) \Rightarrow K_{j}=\frac{\rho_{j}(\omega-\beta)}{\rho_{j+1} \operatorname{sen}\left(\psi_{j+1}-\psi_{j}-\omega \tau_{j}\right)}
\end{aligned}
$$

Portanto, as fórmulas (6) e (9) são as amplitudes e os pesos sinápticos, isto é, são as equações (6) e (5) do Capítulo 5, respectivamente.

No caso das equações (7) e (8) do Capítulo 6, considerando o mesmo sistema dinâmico (1), tem-se que: 


$$
\dot{z}_{j}(t) \approx \frac{z_{j}(t+h)-z_{j}(t)}{h}
$$

Substituindo (10) em (1), segue que:

$$
\begin{gathered}
\frac{z_{j}(t+h)-z_{j}(t)}{h} \approx\left[(\alpha+i \beta)-\rho_{j}^{2}\right] z_{j}(t)+K_{j} z_{j+1}\left(t-\tau_{j}\right) \Rightarrow z_{j}(t+h) \\
\approx\left[\left(\alpha h-h \rho_{j}^{2}+1\right)+i h \beta\right] z_{j}(t)+h K_{j} z_{j+1}\left(t-\tau_{j}\right) \Rightarrow \\
\Rightarrow x_{j}(t+h)+i y_{j}(t+h) \approx \\
\approx\left[\left(\alpha h-h \rho_{j}^{2}+1\right)+i h \beta\right]\left[\rho_{j} \cos \left(\omega t+\psi_{j}\right)+i \rho_{j} \operatorname{sen}\left(\omega t+\psi_{j}\right)\right] \\
+h K_{j}\left[\rho_{j+1} \cos \left(\omega t+\psi_{j+1}-\omega \tau_{j}\right)+i \operatorname{sen}\left(\omega t+\psi_{j+1}-\omega \tau_{j}\right)\right] \\
x_{j}(t+h)+i y_{j}(t+h) \approx\left[\left(\alpha h-h \rho_{j}^{2}+1\right) \rho_{j} \cos \left(\omega t+\psi_{j}\right)-h \beta \rho_{j} \operatorname{sen}\left(\omega t+\psi_{j}\right)+\right. \\
\left.+h K_{j} \rho_{j+1} \cos \left(\omega t+\psi_{j+1}-\omega \tau_{j}\right)\right]+i\left[\left(\alpha h-h \rho_{j}^{2}+1\right) \rho_{j} \operatorname{sen}\left(\omega t+\psi_{j}\right)+h \beta \rho_{j} \cos (\omega t+\right. \\
\left.\left.\psi_{j}\right)+h K_{j} \rho_{j+1} \operatorname{sen}\left(\omega t+\psi_{j+1}-\omega \tau_{j}\right)\right]
\end{gathered}
$$

e, finalmente, tem-se que:

$$
\begin{aligned}
& x_{j}(t+h) \approx\left(\alpha h-h \rho_{j}^{2}+1\right) \rho_{j} \cos \left(\omega t+\psi_{j}\right)-h \beta \rho_{j} \operatorname{sen}\left(\omega t+\psi_{j}\right)+h K_{j} \rho_{j+1} \cos (\omega t+ \\
& \left.\psi_{j+1}-\omega \tau_{j}\right) \\
& y_{j}(t+h) \approx\left(\alpha h-h \rho_{j}^{2}+1\right) \rho_{j} \operatorname{sen}\left(\omega t+\psi_{j}\right)+h \beta \rho_{j} \cos \left(\omega t+\psi_{j}\right)+h K_{j} \rho_{j+1} \operatorname{sen}(\omega t+ \\
& \left.\psi_{j+1}-\omega \tau_{j}\right)
\end{aligned}
$$

A seguir será apresentada a codificação conforme o artigo para o anel neural estável que foi proposta pelos autores do Capítulo 2, bem como a codificação do algoritmo apresentado no Capítulo 6, para as simulações, considerando este sistema dinâmico, caótico. Ambas foram feitas em linguagem Fortran 77: 


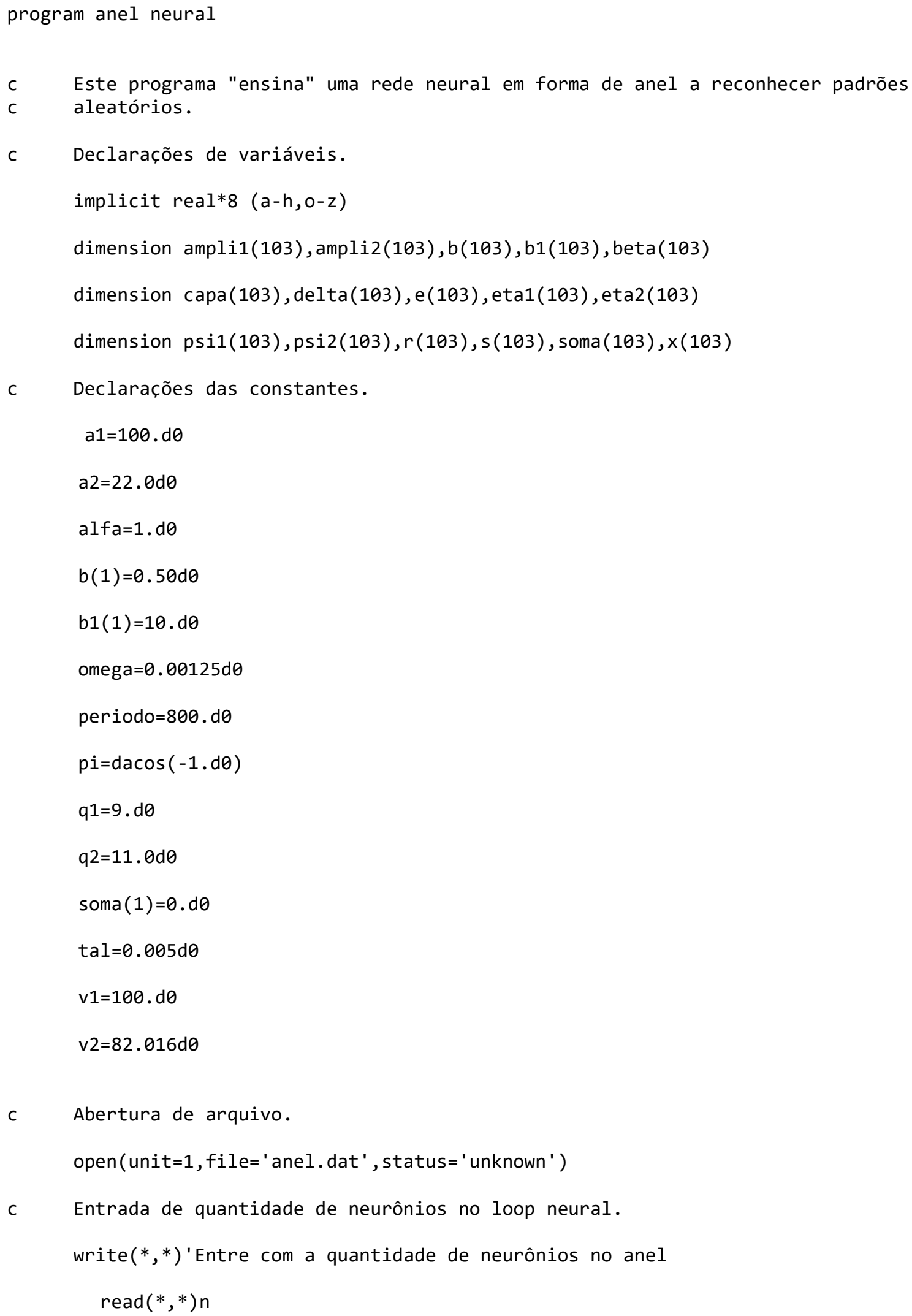


c Cálculo das variáveis beta distribuídas normalmente em torno de 1.d0.

do $i=1, n$

$b(i+1)=(\operatorname{dmod}(a 1 * b(i)+v 1, q 1)) / q 1$

if $(i \cdot$ eq. $n) b(i+1)=b(1)$

$s(i+1)=((b(i+1) * * 0.135 d \theta)-((1 . d \theta-b(i+1)) * * 0.135 d \theta)) / 0.1975 d \theta$

$\operatorname{beta}(i+1)=1 . d 0+(0.01 d \theta * s(i+1))$

enddo

c Cálculo dos padrões de fase.

do $j=1, n$

$b 1(j+1)=(\operatorname{dmod}(a 2 * b 1(j)+v 2, q 2)) / q 2$

$e(j+1)=(0.12 d \theta * b 1(j+1))-0.06 d \theta$

enddo

c Suavização dos padrões de fase via média móvel.

do $k=1, n$

do $1=0,24$

if $(k+1 . g e \cdot 1$. and. $k+1.1$ e.n $)$ soma $(k)=\operatorname{soma}(k)+e(k+1)$

enddo

enddo

do $1=1, n$

$\operatorname{eta} 1(1)=\operatorname{soma}(1) / 25 . d 0$

$\operatorname{psi1}(1)=\left(-2 \cdot d \theta^{*}\right.$ pi*eta1 $\left.(1)\right) /$ periodo

enddo

do $m=1, n$

$\operatorname{eta} 2(m)=\operatorname{eta} 1 m+1)$

if $(m . e q . n)$ eta2 $(m)=\operatorname{eta} 1(1)$

$\operatorname{psi} 2(m)=(-2 . d 0 *$ pi*eta $2(m)) /$ periodo

$\operatorname{delta}(m)=\operatorname{psi2}(m)-\operatorname{psi1}(m)$

enddo 
c Cálculo das amplitudes.

do $i 1=1, n$

$r(i 1)=(($ omega $-\operatorname{beta}($ i1 $)) *(\operatorname{dcotan}(\operatorname{delta}($ i1 $)-($ omega*tal $))))$

$\operatorname{ampli1}(i 1)=\operatorname{dsqrt}(\operatorname{dabs}(\operatorname{alfa}+r(i 1)))$

enddo

do $j 1=1, n$

$\operatorname{ampli2}(j 1)=\operatorname{ampli1}(j 1+1)$

if $(j 1$. eq.n) $\operatorname{ampli2}(j 1)=\operatorname{ampli1}(1)$

enddo

c Cálculo dos pesos sinápticos (acoplamentos).

do $k 1=1, n$

factor $=($ omega $-\operatorname{beta}(k 1)) / \operatorname{dsin}(\operatorname{delta}(k 1)-($ omega*tal $))$

$\operatorname{capa}(k 1)=(\operatorname{ampli1}(k 1) / \operatorname{ampli2}(k 1)) *$ factor

enddo

c Apresentação dos padrões aleatórios.

do $11=1, n$

temp $=(1$. d0/omega $) *((p i / 2 . d 0)-p \operatorname{si1}(11))$

write $(1, *)$ temp, 11

enddo

c Teste para verificar se o anel neural aprendeu o padrão criado.

do $m 1=1, n$

$\arg =(-1 . d 0 /(\operatorname{capa}(m 1) * \operatorname{ampli2}(m 1))) * \operatorname{dsqrt}($ alfa+omega $)$

temp1=tal+((1.d0/omega)*dasin (arg) $)-($ psi2(m1)/omega $)$

write $(1, *)$ temp $1, \mathrm{~m} 1$

enddo

close(1)

end 


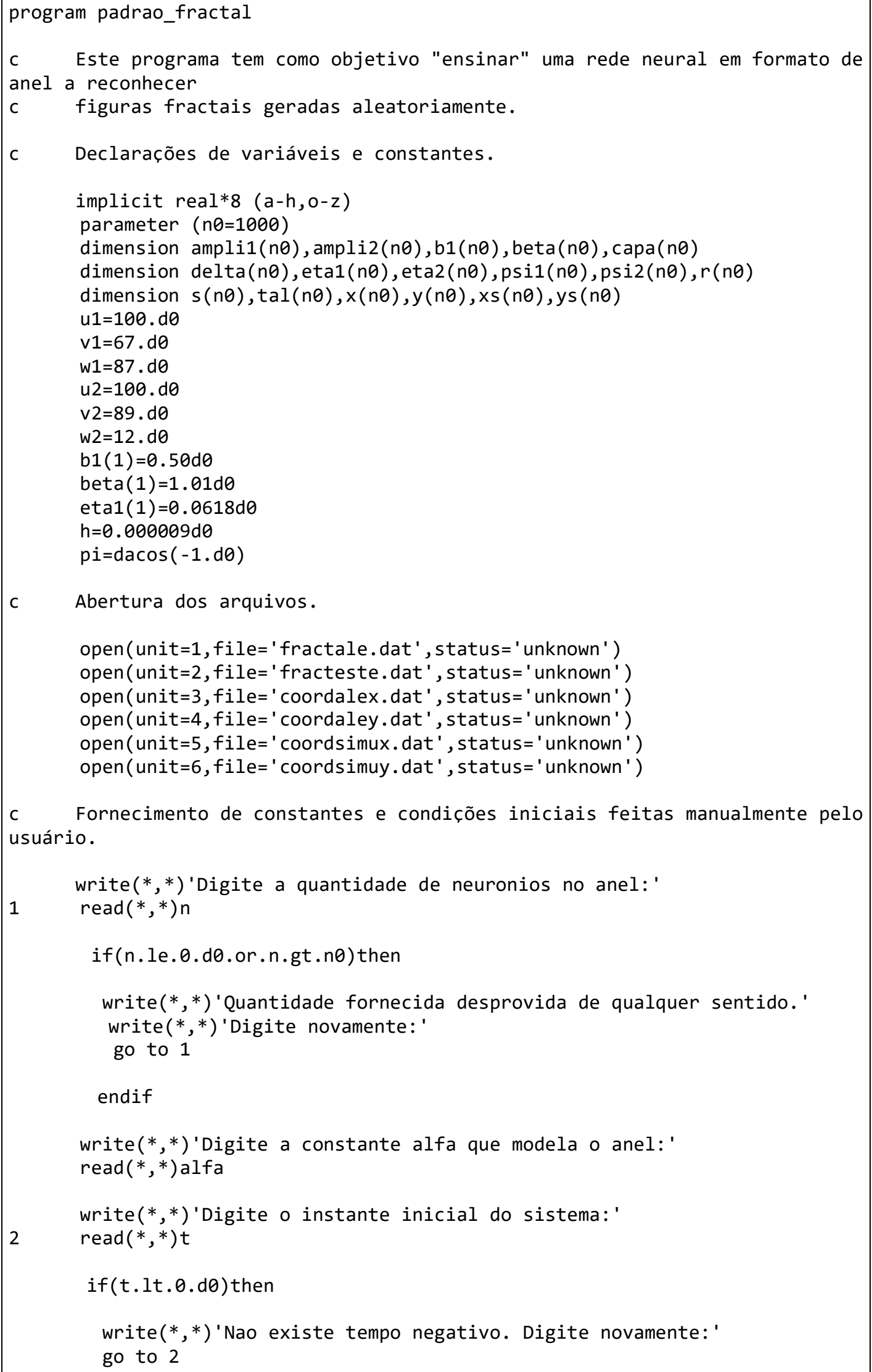




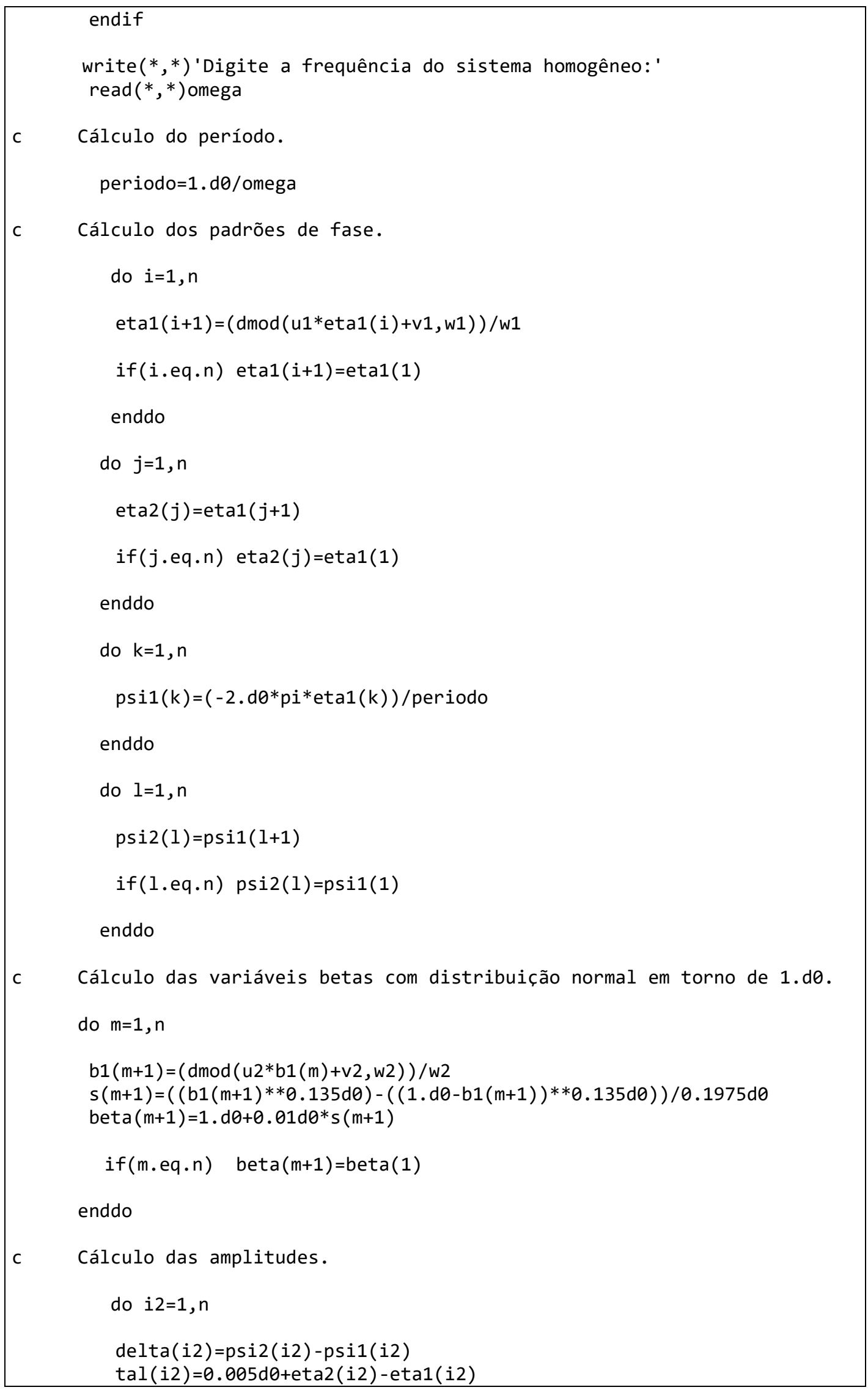




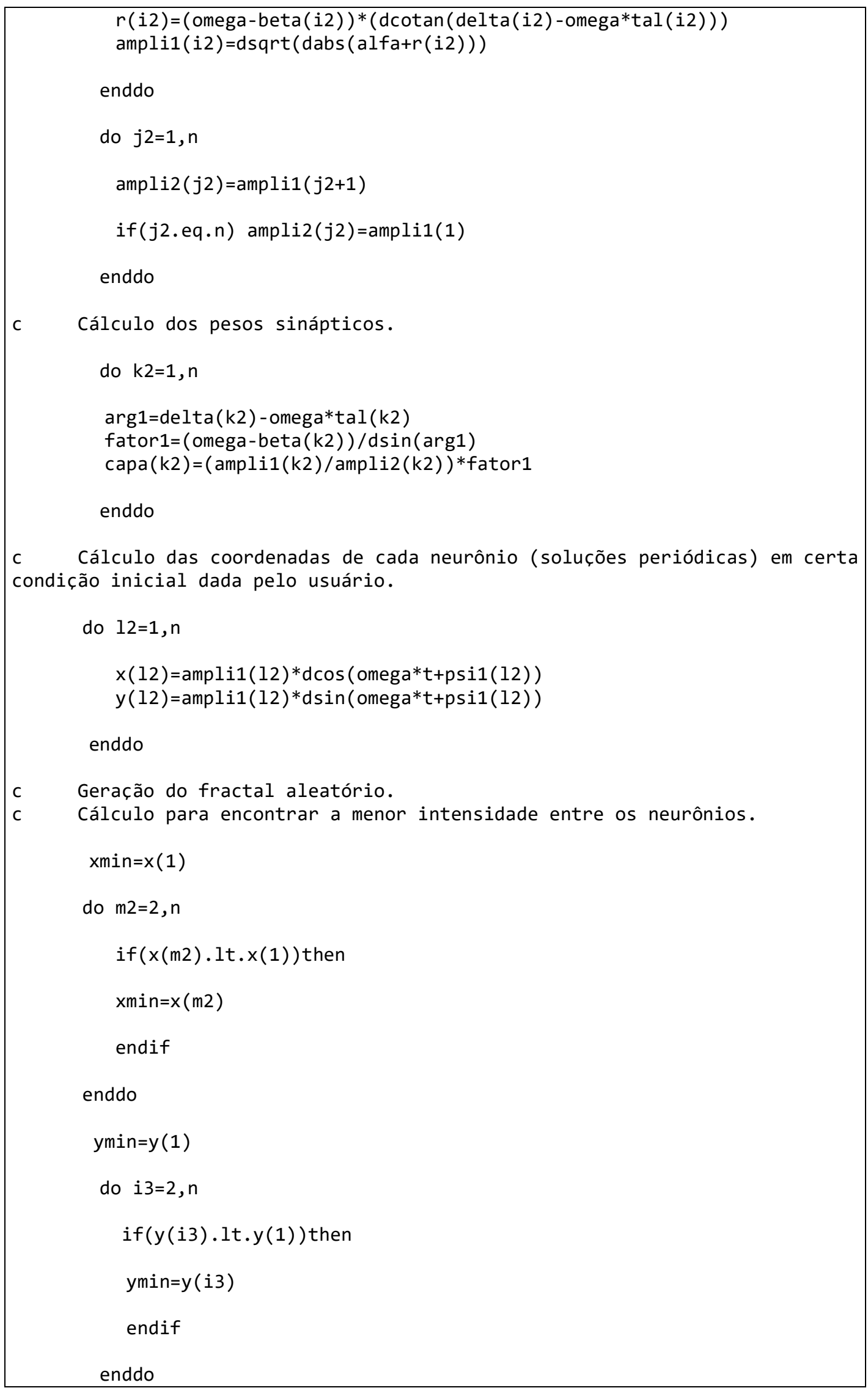


c Cálculo para encontrar a maior intensidade entre os neurônios. $\operatorname{xmax}=x(1)$

do $j 3=2, n$

$\operatorname{if}(x(j 3) \cdot g t \cdot x(1))$ then

$x \max =x(j 3)$

endif

enddo

$\operatorname{ymax}=y(1)$

do $k 3=2, n$

if $(y(k 3) \cdot g t \cdot y(1))$ then

$\operatorname{ymax}=\mathrm{y}(\mathrm{k} 3)$

endif

enddo

c Código para geração do fractal e arquivamento.

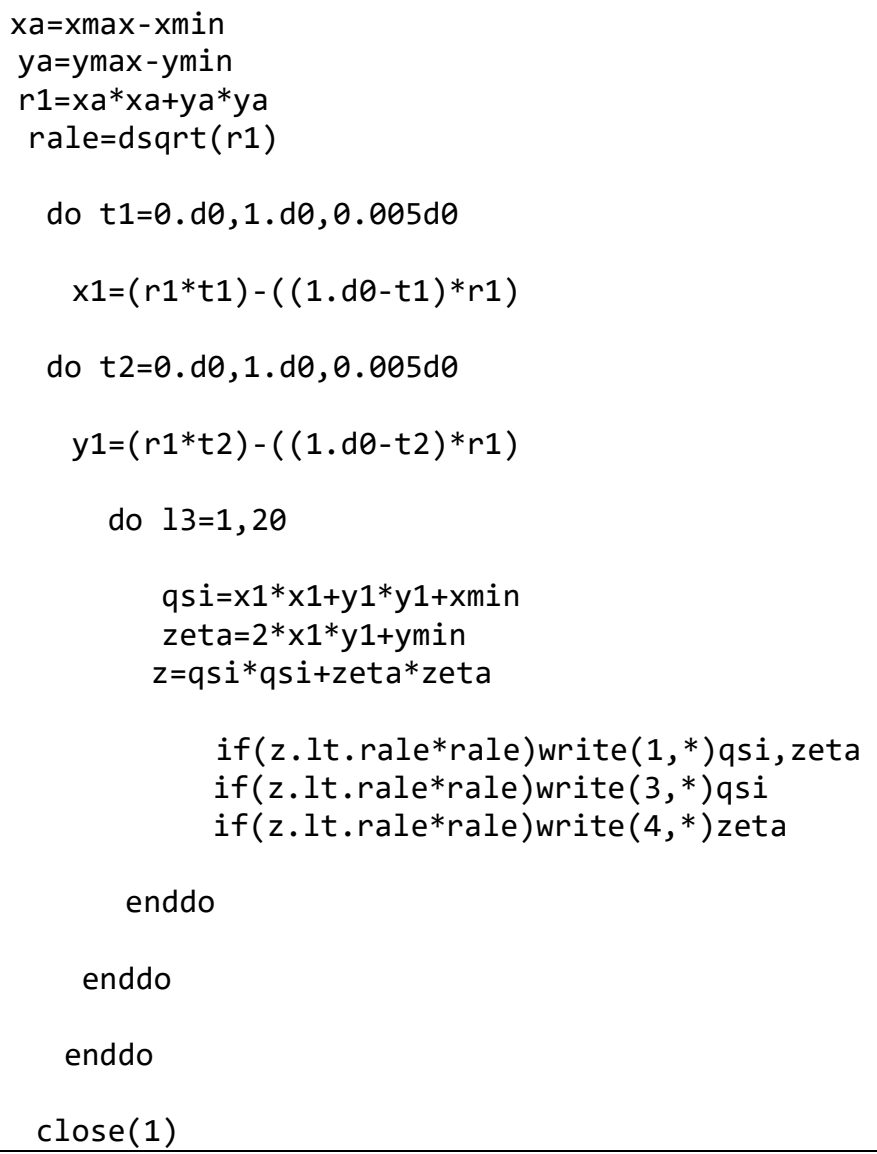




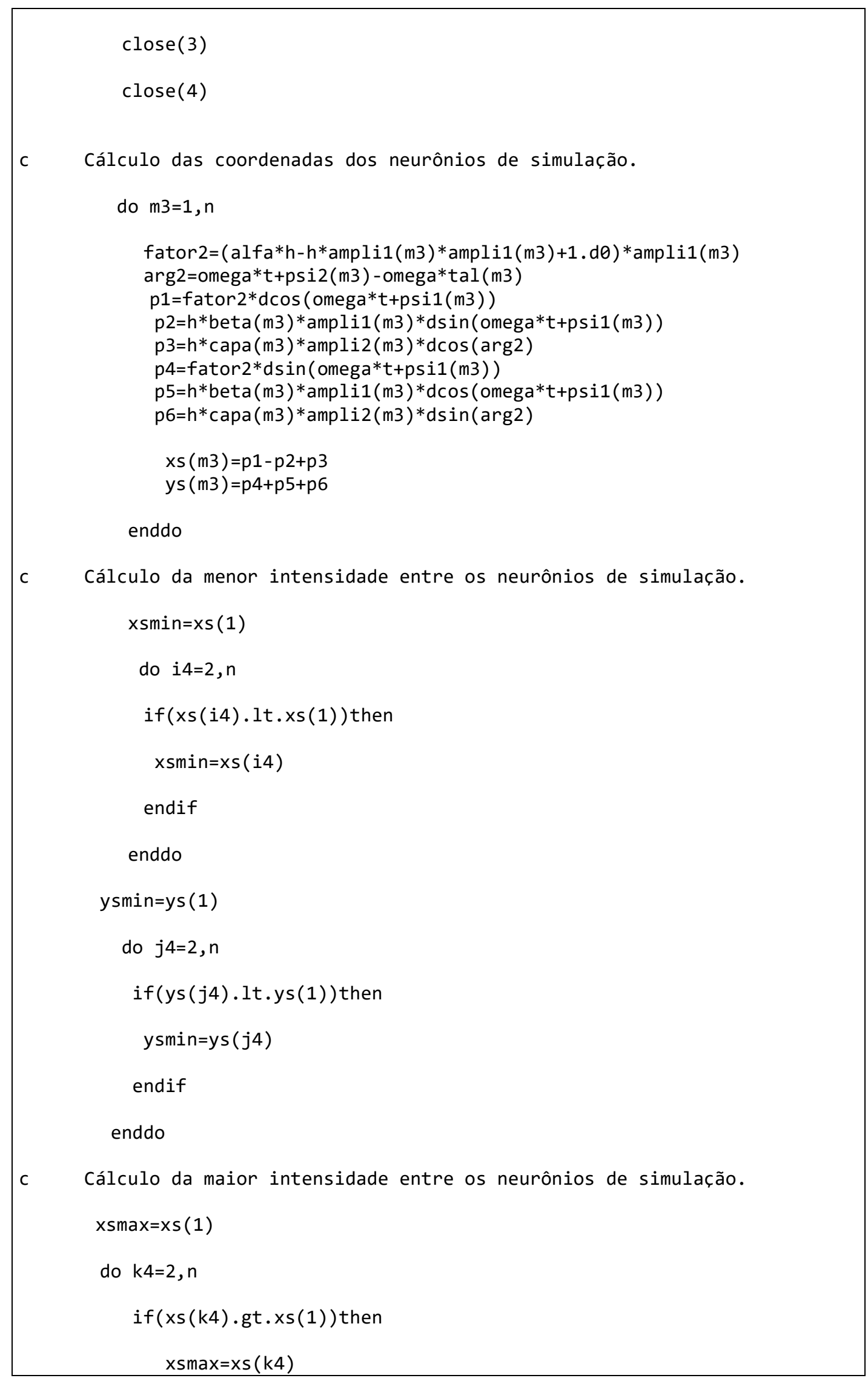




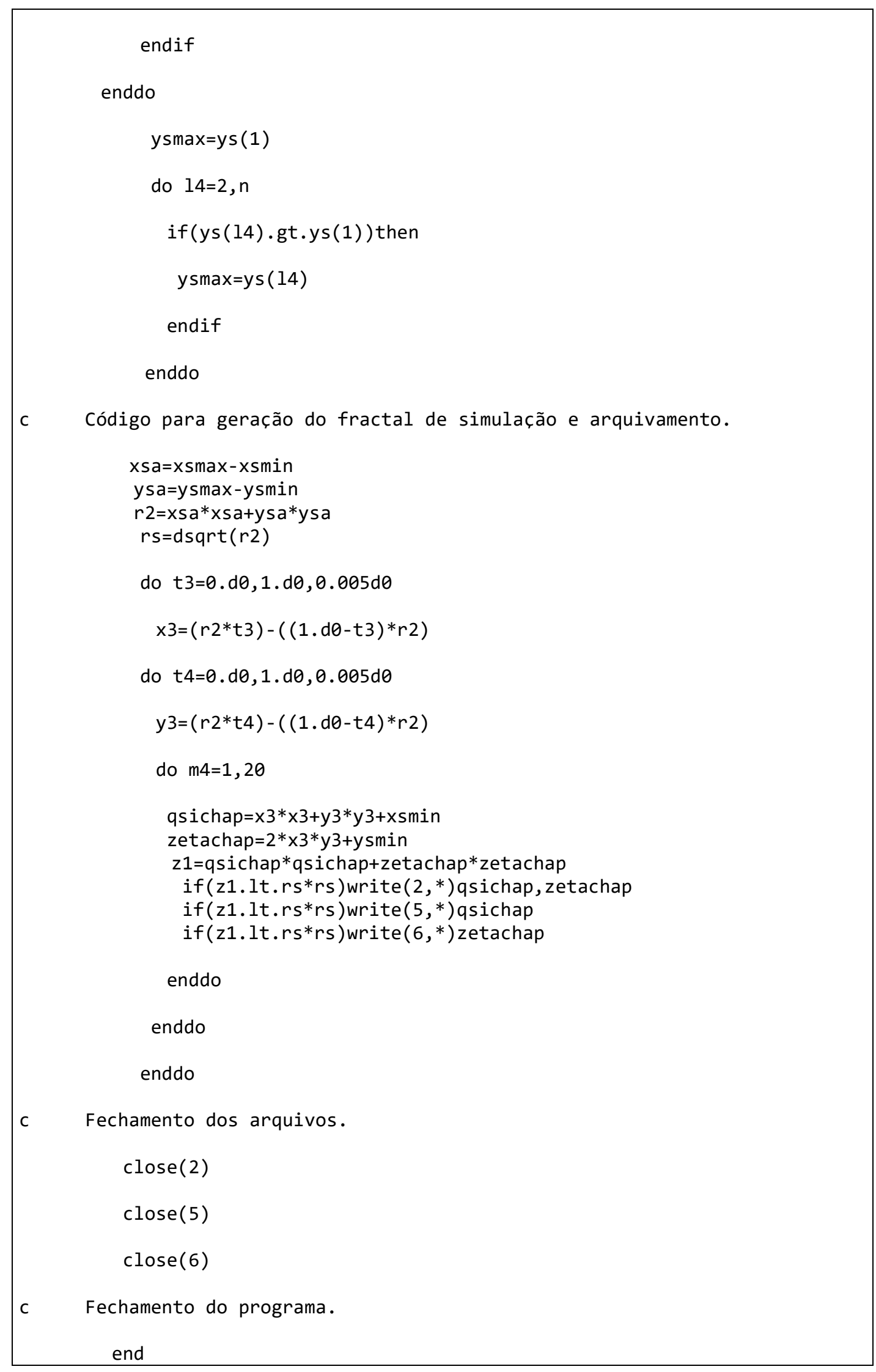


O primeiro programa descreve o processo de construção de figuras estáveis e de reconhecimento. Este programa constrói e reconhece tais figuras.

Considerando o último programa acima, para construir as outras figuras fractais da sexta seção desta tese, é necessário, tão-somente, recodificar as seções: Código para geração do fractal e arquivamento e Código para geração do fractal de simulação e arquivamento, utilizando as equações (9), (10), (11) e (12) daquele capítulo.

Assim, neste Apêndice, apresentamos as demonstrações das fórmulas das amplitudes e pesos sinápticos, onde o anel neural usado neste trabalho foi não homogêneo, bem como as fórmulas das órbitas de reconhecimento dos fractais e os códigos em Fortran 77 para os padrões estáveis e caóticos. 